UNIVERSIDADE DE SÃO PAULO

FACULDADE DE ECONOMIA, ADMINISTRAÇÃO E CONTABILIDADE DEPARTAMENTO DE CONTABILIDADE E ATUÁRIA

PROGRAMA DE PÓS-GRADUAÇÃO EM CONTABILIDADE E CONTROLADORIA

DESENHO E USO DE SISTEMAS DE CONTROLE GERENCIAL FOCADOS NOS CLIENTES: UM ESTUDO EM EMPRESAS BRASILEIRAS SOB A PERSPECTIVA DA TEORIA DA CONTINGÊNCIA

Flavio Roberto Mantovani

Orientador: Prof. Dr. Carlos Alberto Pereira 
Prof. Dr. João Grandino Rodas Reitor da Universidade de São Paulo

Prof. Dr.Reinaldo Guerreiro

Diretor da Faculdade de Economia, Administração e Contabilidade

Prof. Dr. Edgard Bruno Cornachione Junior Chefe do Departamento de Contabilidade e Atuária

Prof. Dr. Luis Eduardo Afonso

Coordenador do Programa de Pós-Graduação em Contabilidade 


\title{
DESENHO E USO DE SISTEMAS DE CONTROLE GERENCIAL FOCADOS NOS CLIENTES: UM ESTUDO EM EMPRESAS BRASILEIRAS SOB A PERSPECTIVA DA TEORIA DA CONTINGÊNCIA
}

\begin{abstract}
Tese apresentada ao Departamento de Contabilidade e Atuária da Faculdade de Economia, Administração e Contabilidade da Universidade de São Paulo como requisito para obtenção do título de Doutor em Ciências
\end{abstract}

Orientador: Prof. Dr. Carlos Alberto Pereira

\author{
Versão Corrigida \\ (versão original disponível na Unidade que aloja o Programa)
}

SÃO PAULO

2012 

FICHA CATALOGRÁFICA

Elaborada pela Seção de Processamento Técnico do SBD/FEA/USP

Mantovani, Flavio Roberto

Desenho e uso de sistemas de controle gerencial focados nos clientes : um estudo em empresas brasileiras sob a perspectiva da teoria da contin-

gência / Flavio Roberto Mantovani. --São Paulo, 2012.

$118 \mathrm{p}$.

Tese (Doutorado) - Universidade de São Paulo, 2012.

Orientador: Carlos Alberto Pereira.

1. Contabilidade gerencial 2. Controladoria 3. Sistemas de controle gerencial I. Universidade de São Paulo. Faculdade de Economia, Administração e Contabilidade. II. Título.

CDD -658.151 
A Deus

Aos meus queridos pais, esposa e filhos. 
Agradeço a Deus, pela sua graça, por iluminar o meu caminho, por encher-me de fé, sempre me auxiliando a trilhar o caminho da perseverança e me ajudando a realizar mais este importante objetivo.

Ao Prof. Dr. Carlos Alberto Pereira, pelo apoio, confiança, incentivo e ensinamentos durante todo o período de orientação.

Aos Professores Drs. Fábio Frezatti e Luciane Reginato pelas sugestões, comentários e orientações durante o exame de qualificação.

Ao Prof. Dr. Diógenes de Souza Bido, pela dedicação, paciência e orientação estatística durante todo o processo de análise dos dados da pesquisa.

Aos Professores Drs. Maria Thereza Pompa Antunes e Aridelmo Teixeira, coordenadores dos cursos de mestrado acadêmico da Universidade Presbiteriana Mackenzie e Fundação Capixaba de Ensino pela adesão dos seus programas no desenvolvimento da pesquisa.

Ao Prof. Dr. Ariovaldo dos Santos pela cessão do banco de dados das maiores e melhores empresas.

A todos os professores do programa, todos os colaboradores da FEA/USP, todos os colegas de curso, todos os meus amigos que me apoiaram durante essa trajetória.

Aos meus familiares, pela paciência, por todo apoio e ajuda que me deram e, tenho certeza, me darão sempre. 


\section{RESUMO}

As mudanças turbulentas no ambiente de negócios e a tendência de novas tecnologias para o gerenciamento da base de clientes sinalizam o caminho aos administradores para a gestão e maximização do valor da base de clientes da empresa. No contexto do aparelhamento aos gestores, os sistemas de controles gerenciais focados nos clientes servem como facilitadores do alcance dos objetivos organizacionais. A forma como são desenhados e a forma como são utilizados podem contribuir diretamente no desempenho do sistema e indiretamente para o desempenho organizacional. Assim, o presente estudo buscou, sob a perspectiva da teoria da contingência, compreender, no ambiente empresarial brasileiro, a influência de fatores contingenciais externos e internos no desenho e uso de sistemas de controle gerenciais focados nos clientes e se ambos, na prática, podem contribuir para a melhoria do desempenho desses sistemas nas organizações. Os dados de uma amostra formada por 83 empresas brasileiras foram coletados através de uma pesquisa tipo survey(levantamento). Para a análise dos dados foi adotada a técnica de Modelagem de Equações Estruturais com o método de estimação PartialLeast Square (PLS). Os resultados comprovaram todas as hipóteses de pesquisa. Conclui-se que as características do ambiente participam sobremaneira nas decisões que envolvem a configuração dos fatores contingenciais internos e estes no desenho de Sistemas de Controle Gerencial (SCG) focados nos clientes. O desenho dos SCG focados nos clientes representa, entre as hipóteses de pesquisa estudadas, aquele que se revelou mais forte em termos de associação com o uso intensivo desses mesmos sistemas.O desenho e o uso de SCG focados nos clientes, considerados na forma de artefatos, representados pela Análise da lucratividade do cliente, Valor vitalício do cliente e Valor econômico do cliente podem, inclusive, contribuir para o desempenho econômico da organização. Os resultados da pesquisa estão sujeitos a algumas limitações: i- os respondentes são, na sua maioria, representantes da área de Controladoria. ii- a amostra, constituída por 83 empresas, foi intencional, portanto, os resultados não podem ser generalizados para a população.Estas limitações remetem a novas oportunidades de pesquisa, tais como: i- verificar a possibilidade de estabelecer um arranjo (fit) entre fatores contingenciais, desenho, uso de SCG focados nos clientes e desempenho; iirealizar este modelo de pesquisa com outro público alvo; iii- verificar o impacto de variáveis como "satisfação do cliente"; "lealdade do cliente" e "retenção do cliente" no desempenho econômico da organização. 


\begin{abstract}
The changes in the turbulent business environment and the trend of new customer valuation technologies are evidences that challenge the management team to manage and maximize the value of the company customer basis. In the context of managerial tools, the customer oriented management control systems trigger a process that enables the management to reach the company targets and goals. The way they are designed and the way in which they are used can directly contribute to the system performance and indirectly for the economic organizational performance. Therefore, this study sought, based on the contingency theory to understand, in the Brazilian business market, the influence of the environment and internal contextual contingency factors over the design and use of the customers oriented management control systems and if both, in practice, can contribute to the improvement of the model and the own performance of the organization. The data of a sample made up of 83 Brazilian companies have been collected by means of a survey. For the data analysis was adopted the SEM (Structural Equation Modeling) technique and PLS (Partial Least Squares) as a method for estimation. The outcomes have proved all of the hypotheses of this research. It is therefore concluded that the characteristics of the environment are rightly taking part on the decisions that involve the configuration of these internal contextual contingency factors and these on the design of customer oriented management control systems. The design of the customer oriented MCS (Management Control Systems) represents, among all the hypotheses that were studied, the one which has shown itself to be stronger in terms of association with the intensive use of these systems. The design and use of customer oriented MCS which are considered in this study to be in the form of certain artifacts were represented by the Customer Profitability Analysis; Customer Life time Value; and Customer Equity and in its set can even contribute to the overall performance to the firm. The results of the research are subject to certain restrictions: $i$ - the-respondents are in its majority, representatives of the Controllership area. ii- the sample, consisting of 83 companies was intentional, therefore, the results may not be widespread for the population. These constraints address to new opportunities of research, such as: $i$ - to verify the possibility of establishing a fitting-out between internal contextual factors, design, use of customer oriented MCS and performance; ii- have to carry out this model of research with the other public target; iii- to see the impact of variables such as "satisfaction of the customer"; "loyalty of the customer" and "retention of the customer" on the economic performance of the organization.
\end{abstract}





\section{SUMÁRIO}

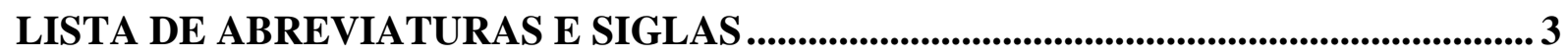

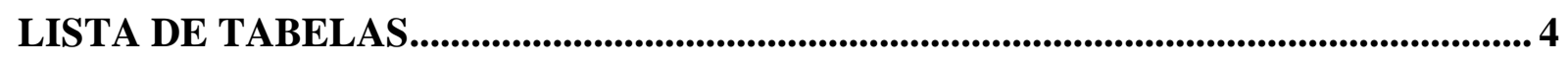

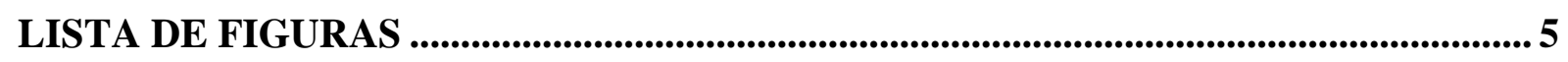

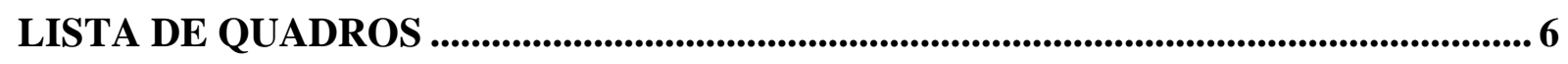

1 INTRODUÇÃ

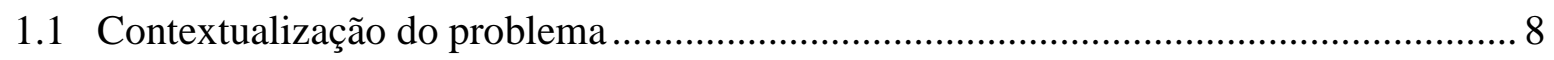

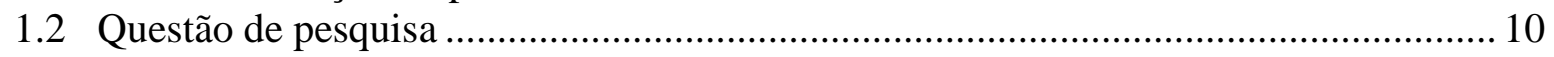

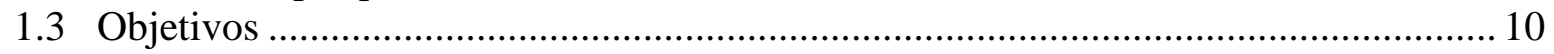

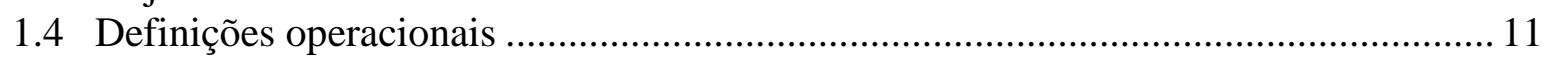

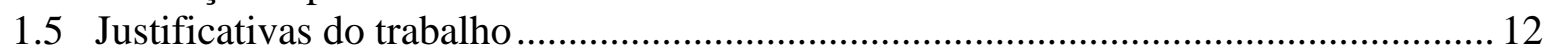

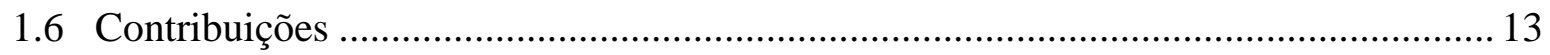

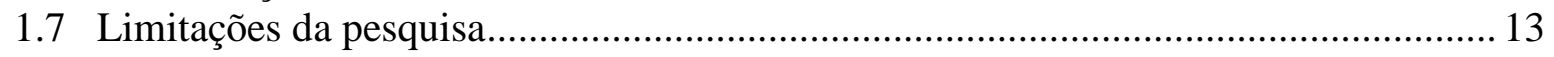

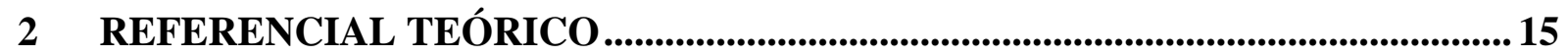

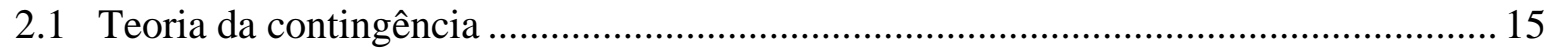

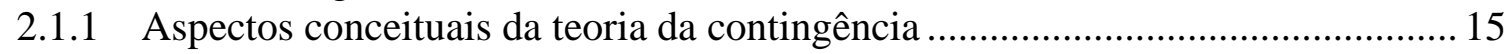

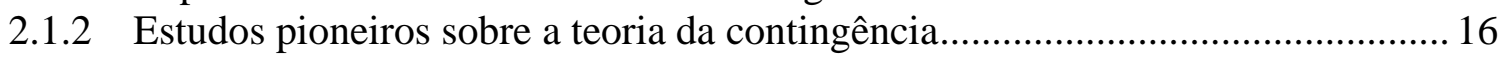

2.1.3 Construtos da pesquisa em relação à abordagem contingencial .......................... 19

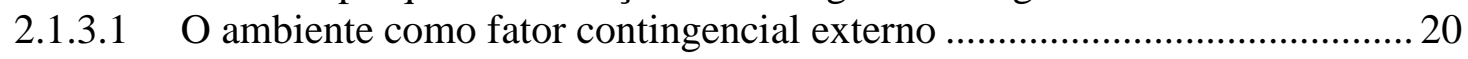

2.1.3.2 A estratégia como fator contingencial interno ........................................ 21

2.1.3.3 A estrutura como fator contingencial interno........................................... 23

2.1.3.4 A tecnologia da informação como fator contingencial interno .................... 23

2.1.3.5 O porte da organização como fator contingencial interno .......................... 25

2.2 Controle gerencial, Sistemas de Controle Gerencial, Controladoria e Desempenho ... 25

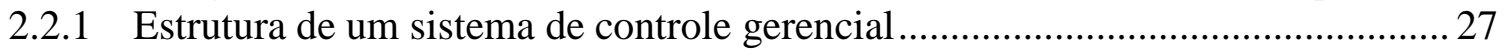

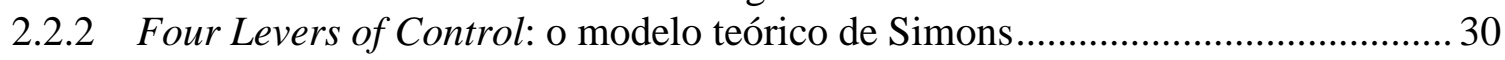

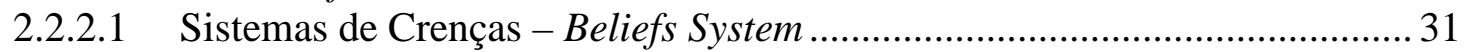

2.2.2.2 Sistemas de Restrições - Boundary Systems ................................................ 32

2.2.2.3 Sistemas de Controle Diagnóstico - Diagnostic Control System ................. 32

2.2.2.4 Sistemas de Controle Interativo - Interactive Control System ...................... 34

2.2.2.5 Tensões dinâmicas - Dynamic Tensions .................................................. 35

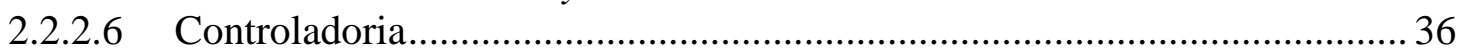

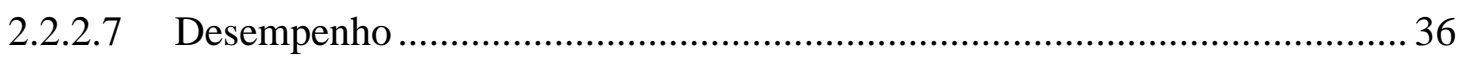

2.3 Sistemas de controle gerenciais focados no cliente ................................................ 37

2.3.1 Análise da lucratividade do cliente - (Customer Profitability Analysis) .............. 38

2.3.2 Valor vitalício do cliente ou Valor do relacionamento com o cliente (Customer

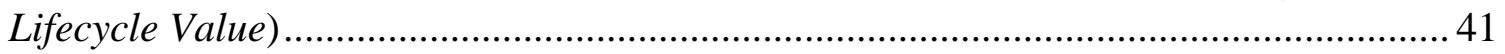

2.3.2.1 Componentes do valor vitalício do cliente ................................................ 43

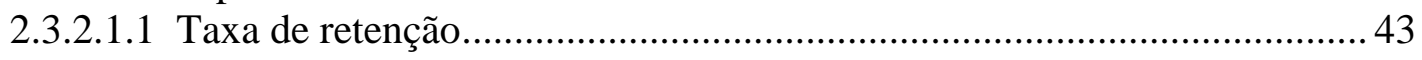

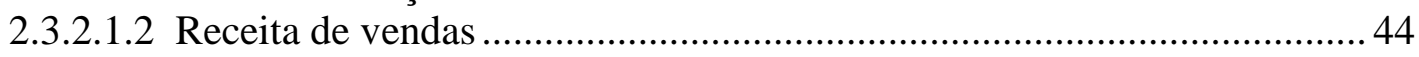

2.3.2.1.3 Custos para servir o cliente .............................................................. 45

2.3.3 Valor econômico do cliente ou valor do ativo em cliente (Customer Equity) ..... 45

2.3.4 Estudos recentes sobre a contabilidade focada no cliente.................................... 48

2.3.4.1 MCMANUS, L.; GUILDING C. Exploring the potential of customer accounting: a synthesis of the accounting and marketing literatures. Journal of Marketing Management, v. 24, n. 7-8, p.771-795, 2008. 
2.3.4.2 HELGESEN, O. Customer accounting and customer profitability analysis for the order handling industry. A managerial accounting approach. Industrial Marketing Management, v. 36, p. 757-769, 2007.

2.3.4.3. LIND, J.; STRÖMSTEN, T. When do firms use different types of customer accounting? Journal of Business Research, v. 59, n. 12, p. 1257-1266, 2006.

2.3.4.4 MCMANUS, L.An examination of customer accounting in an Australian Context. Dissertation submitted in fullfilment of the requirements of the degree of Doctor of Philosofy. Griffithy University. January. 2006.

2.3.4.5 MALMI, T.; RAULAS, M.; SEHM, J.An empirical study on customer profitability accounting, customer strategies and corporate performance. Paper presented at the EAA Conference. Prague: April 2004.

2.3.4.6 GUILDING, Chris; MCMANUS, Lisa.The incidence, perceived merit and antecedents of customer accounting: an exploratory note. Accounting, Organizations and Society, v. 27, p. 45-59, 2002.

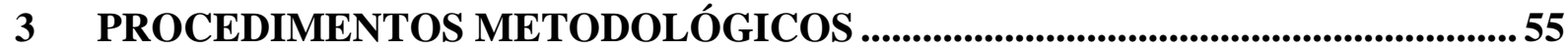

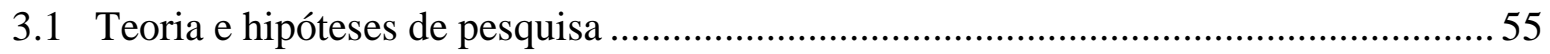

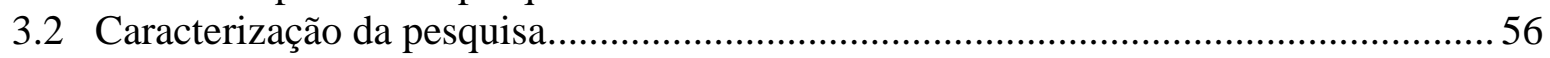

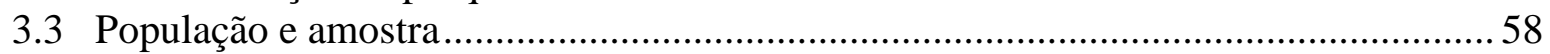

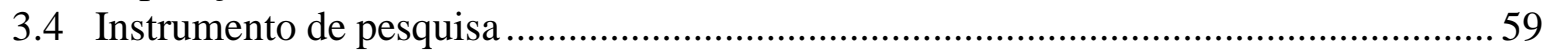

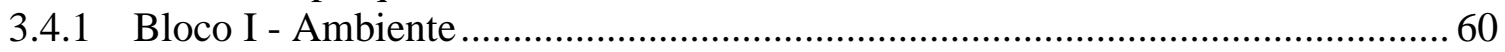

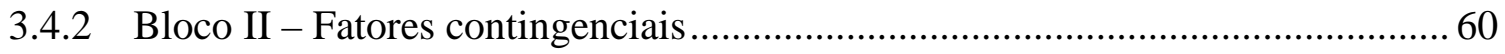

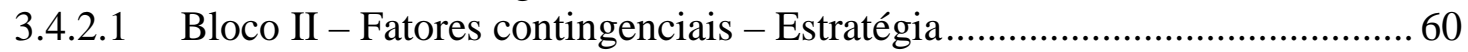

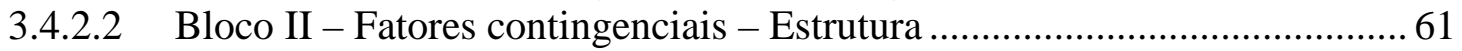

3.4.2.3 Bloco II - Fatores contingenciais - Tecnologia..........................................62 62

3.4.2.4 Bloco II - Fatores contingenciais - Porte da organização ............................ 62

3.4.3 Bloco III - Atributos dos Sistemas de Controle Gerencial Focados nos Clientes62

3.4.3.1 Bloco III - Atributos dos Sistemas de Controle Gerencial Focados nos Clientes - Desenhos do sistema de informação..........................................63

3.4.3.2 Bloco III - Atributos dos Sistemas de Controle Gerencial Focados nos

Clientes - Percepção sobre relevância e valor agregado .............................. 63

3.4.4 Bloco IV - Uso dos Sistemas de Controle Gerencial Focados nos Clientes......... 64

3.4.5 Bloco V - Desempenho dos Sistemas de Controle Gerencial Focados nos

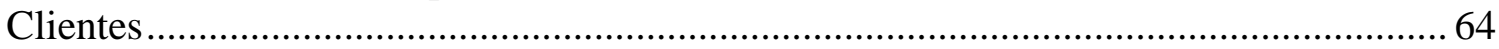

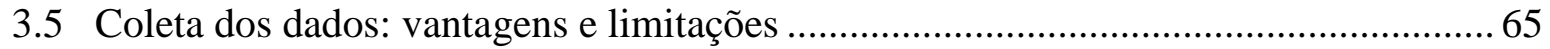

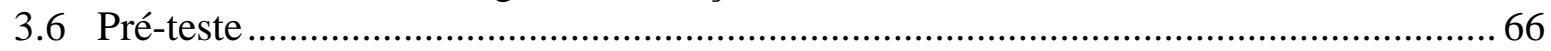

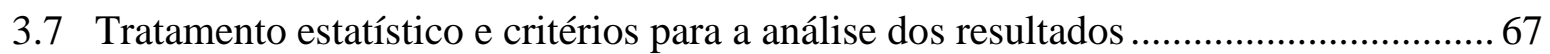

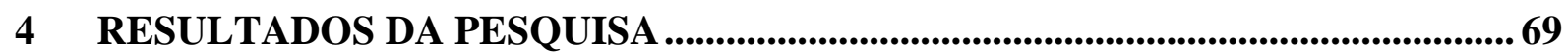

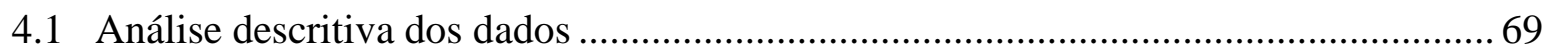

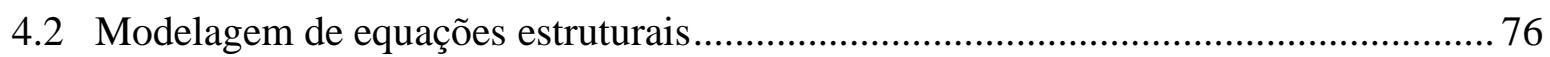

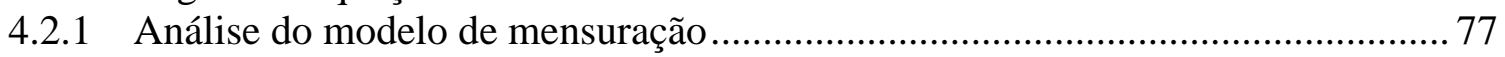

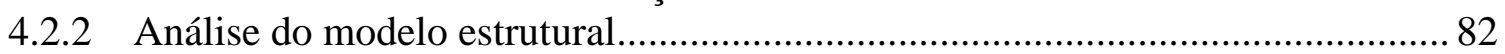

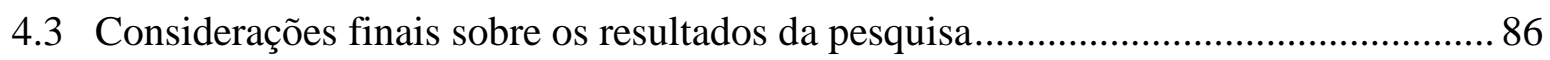

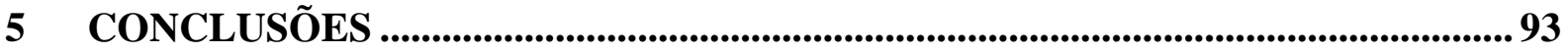

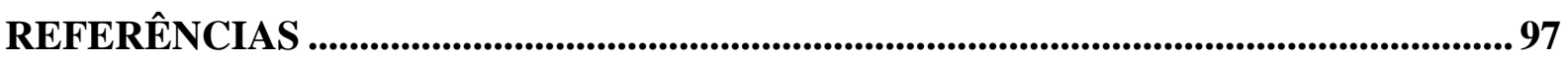

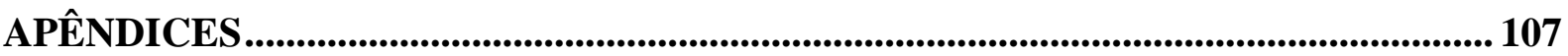




\section{LISTA DE ABREVIATURAS E SIGLAS}

ABC: ActivityBasedCosting

ALC: Análise da Lucratividade do Cliente

BI: Business Intelligence

CE: Customer Equity

CFC: Contabilidade Focada no Cliente

CLV: CustomerLifetimeValue

CRM: Customer Relationship Management

EDI: Electronic Data Interchange

ERP: Enterprise Resource Planning

FIPECAFI: Fundação Instituto de Pesquisas Contábeis, Atuariais e Financeiras

MCS: Management Control Systems

MEE: Modelagem de Equações Estruturais

PLS: Partial Least Square

PLS-PM: Partial Least Square - Path Modeling

ROC: Return on Customer

ROI: Return on Investment

SCG: Sistema de Controle Gerencial

SCGFC: Sistema de Controle Gerencial Focado nos Clientes

SCM: Supply Chain Management

SPSS: Statistical Package for the Social Sciences

VEC: Valor Econômico do Cliente

VL: Variável Latente

VME: Variância Média Explicada

VVC: Valor Vitalício do Cliente 


\section{LISTA DE TABELAS}

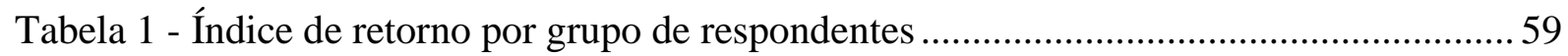

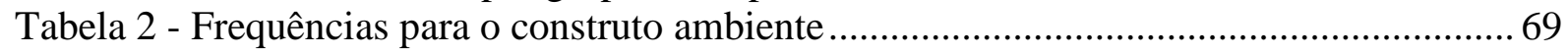

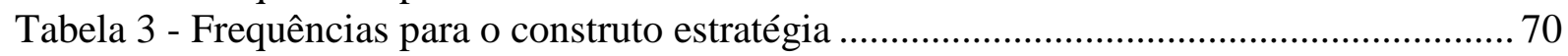

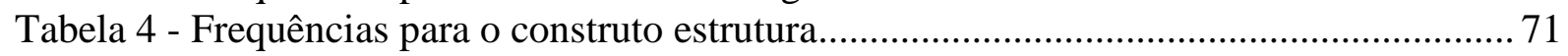

Tabela 5 - Frequências para o construto tecnologia ........................................................... 71

Tabela 6 - Estatísticas descritivas do construto "análise da lucratividade dos clientes".......... 72

Tabela 7 - Estatísticas descritivas do construto "valor vitalício do cliente" ............................. 73

Tabela 8 - Estatísticas descritivas do construto "valor econômico do cliente"....................... 73

Tabela 9 - Estatísticas descritivas do construto "uso diagnóstico" ........................................... 74

Tabela 10 - Estatísticas descritivas do construto "uso interativo" ............................................ 74

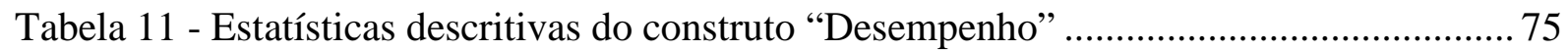

Tabela 12 - Empresas por atividade econômica....................................................................... 75

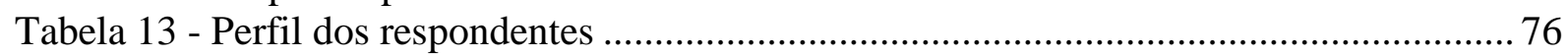

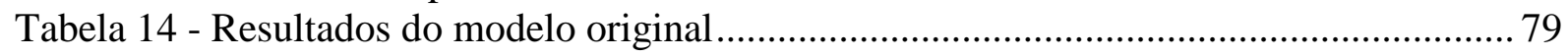

Tabela 15 - Matriz de correlações entre as variáveis do modelo original ................................ 80

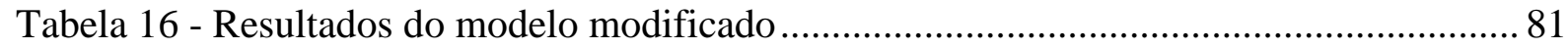

Tabela 17 - Matriz de correlações entre as variáveis do modelo modificado ........................... 82

Tabela 18 - Modelo estrutural - relacionamentos entre os construtos.................................... 85

Tabela 19 - Resultados da VL ambiente e os efeitos na VL Fatores Contingenciais Internos 87

Tabela 20 - Resultados da VL ambiente e os efeitos nos atributos dos SCGFC..................... 88

Tabela 21 - Resultados da VL Fatores Contingenciais Internos e os efeitos nos atributos dos

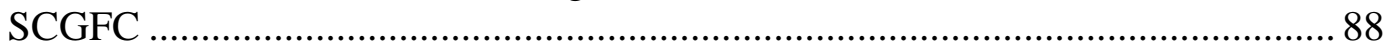

Tabela 22 - Resultados da VL Atributos dos SCGFC e os efeitos no uso intensivo dos SCGFC

Tabela 23: Resultados da VL Atributos dos SCGFC e os efeitos no uso intensivo dos SCGFC 


\section{LISTA DE FIGURAS}

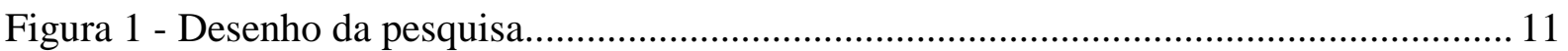

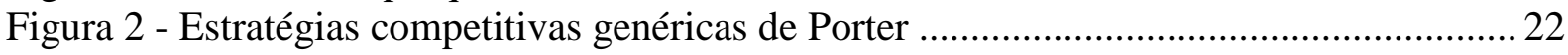

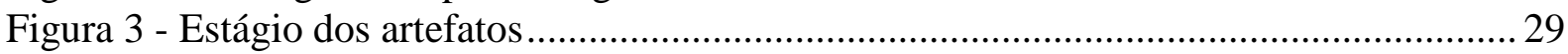

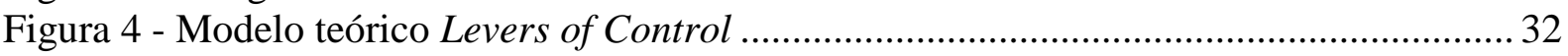

Figura 5 - Estágios do desenvolvimento da contabilidade focada no cliente........................... 38

Figura 6 - Clientes com a mesma receita e características de custos desiguais ....................... 41

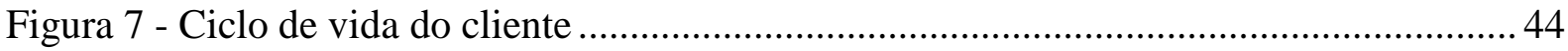

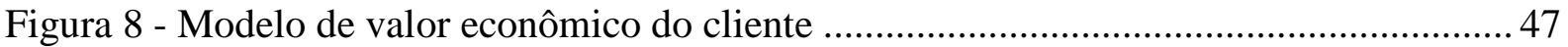

Figura 9 - Hipóteses de pesquisa - Visão dimensional dos constructos ...................................56

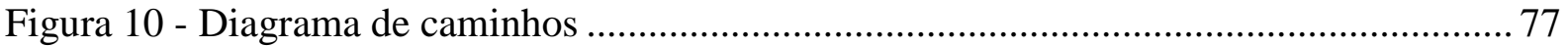

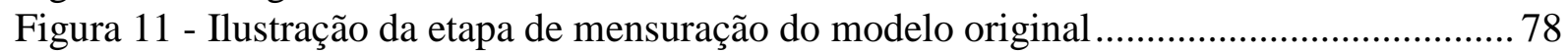

Figura 12 - Ilustração da etapa de mensuração do modelo modificado .................................... 81

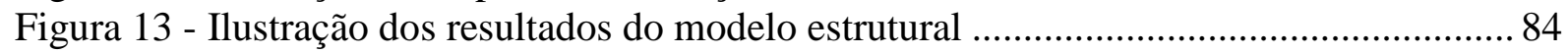

Figura 14 - Ilustração do modelo estrutural - Estatísticas t de student ................................... 85

Figura 15 - Coeficientes estruturais na variável desempenho dos SCGFC............................ 91 


\section{LISTA DE QUADROS}

Quadro 1 - Características dos sistemas mecânicos e orgânicos............................................. 17

Quadro 2 - Principais pesquisas seminais da teoria da contingência ....................................... 19

Quadro 3 - Classificação dos artefatos no desenho de sistemas de controle gerencial ............ 29

Quadro 4 - Dimensões do sistema de controle gerencial..................................................... 35

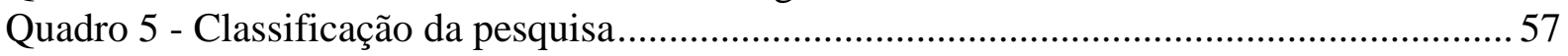

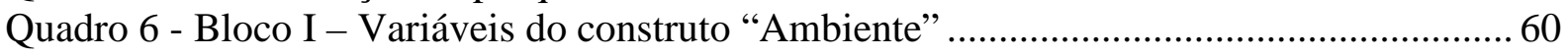

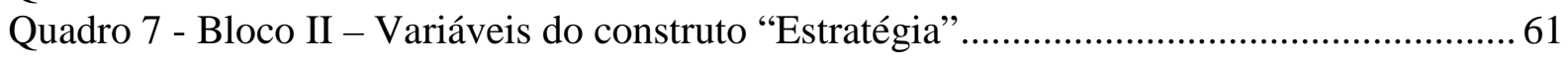

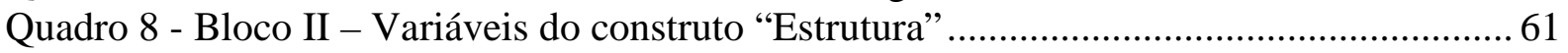

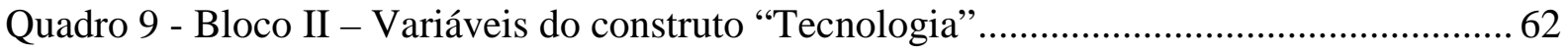

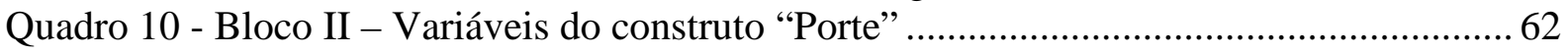

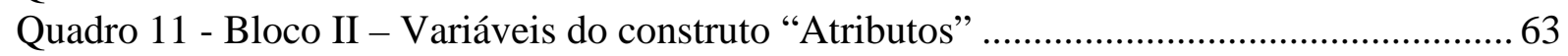

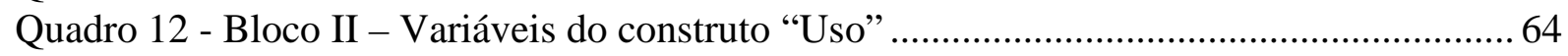

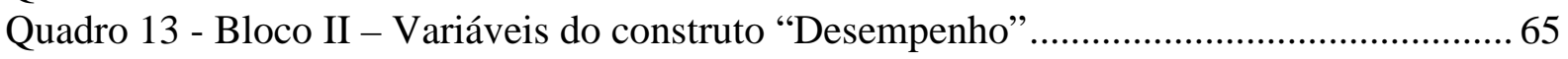

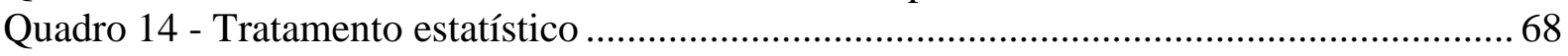

Quadro 15 - Classificação dos coeficientes de correlação ...................................................... 83

Quadro 16 - Classificação do efeito explicativo de uma variável latente ................................ 83

Quadro 17 - Hipóteses de pesquisa e resultados alcançados ................................................... 86 


\section{INTRODUÇÃO}

A importância do cliente para o sucesso a longo de prazo de qualquer empreendimento tem representado tema central nas discussões na área de negócios. As empresas, na busca pela competitividade, descobriram nos clientes uma oportunidade de alavancar seus resultados. Isto se deve à constatação de que todas as empresas têm clientes e nenhuma delas pode existir indefinidamente se fracassar no atendimento às suas necessidades (ATKINSON et al., 2000).

A perspectiva observada por Peppers e Rogers (2005) de que os clientes são diferentes colabora na compreensão dos desejos e necessidades de produtos e serviços, a fim de possibilitar uma evidenciação clara, da sua proposição de valor (DESARBO et al., 2001). Existe, portanto, uma plataforma para os gestores compreenderem os efeitos dessas diferenças entre os clientes, o que revela a utilidade e aplicação da contabilidade focada no cliente (KAPLAN; NARAYANAN, 2001).

Para Gupta e Lehmann (2006), os clientes são importantes ativos da empresa e representam a razão da existência de qualquer organização. Sem clientes a empresa não gera receitas, nem resultados e consequentemente não possuirá valor de mercado. Na mesma linha, Blattberg et al. (2001) argumentam que o cliente é um ativo financeiro que as empresas devem avaliar, gerir e maximizar, assim como qualquer outro ativo, se quiserem conquistar uma vantagem competitiva.

Por anos, os clientes vêm sendo incluídos e focados nos estudos de marketing. Contudo, nos últimos quarenta anos, houve um aumento na intensidade dessa atividade e as últimas décadas testemunharam o surgimento de uma série de desenvolvimentos em relação à fidelidade, lucratividade e valor do cliente (WEIR, 2008).

Os conceitos de valor e lucratividade do cliente são predominantemente encontrados na literatura de marketing e em menor número na literatura da contabilidade de hotéis e bancos. De maneira geral, na literatura contábil, os conceitos de valor e lucratividade do cliente são conhecidos como customeraccounting ou contabilidade focada no cliente (GUILDING; MCMANUS, 2002; LIND; STRÖMSTEN, 2006; WEIR, 2008). 
Contudo, como constatam McManus e Guilding (2008), existe certo distanciamento, dos gerentes de contabilidade gerencial, pelo interesse da contabilidade do cliente, já que os sistemas de controle gerenciais tendem a ser apropriados para produtos, serviços ou territórios geográficos e raramente para clientes ou segmentos de clientes.

Juntando-se aos trabalhos em contabilidade gerencial que abordaram a contabilidade do cliente, a presente pesquisa vai analisar a interação entre o desenho e o uso de sistemas de controle gerencial focados nos clientes, sob a perspectiva da influência de fatores contingenciais.

\subsection{Contextualização do problema}

Os clientes representam a existência da organização. Assim como muitos outros clichês, parece ser verdade que, sem clientes, uma empresa não tem vendas, nem lucros e consequentemente não possui valor de mercado (GUPTA; LEHMANN, 2006).

Existem duas razões fundamentais para as organizações adotarem a abordagem do valor do cliente. Primeiro, uma gama de novas tecnologias convergem para tornar possível o gerenciamento da base de clientes. Segundo, as capacidades propiciadas pelo surgimento dessas tecnologias e as mudanças turbulentas no ambiente de negócios requerem da gerência a maximização do valor da base de clientes da empresa (BLATTBERG; GETZ; THOMAS, 2001).

Os gestores, por sua vez, na busca pela continuidade dos negócios necessitam se aparelhar para lidar com profundas mudanças tecnológicas, pela rapidez da informação, relações comerciais tensas e por um ambiente cada vez mais competitivo e incerto. Nesse contexto, os artefatos contábeis servem como facilitadores do alcance dos objetivos organizacionais (ESPEJO, 2008).

Nesse sentido, o Sistema de Controle Gerencial (SCG), sistema que perpassa toda a estrutura organizacional e fornece insumos para decisões estratégias, táticas e operacionais, conectando as pessoas com as suas respectivas atividades organizacionais, deve ser estruturado para 
contribuir com o processo decisório e o alcance da vantagem competitiva, remunerando adequadamente o capital investido (DECHOW; GRANLUND; MOURITZEN, 2007).

A premissa para compreender o papel da contabilidade é a consideração do contexto em que ela e seus artefatos operam. Elementos de natureza humana, questões políticas, de poder e social exercem fortes influências sobre a concepção e o uso dos artefatos da contabilidade gerencial (FREZATTI et al., 2009).

Considerando que esses conceitos, sistemas e ferramentas operam dentro de um contexto organizacional sob certas contingências (ambientais, tecnológicas, estratégicas e estruturais), os artefatos contábeis devem ser postos à reflexão, ao invés de serem aplicados indistintamente como práticas universais ou verdades absolutas, independentemente de tempo e espaço (ESPEJO, 2008).

A abordagem contingencial, aplicada à Contabilidade Gerencial, baseia-se na premissa de que não há um único modelo de sistemas de controle gerencial que se aplique de forma efetiva e eficaz a todo tipo de organização, variando de acordo com a influência dos fatores contextuais (DONALDSON, 2001).

O cliente ou a base de clientes da empresa, como visto no tópico anterior, representa tema central nas pesquisas de marketing e somente muito recentemente tem sido estudado por pesquisadores da contabilidade gerencial sob a ótica da contabilidade focada no cliente (GUILDING; MCMANUS, 2002; LIND; STRÖMSTEN, 2006) ou ainda como uma categoria da contabilidade gerencial estratégica (CADEZ; GUILDING, 2008).

Fatores contingenciais como ambiente, estratégia, estrutura e porte empresarial são variáveis que influenciam a escolha e o respectivo uso de instrumentos, técnicas ou práticas contábeis. Assim sendo, o desenho e o uso de sistemas de contabilidade focados nos clientes devem igualmente estar apropriados para auxiliar os gestores a atingir os objetivos organizacionais. 


\subsection{Questão de pesquisa}

Quais são as influências dos fatores contingenciais no desenho dos sistemas de controle gerencial focados nos clientes, a influência deste desenho no seu uso e a de ambos - desenho e uso - no desempenho do sistema?

\subsection{Objetivos}

O objetivo geral desta pesquisa reside em investigar os relacionamentos entre os atributos do sistema de contabilidade focado nos clientes, os fatores contingenciais, a intensidade do uso desses sistemas e o seu desempenho.

Para atender o objetivo geral desta pesquisa são estabelecidos os seguintes objetivos específicos:

Explicitar, através da revisão da literatura, os fatores contingenciais que afetam o desenho e uso de sistemas de controle gerencial focados nos clientes, tais como: ambiente, estratégia, estrutura organizacional, tecnologia e porte.

Investigar empiricamente em empresas brasileiras a influência dos fatores contingenciais sobre o desenho e o uso de SCG focados nos clientes.

Verificar, com a utilização de técnicas estatísticas apropriadas, a existência de relacionamentos entre as variáveis de pesquisa estudadas. 


\subsection{Definições operacionais}

Uma vez definida a questão de pesquisa e os objetivos geral e específico, torna-se necessário apresentar as definições operacionais dos elementos do desenho da pesquisa na figura 1.

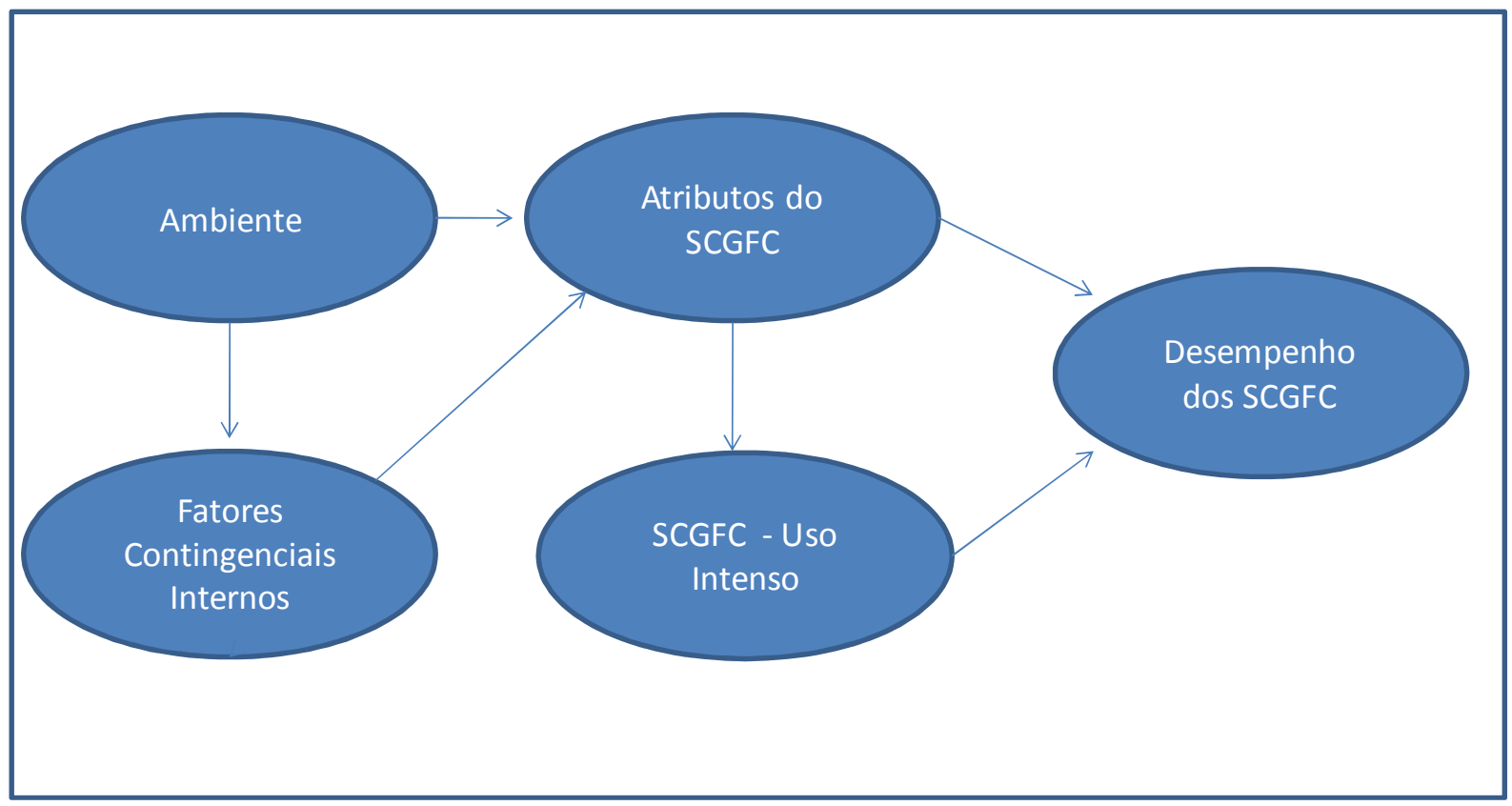

Figura 1 - Desenho da pesquisa

Na figura 1 os círculos simbolizam os principais construtos da pesquisa e estão representados pelas incertezas do ambiente, fatores contingenciais internos (estratégia, estrutura, tecnologia e porte), atributos do Sistema de Controle Gerencial Focado nos Clientes (SCGFC), o uso intenso e a sua performance. As setas indicam o relacionamento, que se espera verificar, entre as próprias variáveis latentes pesquisadas.

As definições operacionais que suportam a presente pesquisa são apresentadas abaixo:

Fatores contingenciais - São variáveis internas e externas que influenciam os atributos dos sistemas de controle gerencial (CHENHALL, 2003). As variáveis utilizadas na pesquisa são: ambiente, estratégia, estrutura, tecnologia e porte organizacional.

Atributos do Sistema de controle gerencial focado nos clientes - representa as características de um conjunto de técnicas e práticas orientadas à avaliação das receitas ou do valor presente do lucro, atribuído a um cliente ou grupo de clientes (GUILDING; MCMANUS, 2002). Tais características podem, segundo Weir (2008), ser agrupadas em três 
conjuntos: i- análise da lucratividade do cliente; ii- valor vitalício do cliente; iii- valor econômico do cliente.

Uso intenso do sistema de controle gerencial focado nos clientes - De acordo com Simons (1995), o uso de sistemas de controle gerencial pode ser diagnóstico ou interativo. Nesta pesquisa, o uso intenso representa a forma combinada do uso diagnóstico com o uso interativo (FERREIRA; OTLEY 2010).

Desempenho do sistema de controle gerencial focado no cliente - representada em termos de utilidade percebida e satisfação do usuário. Como consequência, esses indivíduos tomam melhores decisões e se aproximam mais de suas metas organizacionais (FREZATTI; AGUIAR; REZENDE, 2006).

\subsection{Justificativas do trabalho}

A influência que os clientes exercem direta ou indiretamente no desempenho das empresas pode provocar interesse aos administradores que desejam compreender os efeitos práticos da aplicação de suas estratégias no negócio. O uso da contabilidade focada no cliente apresentase como artefato da contabilidade gerencial para prover subsídios ao processo de gestão empresarial e, dessa forma, contribuir para melhorar o desempenho da empresa.

Outro aspecto relevante da pesquisa é a característica interdisciplinar que a reveste, visto que se busca verificar o relacionamento de variáveis da contabilidade focada no cliente com recursos ou competências estratégicas e o seu efeito traduzido no desempenho da empresa. Assim, as áreas do conhecimento da Contabilidade Gerencial, Marketing, Estratégia e Finanças vão se entrelaçar formando um arcabouço próprio que se reveste de grande importância para a contabilidade gerencial.

Na questão da contribuição de outras áreas para a pesquisa em Contabilidade Gerencial, Chenhall e Langfield-Smith (2007), na sua avaliação crítica sobre pesquisas relacionadas à teoria da contingência, lembram que a literatura de marketing identifica um rico contexto que possui grande relevância para as pesquisas em Sistemas de Controle Gerencial. 
Além disso, vêm agregar às pesquisas em contabilidade gerencial os trabalhos que procuraram estudar os artefatos dos SCG focados nos clientes, como é o exemplo das pesquisas desenvolvidas por Guilding e McManus (2002), Malmiet al. (2004), Lind e Strömsten (2006), Helgesen (2007), Lord (2007), McManus e Guilding (2008) e Weir (2008).

\subsection{Contribuições}

As principais contribuições deste trabalho referem-se: i- ao estudo paralelo das pesquisas desenvolvidas por McManus (2006) permitindo avaliar e relacionar os resultados obtidos; iiadicionar às pesquisas em contabilidade gerencial a temática referente à contabilidade focada no cliente, o relacionamento entre fatores contingenciais e seus principais construtos, e o efeito no desempenho do sistema.

A abordagem dos fatores internos e externos à organização influenciando, o desenho e o uso de sistemas de controle gerenciais, reveste o presente estudo, de um caráter multidisciplinar, haja vista sua integração com a área de marketing, notadamente no interesse de obter respostas às demandas surgidas na gestão do relacionamento com o cliente.

Do ponto de vista pragmático, entende-se que a pesquisa possa servir de orientação aos administradores, a medida, que evidencia a influência exercida pelos fatores contingenciais na composição de sistemas de controle gerencial focados nos clientes. Além disso, visa enfatizar, que o uso de sistemas de controle gerencial, quer na forma de diagnóstico, quer na forma interativa e tanto melhor no seu conjunto, podem gerar benefícios pela plena utilização dos artefatos, alcançando o desempenho desejado.

\subsection{Delimitações da pesquisa}

$\mathrm{Na}$ operacionalização da pesquisa, foram considerados fatores internos e externos à organização, os quais, pelas suas características próprias, exercem influência nas decisões dos administradores em relação, às suas escolhas quanto ao modelo de sistemas de controle gerenciais focados nos clientes, que mais se adequam ao processo de gestão. 
Em relação à abordagem dos fatores internos, que podem ser qualificados como um conjunto de características únicas, que as organizações adotam para se ajustar as forças do ambiente e obter a eficácia, foi admitido especificamente às seguintes variáveis: estratégia, estrutura, tecnologia e porte organizacional.

A investigação dos efeitos dos fatores internos e externos exercidos nos sistemas de controle gerencial focados nos clientes se limitou a discutir, aspectos relacionados tanto ao desenho, quanto ao uso, em detrimento de qualquer aspecto qualitativo da sua informação.

Quanto ao desenho foram consideradas especificamente as seguintes configurações: i- análise da lucratividade do cliente; ii- valor vitalício do cliente; iii- valor econômico do cliente. Em relação ao uso foram observados os seguintes aspectos: i- uso diagnóstico e ii- uso interativo.

A teoria da contingência serviu de base para a abordagem das dimensões dos fatores internos e externos e das dimensões dos sistemas de controle gerenciais focados nos clientes. Como eixo central das fundamentações, análises e discussões do trabalho, sua utilização foi privilegiada sobre outra teoria que também pudesse ser aplicada.

O universo pesquisado contempla vários segmentos relevantes da economia nacional, representados pelo ranking da revista Exame Maiores e Melhores e pelas empresas representadas pelo grupo dos alunos matriculados nos cursos de pós graduação em Contabilidade. Assim, dadas as características das amostras estudadas, os resultados da pesquisa não podem ser generalizados para a população de empresas brasileiras.

Em relação aos respondentes da pesquisa realizada, optou-se pela escolha de profissionais envolvidos na gestão das áreas de controladoria e finanças. Assim sendo, deve-se ressaltar, que os resultados da pesquisa refletem apenas as percepções desse grupo exclusivo de executivos. 


\section{REFERENCIAL TEÓRICO}

\subsection{Teoria da contingência}

\subsubsection{Aspectos conceituais da teoria da contingência}

Estudos contemporâneos sobre as organizações proporcionaram o surgimento de uma nova perspectiva teórica: a estrutura da organização e seu funcionamento são dependentes da sua interface com o ambiente externo. Assim, diferentes ambientes requerem diferentes desenhos organizacionais para obter a eficácia. Torna-se, portanto, imperativo um modelo apropriado para cada situação (CHIAVENATO, 2004).

A teoria da contingência também existe dentro do contexto da mudança ambiental evolucionária. A premissa básica é que desempenhos mais altos estão associados a empresas que desenvolvem um ajuste mais benéfico com seu ambiente. Desse modo, o desempenho organizacional pode ser visto como resultado conjunto das forças ambientais e das ações estratégicas da empresa (WRIGHT; KROLL; PARNELL, 2000, p.32).

De acordo com Donaldson (2001, p.1), a essência do paradigma da teoria da contingência reside na eficácia das organizações, que é alcançada através do ajustamento das suas próprias características, tal como sua estrutura, com as contingências que refletem a situação da organização.

Para a abordagem contingencial são as características ambientais que condicionam as características organizacionais. É no ambiente que estão as explicações causais das características das organizações. Assim, não há uma única melhor maneira (the best way) de se organizar. Tudo depende (it depends) das características ambientais relevantes para a organização (CHIAVENATO, 2004, p.500).

Donaldson (2001) conceitua contingência como sendo qualquer variável que modera o efeito de uma característica organizacional no desempenho da organização. Os pesquisadores têm estudado a contingência sob vários aspectos, tais como o ambiente (BURNS; STALKER, 1961 apud CHIAVENATO, 2004), o porte (CHILD, 1975 apud CHIAVENATO, 2004) e estratégia organizacional (CHANDLER, 1962 apud CHIAVENATO, 2004). 


\subsubsection{Estudos pioneiros sobre a teoria da contingência}

“A Teoria da Contingência surgiu a partir de várias pesquisas feitas para verificar os modelos de estruturas organizacionais mais eficazes em determinados tipos de empresas.[...] Os resultados das pesquisas conduziram a uma nova concepção de organização: a estrutura da organização e seu funcionamento são dependentes da interface com o ambiente externo" (CHIAVENATO, 2004, p.504).

\section{Burns e Stalker}

Tom Burns e G.M. Stalker, dois sociólogos, pesquisaram indústrias inglesas para verificar a relação entre práticas administrativas e ambiente externo dessas indústrias (CHIAVENATO, 2004, p.506). Na opinião de Donaldson (2001, p.37), Burns e Stalker proporcionaram a contribuição mais fundamental para a teoria orgânica, propondo uma teoria que provou ser de interesse por muitos acadêmicos. Esses autores encontraram diferentes procedimentos administrativos nas indústrias e os classificaram em dois tipos: "mecanicistas" e "orgânicos".

A estrutura mecanicista enfatiza a hierarquia, de modo que a organização é dividida em tarefas especializadas, cujos ocupantes ficam dependentes dos seus subordinados, já que são estes que retêm a maior parte da informação e do conhecimento. A imagem de uma estrutura mecanicista é de uma estrutura hierárquica, com forte poder de controle, que determina rigorosamente os papéis dos níveis inferiores (DONALDSON, 2001).

Para Chiavenato (2004), esses distintos procedimentos administrativos são denominados de sistemas "mecanicistas" e "orgânicos". No sistema mecanicista, as tarefas são divididas por especialistas e de maneira claramente definida. As operações são reguladas por instruções, regras e decisões emitidas pelos superiores. A administração ocorre por uma hierarquia rígida e opera um sistema vertical descendente e ascendente.

Por outro lado, na estrutura orgânica, a compreensão das tarefas é amplamente dividida entre os empregados que utilizam suas prerrogativas para aceitarem a responsabilidade e o trabalho de modo flexível. A imagem de uma estrutura orgânica reflete uma rede ligando todas as funções na qual os especialistas colaboram de modo frequente e ad hoc (DONALDSON, 2001). 
Os sistemas orgânicos, na opinião de Chiavenato (2004), são sistemas adaptáveis a condições ambientais instáveis, quando os problemas e exigências de ação não podem ser fragmentados e distribuídos entre especialistas numa hierarquia definida. Os trabalhos são flexíveis em termos de métodos, obrigações e poderes, pois devem ser constantemente redefinidos. A interação é lateral e vertical, não se atribuindo onisciência aos superiores.

O argumento contingente de Burns e Stalker é que a forma mecanicista de organização é apropriada para condições ambientais estáveis, isto é, baixas taxas de mudanças tecnológicas e mercado, enquanto a forma orgânica é apropriada para condições ambientais de altas taxas de mudanças e inovação. O quadro abaixo apresenta as principais características entre os sistemas mecânicos e orgânicos.

Quadro 1 - Características dos sistemas mecânicos e orgânicos

\begin{tabular}{|c|c|c|}
\hline CARACTERÍSTICAS & SISTEMAS MECÂNICOS & SISTEMAS ORGÂNICOS \\
\hline Estruturaorganizacional & Burocrática, permanente, rígida, e definitiva & Flexível, mutável, adaptativa e transitória \\
\hline Autoridade & Baseada na hierarquia e no comando & Baseada no conhecimento e na consulta \\
\hline Desenho de cargos e tarefas & $\begin{array}{l}\text { Definitivo, cargos estáveis e definitivos. } \\
\text { Ocupantesespecialistas e univalentes }\end{array}$ & $\begin{array}{l}\text { Provisório. Cargos mutáveis, redefinidos } \\
\text { constantemente. Ocupantespolivalentes }\end{array}$ \\
\hline Processodecisorial & $\begin{array}{c}\text { Decisões são centralizadas na cúpula da } \\
\text { organização } \\
\end{array}$ & $\begin{array}{c}\text { Decisões descentralizadas ad hoc ( aqui e } \\
\text { agora) }\end{array}$ \\
\hline Comunicações & Quasesempreverticais & Quasesemprehorizontais \\
\hline Confiabilidadeem & $\begin{array}{c}\text { Regras e regulamentosformalizadospor } \\
\text { escrito e impostospelaempresa }\end{array}$ & $\begin{array}{c}\text { Pessoas e comunicações informais entre as } \\
\text { pessoas }\end{array}$ \\
\hline Princípiospredominantes & Princípiosgerais da TeoriaClássica & $\begin{array}{c}\text { Aspectosdemocráticos da TeoriaRelações } \\
\text { Humanas }\end{array}$ \\
\hline Ambiente & Estável e permanente & Instável e dinâmico \\
\hline
\end{tabular}

FONTE: Chiavenato (2004, p.507)

\section{Chandler}

Chandler (1962) realizou uma investigação histórica sobre as mudanças estruturais de quatro grandes empresas americanas - a DuPont, a General Motors, a Standard Oil Co e Sears Roebuck - relacionando-as à estratégia de negócios para demonstrar como a estrutura dessas empresas foi sendo continuadamente adaptada e ajustada à sua estratégia (CHIAVENATO, 2004, p. 505). 
Ainda segundo Chiavenato (2004), a estrutura organizacional corresponde ao desenho da organização, representada pela forma que ela assumiu para integrar seus recursos, enquanto a estratégia corresponde ao plano global de alocação de recursos para atender as demandas do ambiente. Para Chandler, as grandes organizações passaram por um processo histórico que envolveu quatro fases distintas: i- acumulação de recursos; ii- racionalização do uso dos recursos; iii- continuação do crescimento e iv- racionalização do uso de recursos em expansão.

Nas suas conclusões, Chandler (1962) argumenta que a estratégia orienta a estrutura, assim como uma estratégia de diversificação sugere uma estrutura divisional para combinar com essas operações diversificadas. Assim, surge o ajustamento entre a estrutura divisional e a estratégia como contingência (DONALDSON, 2001, p. 77) .

\section{Joan Woodward}

Joan Woodward (1958), socióloga industrial, organizou uma pesquisa para avaliar se a prática dos princípios de administração proposta pelas teorias administrativas se correlacionava com o êxito do negócio. A pesquisa envolveu 100 firmas inglesas de vários negócios e tamanhos, classificadas em três grupos de tecnologia de produção: i- produção unitária ou oficina, iiprodução em massa ou mecanizada e iii- produção em processo ou automatizada (CHIAVENATO, 2004).

As conclusões de Woodward são as seguintes: a) o desenho organizacional é afetado pela tecnologia usada pela organização: as firmas de produção em massa bem sucedidas tendem a ser organizadas em linhas clássicas; b) há uma forte correlação entre estrutura organizacional e previsibilidade das técnicas de produção: a previsão de resultados é alta para a produção por processo contínuo e baixa para oficina; c) as empresas com operações estáveis necessitam de estruturas diferentes das organizações com tecnologia mutável: organizações estruturadas e burocráticas com sistema mecanicista são mais apropriadas para operações estáveis, enquanto a organização inovadora e com tecnologia mutável requer um sistema orgânico e adaptativo; d) sempre há o predomínio de alguma função na empresa: a importância de cada função depende da tecnologia utilizada. 
Quadro 2 -Principais pesquisas seminais da teoria da contingência

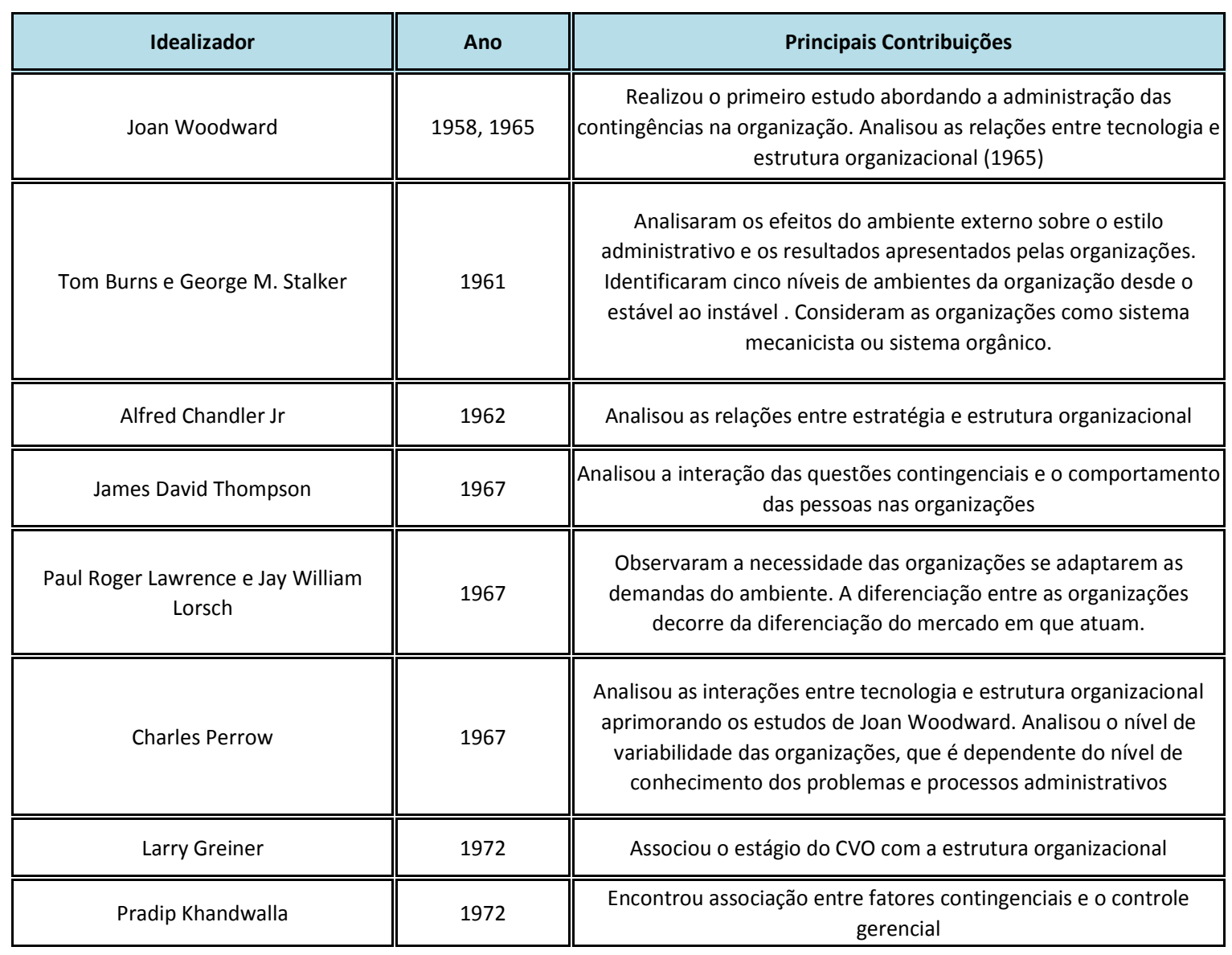

FONTE: Oliveira (2008, p. 291-292)

\subsubsection{Construtos da pesquisa em relação à abordagem contingencial}

Em consonância com os fundamentos da teoria da contingência, o desenho dos sistemas de controle gerencial segue os mesmos princípios, ou seja, não há um único e universal sistema de controle gerencial que pode ser de utilidade para todas as organizações em todas as circunstâncias (FERREIRA;OTLEY, 2010).

A eficácia de um sistema de controle gerencial é contingente de circunstâncias particulares enfrentadas pela empresa, as quais são importantes para a escolha do sistema de controle gerencial apropriado (CHENHALL, 2003). Baseados na premissa da não universalidade do desenho de sistemas de controle gerencial, pesquisadores têm estudado como diferentes variáveis, tais como a natureza do ambiente externo, a estrutura organizacional, tecnologia, porte e estratégia, influenciam o desenho de sistemas de controle gerencial (ABDEL- 
KADER; LUTHER, 2008; CHENHALL; MORRIS, 1986; GORDON; NARAYANAN, 1984, KHANDWALLA, 1972;MERCHANT, 1984; SIMONS, 1987).

As organizações, na busca da sua eficácia, procuram ajustar suas características, levando em conta os fatores contingenciais. Os sistemas de controle gerencial devem suportar esse processo e seu desenho deve corresponder a essas variáveis conjunturais. Neste tópico, são abordados os construtos utilizados para mensurar os fatores contingenciais.

\subsubsection{1 $O$ ambiente como fator contingencial externo}

Ambiente é o contexto que envolve externamente a organização. É a situação dentro da qual uma organização está inserida, de modo que tudo o que ocorre externamente no ambiente passe a influenciar internamente o que ocorre na organização (CHIAVENATO, 2004, p.512).

As características das forças presentes no ambiente e o seu estado de constante modificação demanda das organizações flexibilidade e adaptação, pois estas refletem diretamente em seus resultados, que espelham e determinam suas condições de continuidade num ambiente essencialmente dinâmico (PEREIRA, in: CATELLI, 1999).

Ao nível fundamental, os sistemas de controle gerencial são desenhados com o objetivo de suprir os administradores, nos processos de tomada de decisão, com informações que sabidamente são influenciadas pela natureza do ambiente externo. Nesse sentido, permite aumentar a eficácia organizacional, permitindo às empresas a melhor maneira de lidar com as incertezas e a imprevisibilidade do ambiente externo (FERREIRA; OTLEY, 2010).

O estudo de Chong e Chong (1997) revelou que o uso de artefatos contemporâneos do sistema de controle gerencial contribui para reduzir as incertezas e assim melhorar o processo de tomada de decisão. Consistentemente, Abdel-Kader e Luther (2008) identificaram que as empresas que atuam em ambientes de alta incerteza adotam práticas sofisticadas de contabilidade gerencial.

Os autores Guilding e McManus (2002), em seu trabalho pioneiro, estudaram os efeitos de fatores contingenciais, tais como intensidade da competição e orientação para mercado, no 
uso e na percepção do mérito, de práticas relacionadas aos sistemas de controle gerencial focados nos clientes.

As variáveis do construto ambiente serão operacionalizadas baseadas na taxonomia desenvolvida por Khandwalla (1972), que sugere que, quanto maior o nível de competição, maior é a exigência de sistemas de controle gerenciais. Este modelo tem sido utilizado nas pesquisas em contabilidade gerencial, normalmente, quando se deseja averiguar as associações entre o fator contingencial ambiente e o desenho de sistemas de controle gerencial (GORDON; NARAYANAN, 1984; GUILDING; MCMANUS 2002; SHARMA 2002; ESPEJO 2008).

Dessa forma, o construto ambiente reveste-se das características observadas nas diferentes dimensões da competitividade e será mensurada através dos níveis de intensidade quanto: a) vendas e distribuição; b) qualidade e variedade de produtos; c) preço; d) market-share; e) serviços ao cliente.

\subsubsection{A estratégia como fator contingencial interno}

O termo estratégia pode ser visto num grande espectro de conceitos contando ainda com inúmeras aplicações na prática. No contexto da empresa, de acordo com Wright, Kroll e Parnell (2000, p.24), a estratégia refere-se aos planos da alta administração para alcançar resultados consistentes com a missão e os objetivos gerais da organização.

O foco da estratégia empresarial é melhorar a posição competitiva de produtos e serviços da organização no setor ou segmento em que atua, podendo ser classificada em: competitiva (enfrentando todos os concorrentes para obter vantagem); cooperativa (trabalhando com um ou mais concorrentes para obter vantagem em relação aos demais); ou utilizar ambos os sistemas (HUNGER; WHEELEN, 2002).

Porter (1990) apud Hunger e Wheelen (2002) propõe duas estratégias competitivas "genéricas" para superar o desempenho dos seus concorrentes: menor custo e diferenciação. Essas estratégias são chamadas de genéricas porque podem ser seguidas por uma empresa de qualquer tipo ou tamanho, até mesmo por organizações sem fins lucrativos. 
- Estratégia de menor custo é a capacidade de uma empresa ou unidade de negócios projetar, produzir e comercializar, com mais eficiência que os concorrentes, um produto comparável ao deles.

- Estratégia de diferenciação é a capacidade de oferecer ao comprador um produto de valor único e superior em termos de qualidade, recursos especiais ou serviços pós venda.

Ainda, de acordo com Porter (1990), quando as estratégias de menor custo e diferenciação têm como alvo um amplo mercado de massa são respectivamente chamadas de liderança de custo e de diferenciação. Porém, quando se concentram em um nicho de mercado (alvo restrito), as duas estratégias são chamadas respectivamente de foco em custo e de diferenciação focalizada.

A figura 2 representa, em forma de matriz, a relação dos tipos de estratégia, levando-se em conta o vértice da vantagem competitiva e a sua respectiva conjugação com o escopo competitivo, definido em termos de alvo amplo e alvo estreito.

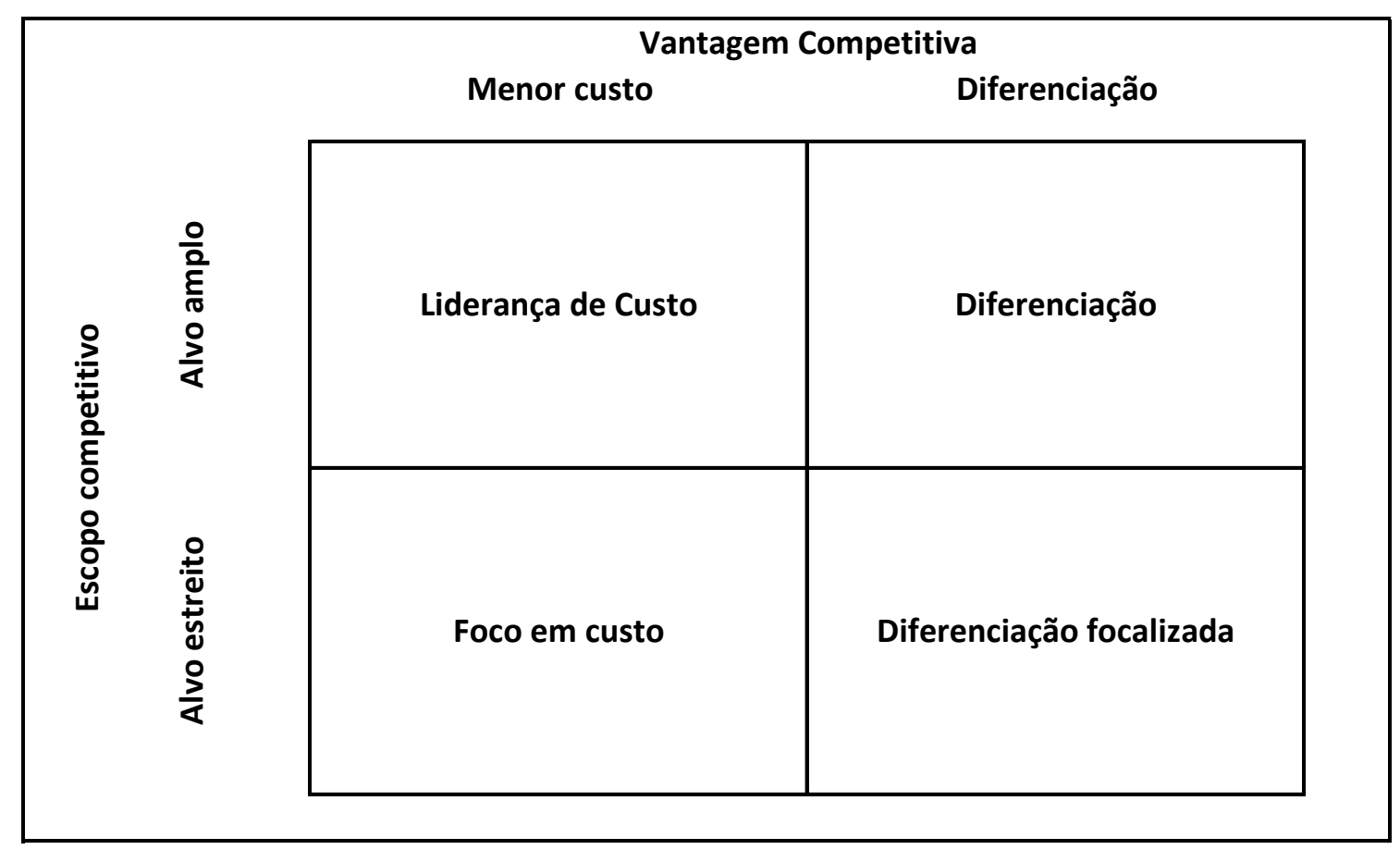

Figura 2 -Estratégias competitivas genéricas de Porter FONTE: Hunger e Wheelen (2002, p.109) 
As variáveis do construto estratégia serão operacionalizadas baseadas no conceito de estratégias competitivas, estabelecido por Porter (1990) e adaptadas dos estudos de Chenhall e Langfield-Smith (1998) e Chenhall (2005). Serão observados os níveis de importância das seguintes variáveis de pesquisa: a) fornecer produtos de alta qualidade; b) custos de produção baixos; c) fornecer produtos diferenciados; d) fornecer produtos de preço baixo; e) modificar o desenho e introduzir novos produtos rapidamente; f) modificar o volume/mix dos produtos oferecidos; g) fazer entregas rápidas; h) fornecer um serviço efetivo de pós venda; i) disponibilidade imediata de produtos; j) customizar produtos e serviços às necessidades dos clientes.

\subsubsection{A estrutura como fator contingencial interno}

A estrutura organizacional refere-se aos modos pelos quais as tarefas e responsabilidades são alocadas aos indivíduos e também a maneira como os indivíduos são agrupados em escritórios, departamentos e divisões (WRIGHT; KROLL; PARNELL, 2000). Para Chenhall (2003), a estrutura organizacional representa a atribuição formal de papéis para os membros da organização ou, ainda, tarefas para grupos, para assegurar que as atividades da organização sejam cumpridas.

De acordo com Chenhall (2003), a estrutura organizacional pode ser operacionalizada sob vários aspectos: i- em termos de descentralização de autoridade; ii- em termos de estruturação de atividades; iii- interdependência e iv- orientação orgânica-mecanicista.

O construto estrutura será operacionalizado com base na abordagem orgânica de Burns e Stalker (1961) e as variáveis observadas serão aquelas mencionadas nos trabalhos de Gordon e Narayanan (1984) e Sharma (2002), ou seja: a) delegação; b) formalidade; c) nível dos tomadores de decisão; d) estilo gerencial; e) especialização.

\subsubsection{A tecnologia da informação como fator contingencial interno}

A tecnologia no contexto organizacional possui vários significados num sentido amplo, Chenhall (2003) define tecnologia como a maneira que a organização opera, isto é, como ela transforma seus recursos em produtos ou serviços e inclui: hardware, tais como máquinas e ferramentas, materiais, pessoas, software e conhecimento. 
A tecnologia, estudada como fator contingencial, em pesquisas sobre sistemas de controle gerencial, normalmente é associada às práticas de manufatura, tais como JIT, TQM, FM e AMT e a tecnologia da informação (BURNS; VAIVIO, 2001; CHENHALL, 2003; HYVÖNEN, 2007). Na presente pesquisa, a tecnologia será observada na dimensão da tecnologia da informação.

Pode-se entender, por tecnologia da informação, todo software e hardware de que uma empresa necessita para atingir seus objetivos organizacionais. As tecnologias de armazenagem de dados, de comunicação e de redes, juntamente com as pessoas necessárias para acioná-las e administrá-las, representam recursos que podem ser compartilhados por toda a organização e constituem a infraestrutura de tecnologia da informação (LAUDON; LAUDON, 2007).

O desenvolvimento da tecnologia da informação permitiu inovar e mudar a forma de coletar, mensurar, analisar e comunicar a informação dentro e entre as organizações, pela adoção de tecnologias tais como: enterprise resource planning; e-commerce; internet electronic data interchange, e reuniões eletrônicas (BURNS; VAIVIO, 2001).

São muitas as pressões sofridas pela contabilidade, pela sua eficiência funcional no que se refere a produção da informação para decisão e suporte ao controle. A informação contábil deve ser correta, consistente, objetiva, sistemática, em tempo, rápida, eletrônica e eficiente no seu custo de obtenção. A tecnologia da informação pode auxiliar na realização de todos esses objetivos (GRANLUND, 2007).

As variáveis do construto tecnologia da informação serão operacionalizadas baseadas no conceito de Laudon e Laudon (2007) e adaptadas do estudo de Hyvönen (2007). Serão observados os níveis de utilização das seguintes variáveis de pesquisa: a) e-commerce; b) Enterprise Resource Planning - ERP; c) gestão do relacionamento com o cliente - Customer Relationship Management - CRM; d) gestão da cadeia de suprimentos - Supply Chain Management-SCM; e) Data Warehousing; f) Troca eletrônica de informações - Electronic Data Interchange - EDI; g) Sistemas de Inteligência de Negócios - Business Intelligence- BI. 


\subsubsection{O porte da organização como fator contingencial interno}

O porte da organização é uma variável amplamente utilizada nas pesquisas sobre fatores contingenciais e sistemas de controle gerenciais. Não apenas pela sua capacidade de capturar muito da complexidade das organizações, mas, sobretudo, por indicar a necessidade de sistemas formais de controle gerenciais (FERREIRA; OTLEY, 2010).

Organizações grandes geralmente por terem acesso a uma fonte maior de recursos financeiros, humanos, técnicos e conhecimento vão, provavelmente, se beneficiar da economia de escala dos seus investimentos na adoção, implementação e uso de sistemas contemporâneos de controles gerenciais (FERREIRA; OTLEY, 2010).

Empresas grandes são aquelas que em primeiro lugar adotam sistemas contemporâneos de controle gerenciais. O estudo de Hoque e James (2000) revelou evidências empíricas de que o uso do Balanced Scorecard está associado ao porte da empresa. Ainda, o trabalho de AbdelKader e Luther (2008) indicou a existência de associação positiva entre o porte da empresa e o emprego de práticas sofisticadas de controle gerencial.

As variáveis do construto porte da organização serão operacionalizadas baseadas na pesquisa de Ferreira e Otley (2010) e observadas a partir de: a) valor das vendas líquidas e b) número de empregados.

\subsection{Controle gerencial, Sistemas de Controle Gerencial, Controladoria e Desempenho}

Os termos contabilidade gerencial, sistemas de contabilidade gerencial, sistemas de controle gerencial e controle organizacional são, algumas vezes, utilizados como forma alternativa (CHENHALL, 2003, p.129). No entanto, como observam Frezatti et al. (2009, p.12), esses termos podem parecer sinônimos, mas realmente não o são, cabendo a cada um deles conceitos bem específicos.

Muitos autores, na opinião de Merchant e Otley (2007), quando não se referem ao termo Controle como sinônimo de poder, o fazem para destacá-lo como parte de um processo genérico da administração, que envolve: 1- o estabelecimento de objetivos; 2- a decisão pela 
melhor estratégia para alcançar esses objetivos; 3- implementar as estratégias escolhidas; e 4assegurar-se de que nada, ou o mínimo possível, dê errado.

Como lembra Langfield-Smith (2007, p.754), os tipos de controles têm sido categorizados de várias maneiras. A autora cita como exemplos: formal e informal (Anthony et al., 1989), comportamentais e resultados (Ouchi, 1977), mercado, burocrático e grupos sociais (Ouchi, 1977), administrativo e social (Hopwood, 1976), resultados, ação e pessoais (Merchant, 1985), burocráticos e orgânicos (Chenhall, 2003), e diagnóstico e interativo (Simons, 1995).

Uma referência do domínio dos sistemas de controle gerencial nos é dada por Merchant e Otley (2007, p.785) que assim os define: em termos gerais um SCG é desenhado para auxiliar uma organização a adaptar-se ao seu ambiente e a cumprir certos objetivos críticos de grupos de stakeholders, mais concentrado especificamente em acionistas nas organizações comerciais.

Uma outra definição de Controle gerencial é dada por Anthony e Govindarajan (2008) como o processo pelo qual os gestores influenciam os outros membros de uma organização para implementar suas estratégias. Consideram que esse processo envolve uma série de atividades que incluem: planejamento, coordenação, comunicação, avaliação, decisão e influência sobre pessoas.

O conceito de processo é compartilhado por Giraudet al. (2011, p.2) que observam que o Controle Gerencial pode ser definido como um processo, no qual a empresa estabelece objetivos de desempenho e esforça-se ao máximo para alcançá-los ao longo do tempo. Além das ações tomadas para atingir esses objetivos, esse processo envolve lidar com as ameaças externas e as dificuldades internas.

Frezatti et al. (2009, p.13), citando Anthony e Govindarajan (2008), descrevem Controle Gerencial como o conjunto de atividades desenvolvidas para assegurar que os planos gerenciais sejam atingidos. Esse conjunto de atividades demanda recursos e estrutura para que as atividades sejam desenvolvidas.

Sob uma ótica mais abrangente, Merchant e Van der Stede (2007) destacam que o controle gerencial inclui todos os mecanismos ou sistemas usados para assegurar que o comportamento 
e as decisões dos empregados estejam consistentes com os objetivos e estratégias da organização.

\subsubsection{Estrutura de um sistema de controle gerencial}

Um sistema de controle gerencial é estruturado baseado em duas dimensões fundamentais: idesenho e ii- uso. O desenho de SCG, de acordo com Ferreira e Otley (2009) vem sendo conceitualizado de duas formas. A primeira reúne os atributos dos SCG, segmentado pelas características da informação, Gordon e Miller (1976), Amigoni (1978), Merchant (1981), Chenhall e Morris (1986) e Simons (1987) e o segundo, pelas características dos artefatos empregados que os compõem.

Um exemplo de aspectos qualitativos da informação gerada pelos SCG pode ser obtido do estudo de Chenhall e Morris (1986), classificando-os com as seguintes características: escopo; tempestividade; nível de agregação e nível de integração. Aguiar, Pace e Frezatti (2009) as descrevem da seguinte forma:

- Escopo é definido em termos de três dimensões: foco, quantificação e horizonte de tempo. A partir dessas três dimensões, o escopo é classificado como sendo estreito ou amplo. O escopo estreito é voltado para eventos internos, quantificados em termos financeiros e horizonte de tempo orientado para o passado. Já o escopo amplo inclui informações voltadas tanto para eventos internos quanto externos, quantificadas em termos financeiros e não financeiros e direcionados tanto para o passado quanto para o futuro.

- Tempestividade se refere à frequência e à velocidade dos relatórios. Frequência diz respeito aos intervalos de tempo requeridos para a produção das informações, enquanto velocidade dos relatórios se refere a defasagem de tempo entre quando uma informação é requerida e quando ela vai estar disponível. Alta tempestividade será obtida quando, na percepção dos usuários, os relatórios forem fornecidos em pequenos intervalos e com pequena defasagem; enquanto, por outro lado, baixa tempestividade ocorrerá quando os intervalos forem maiores, assim como a defasagem. 
- Nível de agregação diz respeito a informações por área funcional, período de tempo ou modelos de decisão. Por sua vez, integração refere-se a informações sobre as atividades e outros departamentos dentro da empresa e sobre o impacto de decisões de um departamento sobre o desempenho dos demais.

A fim de averiguar o nível de racionalidade econômica, Ferreira e Otley (2009) incluíram uma nova característica da informação, a qual denominaram de "custo". Assim, puderam capturar a condição do dispêndio em relação à forma de obter essa informação.

Já em relação às técnicas do SCG, Frezatti et al. (2009) apresentam uma argumentação para a utilização do termo "artefato" que é adotado em razão de trazer uma certa organização aos elementos do controle gerencial, já que o ambiente de trabalho do controle gerencial inclui uma série de elementos de diferentes naturezas que precisam ser tratados, incluindo o que se chama de conceitos, ferramentas, modelos, sistemas, etc.

Ainda, na opinião de Frezatti et al. (2009), os estágios dos artefatos da contabilidade no controle gerencial podem ser classificados em :

Conceitos: são representações mentais de um objeto abstrato ou concreto, que se mostram como um instrumento fundamental do pensamento em sua tarefa de identificar, descrever e classificar os diferentes elementos e aspectos da realidade.

Modelo: é qualquer representação simplificada de objetos, sistemas, processos ou eventos reais, criada com a finalidade de facilitar a compreensão, representando graficamente, facilitando a visualização ou servida como base das regras de referência das relações que ocorrem entre os elementos de um sistema, processo ou evento, do mundo real.

Ferramenta: é qualquer instrumento necessário à prática profissional.

Sistema: conjunto de partes interagentes e interdependentes que conjuntamente formam um todo unitário com determinado objetivo e efetuam determinada função. A figura 3, a seguir, demonstra as diversas condições de um artefato da contabilidade gerencial. 


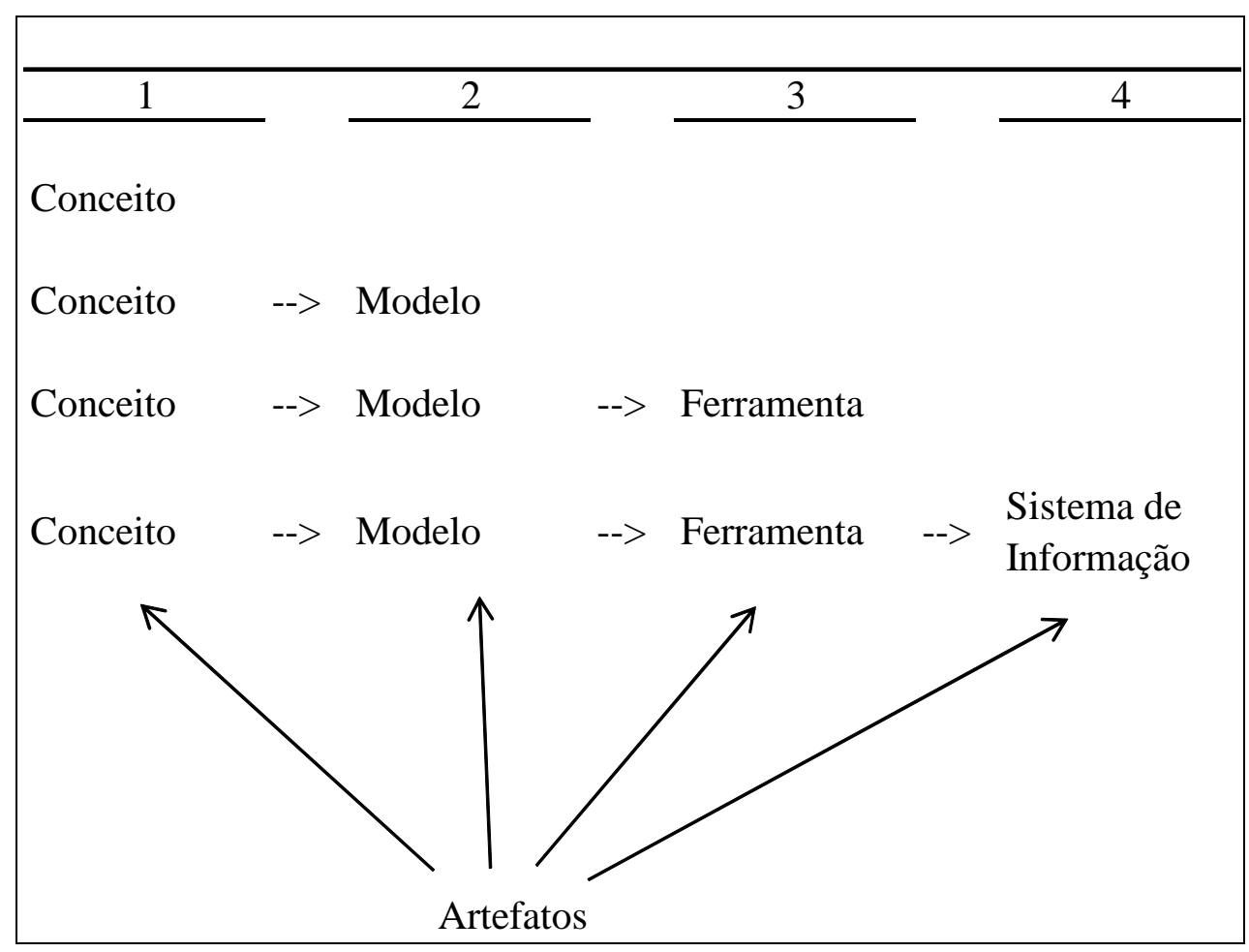

Figura 3 - Estágio dos artefatos

FONTE: Frezatti et al. (2009, p.15)

O desenho de SCG é configurado a partir de um conjunto de técnicas de controle, representado por "artefatos" que normalmente são utilizados de forma conjunta e cobrem uma vasta área de interesse da organização. Entre essas áreas destacam-se: i- planejamento e controle de curto e longo prazo; ii- avaliação de desempenho; iii-custeio do produto; ivinformação de suporte ao processo decisório. As características desses artefatos do SCG são classificadas em tradicionais e contemporâneas (FERREIRA; OTLEY, 2009).

Quadro 3 -Classificação dos artefatos no desenho de sistemas de controle gerencial

\begin{tabular}{|c|c|}
\hline \multicolumn{2}{|c|}{ Desenho de Sistema de Controle Gerencial } \\
\hline \multicolumn{2}{|c|}{ Artefatos } \\
\hline Tradicionais & Contemporâneas \\
\hline Planejamento Estratégico & Balanced Scorecard \\
\hline Orçamentos & Orçamento baseado em atividades \\
\hline Análise das variações & Custeio baseado em atividades \\
\hline Técnicas de custeio & Custo Meta \\
\hline Análise da lucratividade do produto & Análise da lucratividade do cliente \\
\hline Tableau de bord & Valor Econômico Adicionado \\
\hline Lucro Residual & Análise do ciclo de vida do produto \\
\hline Retorno sobre o Investimento & Benchmarking \\
\hline Análise do custo volume lucro & \\
\hline Pesquisa Operacional & \\
\hline
\end{tabular}

FONTE: Adaptado de Ferreira e Otley (2009) 


\subsubsection{Four Levers of Control: o modelo teórico de Simons}

Na opinião de Simons (1995; 2000), os SCG podem ser definidos como sistemas de informação, rotinas e procedimentos formais que os gestores utilizam para manter ou modificar os modelos das atividades organizacionais incluindo informação para o processo de planejamento, orçamento, controle de custos, percepções do ambiente, análise dos concorrentes, avaliação do desempenho, alocação de recursos e recompensa aos empregados.

De acordo com Simons (2000), existem quatro aspectos importantes associados a essa definição: i- são sistemas que provêm informações financeiras e não financeiras que influenciam o processo de decisão e a ação gerencial;ii- representam rotinas e procedimentos formais;iii- são desenhados para serem usados pelos gestores e seu propósito é gerar informação relevante para a gerência;iv- são utilizados para manter ou modificar as atividades dos membros da organização.

A partir dos resultados de uma série de estudos de casos, Simons $(1995 ; 2000)$ desenvolveu o seu modelo teórico "the levers of control framework" para o controle da estratégia empresarial. Segundo Simons, a busca pelo equilíbrio entre inovação e controle reflete o desafio central da gerência. O modelo é composto basicamente em quatro sistemas: i-Sistemas de Crenças (Belief Systems);ii- Sistemas de Restrições (Boundary Systems);iii- Sistemas de Controle Diagnóstico (Diagnostic Control Systems); e iv- Sistemas de Controle Interativo (Interactive Control Systems).

A construção desses quatro sistemas tem como pano de fundo o conceito de Tensões Dinâmicas geradas pelo uso do SCG, as quais ocorrem quando os gerentes têm que atingir objetivos organizacionais que podem ser conflitantes, mas em que a organização deseja certa complementaridade e um balanceamento entre esses objetivos (HENRI, 2006; OYADOMARI et al., 2009).

Na conclusão de Ferreira e Otley (2009), o modelo teórico de Simons tem foco claro na estratégia, abordando uma perspectiva abrangente e completa dos sistemas de controle das organizações, proporcionando, dessa forma, uma tipologia útil para classificar os diferentes usos de SCG. 
Por outro lado, Ferreira e Otley (2005) criticam o modelo de Simons pelas limitações ao seu uso em virtude do forte apelo aos controles, rotinas e procedimentos formais e por atribuir pouca atenção para os controles informais e sociais. Conforme Collier (2005), em empresas pequenas e empreendedoras as formas de controles sociais e culturais tendem a sobressair sobre os demais.

Para os propósitos do presente estudo, considera-se o modelo teórico de Simons como sendo inteiramente adaptável, já que o foco da pesquisa reside no uso de sistemas de controle gerencial de grandes empresas brasileiras, em cujo contexto predominam os controles formais.

\subsubsection{Sistemas de Crenças - Beliefs System}

Um sistema de crenças é o conjunto explícito de definições organizacionais que a alta direção comunica formalmente e reforça sistematicamente para uniformizar valores, propósitos e caminhos para a organização. O Sistema de Crenças representa os controles designados para dar respostas às demandas por inovação e encorajar os funcionários na busca de novas oportunidades (SIMONS, 1995).

Pela comunicação da missão, visão e valores, a alta direção visa inspirar seus colaboradores na busca de novos meios de criação de valor. Os sistemas de crenças são abrangentes e inspiradores de maneira a fluir por todos os níveis da organização. Todavia, não são específicos o suficiente para serem usados como padrões ou mesmo como base de avaliação de desempenho (SIMONS, 1995).

O sistema de Crenças deve influenciar tanto os chamados Controles Pessoais, ou seja, quando

a própria pessoa controla o seu comportamento, quanto o Controle Cultural, em que um conjunto de crenças compartilhadas funciona como um padrão de comportamento para os demais membros organizacionais (MERCHANT; VAN DER STEDE, 2007; OYADOMARI et al., 2009). 


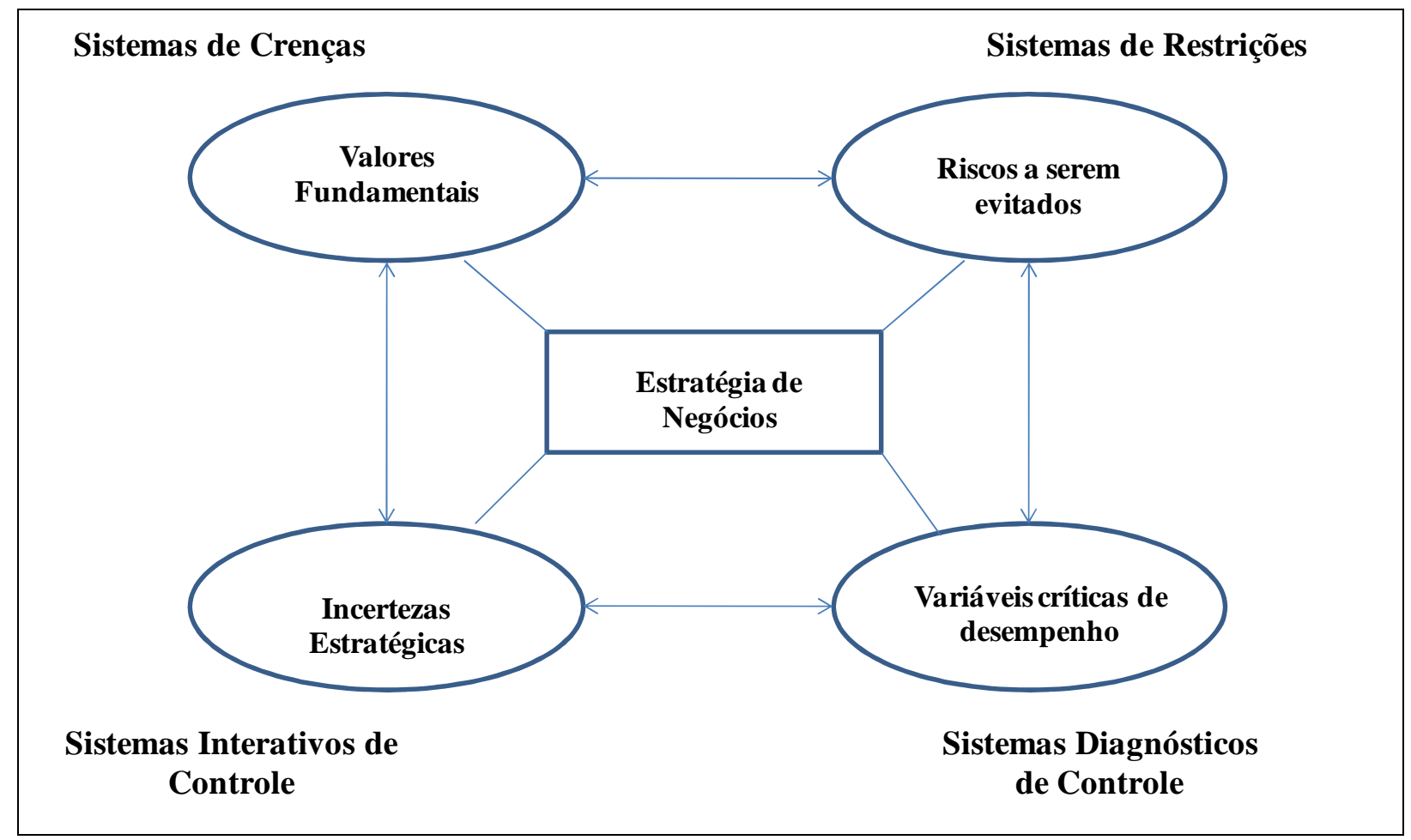

Figura 4 -Modelo teórico Levers of Control FONTE: Simons (1995)

\subsubsection{Sistemas de Restrições - Boundary Systems}

A alta direção utiliza o sistema de restrições para definir um âmbito aceitável na conduta pela busca de oportunidades. O sistema possui dois tipos de restrições: restrições de negócios e restrições estratégicas. As restrições de negócio baseiam-se no código formal de conduta. As restrições estratégicas, por outro lado, são usadas para delimitar o alcance na conduta pela busca de oportunidades no suporte explícito da estratégia (SIMONS, 1995).

Essas duas restrições permitem que a organização obtenha criatividade e flexibilidade pela delegação da tomada de decisão aos níveis mais baixos da organização. Além disso, auxilia os gestores na medida em que delimita o campo de atuação estratégica da empresa e, assim, contribui para evitar a perda de tempo na busca de oportunidades que não representam foco da organização (SIMONS, 1995; OYADOMARI et al., 2009).

\subsubsection{Sistemas de Controle Diagnóstico - Diagnostic Control System}

O Sistema de Controle Diagnóstico ou uso diagnóstico é a forma tradicional de uso do sistema de controle gerencial, o qual tem como propósito avaliar a implementação da 
estratégia de negócios. O sistema de Controle Diagnóstico é focado na implementação de estratégias e na orientação da alta direção através do gerenciamento por exceção para monitorar os resultados organizacionais e compará-los aos padrões pré-estabelecidos a fim de corrigir os possíveis desvios visando manter o curso da estratégia (SIMONS, 1995; 2000; OYADOMARI et al., 2009).

Pela sua natureza, as variáveis críticas de desempenho monitoradas pelo Sistema de Controle Diagnóstico podem ser financeiras ou não financeiras, dependendo dos fatores que a alta direção destaca como sendo cruciais para atingir a estratégia. São exemplos de controles diagnósticos o planejamento do lucro e orçamento, sistemas de metas e objetivos, balancedscorecard, sistemas de monitoramento de projetos e sistemas de planejamento estratégico (SIMONS, 2000).

Em geral, o Sistema de Controle Diagnóstico recebe atenção restrita da alta direção. Na prática, os contadores elaboram relatórios periódicos de exceção para a alta direção. A intervenção desses gestores se inicia somente em caso de desvios substanciais focando suas ações na compreensão das causas e na descrição dos planos de ações corretivos. Assim, o uso diagnóstico representa a forma de assegurar que a organização atinja suas metas e ao mesmo tempo economize tempo dos gestores, já que não é preciso o envolvimento da alta direção no constante monitoramento da estratégia (SIMONS, 1995; 2000).

O uso diagnóstico é descrito como a força negativa que cria restrições e assegura a conformidade às regras. De acordo com Henri (2006), são dois os fatores que representam a força negativa no uso diagnóstico: i- foco nos erros e variações negativas; ii- o sinal dos desvios obtidos quando os resultados e metas são comparados é contrário ao sinal de resposta de ajuste do processo.

As críticas atribuídas ao uso diagnóstico recaem principalmente na orientação de curto prazo, já que o processo de controle leva em conta números contábeis que refletem o desempenho de curto prazo. A problemática reside nas competências empreendedorismo e inovação, uma vez que, os gestores se sentiriam prejudicados se tivessem que gastar mais do que os valores planejados, mesmo que fosse necessário melhorar o desempenho no médio e longo prazos (MERCHANT, 1990; VAN DER STEDE, 2000 apud OYADOMARI, 2009). 


\subsubsection{Sistemas de Controle Interativo - Interactive Control System}

Simons $(1995$; 2000) define sistemas interativos de controle como sistemas formais de informação que os gestores utilizam para envolver-se regular e pessoalmente em decisões sobre as atividades dos seus subordinados. De acordo com Simons (1995), a alta direção pode mudar qualquer sistema diagnóstico em sistema interativo pelo constante interesse e atenção.

Em oposição ao sistema diagnóstico, que se empenha em alcançar as metas planejadas, o sistema interativo demonstra como os sistemas de controle podem possuir um papel na formação de estratégias através do foco na necessidade da inovação e criatividade. Esse sistema encoraja a busca por novas oportunidades e promove o aprendizado organizacional, o qual pode levar à formação de estratégias emergentes (SIMONS, 1995; 2000).

Existem vários aspectos que distinguem sistemas interativos de sistemas diagnósticos. Simons (1995; 2000) destaca:

- A informação gerada por esse sistema é um importante e recorrente tema pelaalta direção;

- Demandam frequente e regular atenção dos gerentes operacionais de todos osníveis da organização;

- $\quad$ Os dados gerados por esse sistema são interpretados e discutidos em reuniõespresenciais com os superiores, subordinados e pares;

- O sistema é um catalisador para desafio contínuo e debate sobre os dados, premissas e planos de ação;

- $\quad$ Fornecer informações sobre os efeitos das incertezas estratégicas sobre a estratégia da empresa (SIMONS, 1995; OYADOMARI et al., 2009).

O uso do sistema interativo representa a força positiva já que os sistemas de controles gerenciais são utilizados para expandir a busca por oportunidades e aprendizado organizacional. O uso interativo foca a atenção e força o diálogo através do reflexo dos sinais enviados pela alta direção. Ele estimula o desenvolvimento de novas ideias e iniciativas que, através do foco nas incertezas estratégicas, conduzem à formulação de novas estratégias. $\mathrm{O}$ 
modo disfuncional, por sua vez, retrata a prática de outras finalidades que não aquelas originalmente estabelecidas pelo uso diagnóstico ou interativo.

O quadro 4 abaixo sintetiza as dimensões do sistema de controle gerencial, segregando-as em desenho e uso. A dimensão desenho é constituída pelas características da informação e técnicas, enquanto a dimensão uso por: diagnóstico, interativo e disfuncional.

Quadro 4 -Dimensões do sistema de controle gerencial

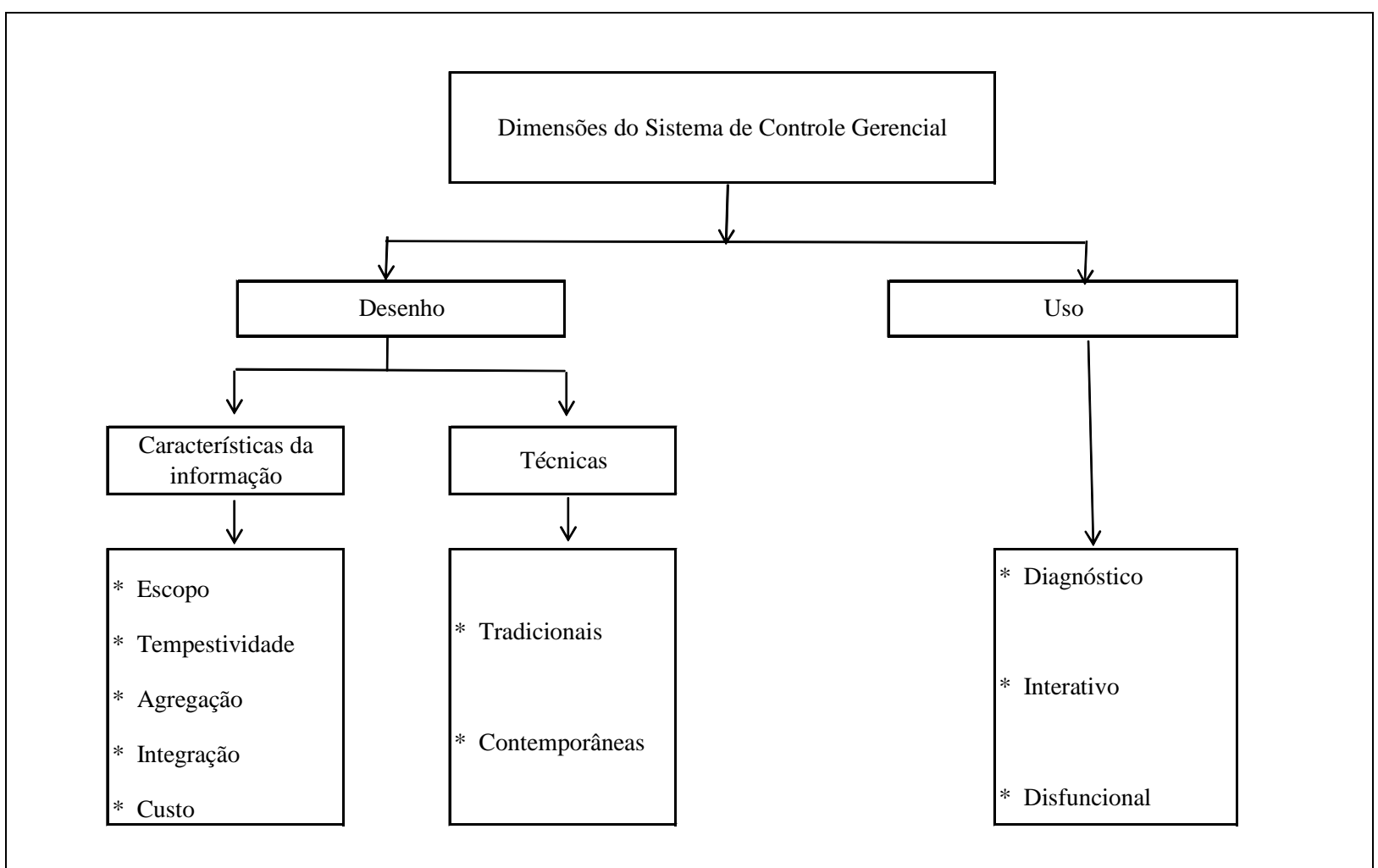

FONTE: Aguiar, Pace e Frezatti (2009)

\subsubsection{Tensões dinâmicas - Dynamic Tensions}

O uso combinado dos sistemas de controle diagnóstico e interativo de maneira a gerenciar as tensões organizacionais culmina com a criação de tensões dinâmicas refletindo a competição (feedback positivo versus feedback negativo) e complementaridade (foco na estratégia planejada e estratégias emergentes) (HENRI, 2006).

Na opinião de Oyadomari (2008, p.32), definem-se tensões dinâmicas como dilemas organizacionais presentes na organização, os quais, geralmente, confrontam visões conflitantes dos objetivos organizacionais como, por exemplo, a busca de objetivos de longo 
prazo, sem perder o foco nos objetivos de curto prazo; o controle racional dos custos, porém sem impedir o processo de inovação; um ambiente que estimule a cooperação entre os gestores, porém sem deixar de estimular a competição pela busca de resultados.

\subsubsection{Controladoria}

Para compreender o papel da Controladoria é preciso resgatar o conceito de Controle Gerencial (Anthony e Govindarajan, 2008 citados por Frezattiet al., 2009) como sendo o conjunto de atividades desenvolvidas para assegurar que os planos gerenciais sejam atingidos. Esse conjunto de atividades demanda recursos e estrutura para que as atividades sejam cumpridas.

Os autores Frezattiet al. (2009, p.13) esclarecem os significados dos termos, recursos e estrutura, dizendo que a Contabilidade Gerencial a partir de um sistema de informações gerenciais proporciona tais recursos e a Controladoria se constitui na estrutura que, geralmente, cuida tanto da contabilidade gerencial como da financeira.

Um conceito abrangente de Controladoria nos é fornecido por Nascimento e Reginato (2007, p.2) que dizem: a área de Controladoria tem a função de promover a eficácia dessas decisões, monitorando a execução dos objetivos estabelecidos, investigando e diagnosticando as razões para a ocorrência de eventuais desvios entre os resultados alcançados e os esperados, indicando as correções de rumo, quando necessárias e, principalmente, suavizando para os gestores as imponderabilidades das variáveis econômicas, através do provimento de informações sobre operações passadas e presentes e de sua adequada comunicação, de forma a sustentar a integridade do processo decisório.

\subsubsection{Desempenho}

Na revisão da literatura sobre a implementação de sistemas de mensuração de desempenho, Bourneet al. (2003) contextualizam o termo desempenho sob a ótica da métrica e da forma de mensurar o desempenho. A primeira é definida como a medida utilizada para quantificar a eficiência e efetividade de uma ação enquanto, no contexto da mensuração, seria o processo de quantificar a eficiência e efetividade de uma ação. 
Na opinião de Oyadomari (2008, p.19), o desempenho pode ser verificado sob várias perspectivas, ou seja, baseado em informações contábeis, com base em valores de mercado, combinando-se informações contábeis e mercado, combinando-se informações monetárias e não monetárias e ainda a inclusão dessas formas operacionalizadas por autoavaliação.

Os autores Merchant e Van Der Stede (2007, p.435) classificam a mensuração do desempenho em três grandes grupos: o primeiro grupo corresponde a um número absoluto, sumarizado, agregado. $\mathrm{O}$ segundo refere-se ao desempenho em relação ao resultado financeiro e o terceiro inclui uma combinação dessas medidas.

A primeira categoria inclui medidas de mercado, como o preço da ação e outras relacionadas ao retorno dos acionistas. A segunda categoria inclui métricas baseadas na contabilidade que, por sua vez, podem ser segregadas em termos residuais, como o lucro líquido depois dos impostos, lucro operacional, lucro residual e valor econômico agregado, ou ainda em termos de resultados ou quocientes, tais como o retorno sobre o investimento, retorno sobre o patrimônio líquido e retorno sobre os ativos operacionais.

A terceira categoria inclui combinações de medidas que podem ser baseadas tanto em mercado como na contabilidade, ou ainda o uso de um ou ambas adicionadas a alguma outra medida financeira ou não financeira, como é o caso da participação do mercado, crescimento das vendas, giro dos inventários e satisfação dos clientes.

\subsection{Sistemas de controle gerenciais focados no cliente}

As empresas, na busca pela competitividade, descobriram nos clientes uma oportunidade de alavancar seus resultados, passando a concentrar neles uma série de ações estratégicas. Isto se deve à constatação de que todas as empresas têm clientes e nenhuma pode existir indefinidamente se não conseguir atender às necessidades desses clientes (ATKINSON et al.,2000). Existindo, portanto, uma plataforma para os gestores compreenderem os efeitos dessas diferenças entre os clientes, o que revela a utilidade e aplicação da contabilidade focada no cliente (KAPLAN; NARAYANAN, 2001).

Os conceitos a respeito da avaliação do valor da lucratividade do cliente são encontrados predominantemente na literatura de marketing e em menor número nas esferas da 
contabilidade, o segmento hoteleiro e bancos (WEIR, 2008). Em geral, na literatura contábil, a avaliação e as métricas da lucratividade do cliente são contextualizadas holisticamente como “customer accounting”, a contabilidade focada no cliente (GUILDING; MCMANUS, 2002; LIND; STRÖMSTEN, 2006).

Na opinião de Weir (2008), na sistematização das práticas da contabilidade focada no cliente, fica evidente a existência de três estágios em seu desenvolvimento, sendo cada um deles relacionado a um conjunto próprio de técnicas e procedimentos. Ainda, segundo Weir (2008), o primeiro estágio refere-se simplesmente ao cálculo do lucro do cliente, denominando-se análise da lucratividade do cliente ou análise da lucratividade de um segmento de clientes. $\mathrm{O}$ segundo estágio leva em conta o resultado obtido do cliente durante todo o seu ciclo de relacionamento, também conhecido como ciclo de relacionamento com o cliente e, no terceiro e último estágio, relaciona-se com a noção de avaliar o cliente como um ativo integrante do patrimônio da empresa, denominando-se valor econômico do cliente.

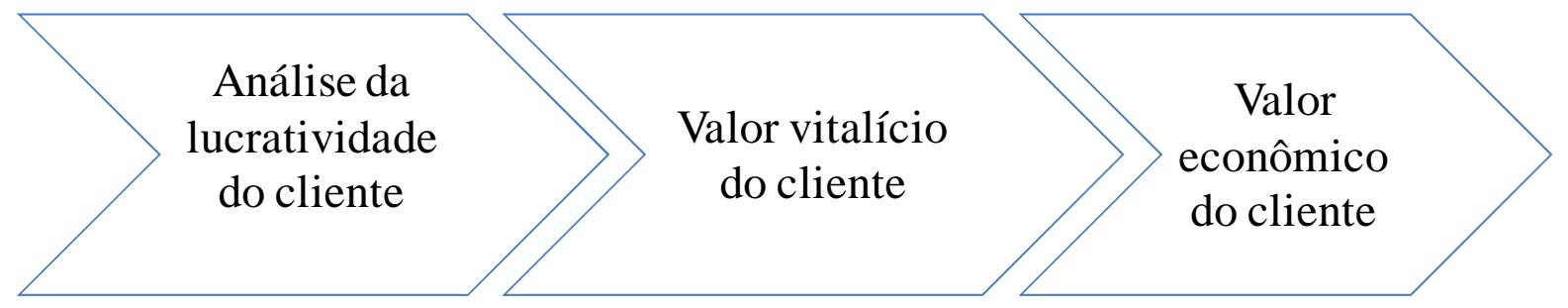

Figura 5 -Estágios do desenvolvimento da contabilidade focada no cliente FONTE: Elaborado pelo autor baseado em Weir (2008)

\subsubsection{Análise da lucratividade do cliente - (Customer Profitability Analysis)}

Os autores Guilding e McManus (2002) reconhecem o artigo titulado como "Customer Profitability Analysis" publicado por Bellis-Jones (1989) como o primeiro trabalho a utilizar a abordagem da Contabilidade Focada no Cliente (CFC) na literatura da contabilidade gerencial. A partir desse marco, o interesse pelas pesquisas sobre o tema vem aumentando e entre as diversas abordagens da contabilidade focada no cliente, a "análise da lucratividade do cliente" é aquela que é mais bem compreendida e das mais amplamente utilizadas (ROSLENDER; HART, 2010).

O aspecto fundamental na Análise da Lucratividade do Cliente (ALC) reside no fato de que se podem obter lucros diferentes entre os vários clientes que adquirem o mesmo produto 
(FOSTER; GUPTA, 1994). Em razão disto, pesquisadores têm discutido a importância em compreender de que maneira os clientes contribuem para a geração do lucro da empresa, pois, dado que mesmos montantes de receita contribuem diferentemente para o lucro, conclui-se que alguns clientes são mais lucrativos do que outros (KAPLAN; NARAYANAN, 2001; REINARTZ et al., 2005; LIND; STRÖMSTEN 2006).

A importância do papel da análise da lucratividade do cliente pode ser observada, na medida em que é utilizada na formulação de estratégias e otimização do lucro das empresas (GUERREIRO et al., 2008). Outro aspecto igualmente importante é a geração da informação para os gestores, de maneira que estes possam alcançar o sucesso na obtenção de um desempenho acima do esperado (ROSLENDER; HART, 2010).

$\mathrm{Na}$ literatura podem-se encontrar diversas abordagens para calcular a lucratividade do cliente, no entanto, em essência, traduz-se numa formulação simples, pois representa o resultado das atividades com determinado cliente (WEIR, 2008). A expressão pode ser dada por:

Receita - Custos e Despesas $=$ Lucro (Prejuízo) do cliente

Na prática, de acordo com Guilding e McManus (2002), a operacionalização dessa abordagem refere-se ao processo de apurar o lucro obtido de um determinado cliente. No cálculo desse lucro são consideradas as receitas e deduzidos os custos específicos de servir o cliente.

Essa abordagem contempla inclusive o conceito da análise da lucratividade de um segmento de clientes. Nas definições de Van Raaij (2005) e Van Triest (2005), a análise da lucratividade do cliente descreve o processo de alocação de receitas e custos para segmentos ou clientes individuais de forma que a lucratividade destes possa ser calculada.

O resultado a partir dessa análise pode ser mais ou menos sofisticado. Malmi et al. (2004) argumentam que, quanto mais sofisticadas forem essas análises, mais provável que as decisões alcancem melhores resultados financeiros. As análises sofisticadas levam em conta o uso do "ABC" (Activity Based Costing), pois se considera que a metodologia de custeio baseada em atividades é o método de custeio mais apropriado, em virtude da alocação dos custos gerais aos clientes específicos, baseado na informação das atividades (KAPLAN; COOPER,1998; KAPLAN; NARAYANAN, 2001; LIND; STRÖMSTEN, 2006). 
O cálculo da rentabilidade do cliente leva em conta, portanto, os custos de atender o cliente. Para Guerreiro et al. (2008), nesse contexto dois temas se destacam na literatura de marketing e contabilidade gerencial: o custo para servir e a rentabilidade de clientes. Os autores consideram, como custos para servir, os custos das atividades administrativas, comerciais e logísticas relacionados ao atendimento ao cliente e que são mensurados utilizando-se a metodologia de custeio baseado em atividades.

Cooper e Kaplan (1991 apud WEIR, 2008) descobriram no estudo de caso que a Kanthal utilizava um tipo de estrutura de custos baseada em atividades para analisar as receitas e custos dos seus clientes. O referido artigo explora os benefícios percebidos pela utilização dessa abordagem em relação à apropriação tradicional dos custos gerais, em relação à análise da lucratividade do cliente. O caso Kantal, assim como outros inúmeros casos acadêmicos, recomenda a utilização do custeio baseado em atividades quando o cliente é colocado no cerne das atenções (GUILDING; MCMANUS, 2002).

Muito embora a literatura não forneça elementos claros de como os custos devem ser alocados aos clientes, alguns pesquisadores têm utilizado outros métodos de custeio como é o caso do custo-meta estudado por Roslender e Hart (2010) e o custo marginal e absorção estudado por Helgesen (2007). Contudo, a literatura tem demonstrado, sob a perspectiva da contabilidade, uma ampla aceitação do “ABC” como base teórica (SMITH; DIKOLLI, 1995; WEIR, 2008).

A análise individual da lucratividade do cliente revela um quadro bastante claro quando comparamos, de um lado, o comportamento do comprador (serviços solicitados, condições de pagamento, preferências) e, de outro, o comportamento do vendedor (serviços oferecidos, descontos, esforços de marketing), ambos ao mesmo nível de geração da receita (VAN RAAIJ, 2005). A figura a seguir ilustra uma situação onde dois clientes com receitas idênticas, mas apresentando características de custos diferentes, podem gerar distintas contribuições para o lucro da empresa. 


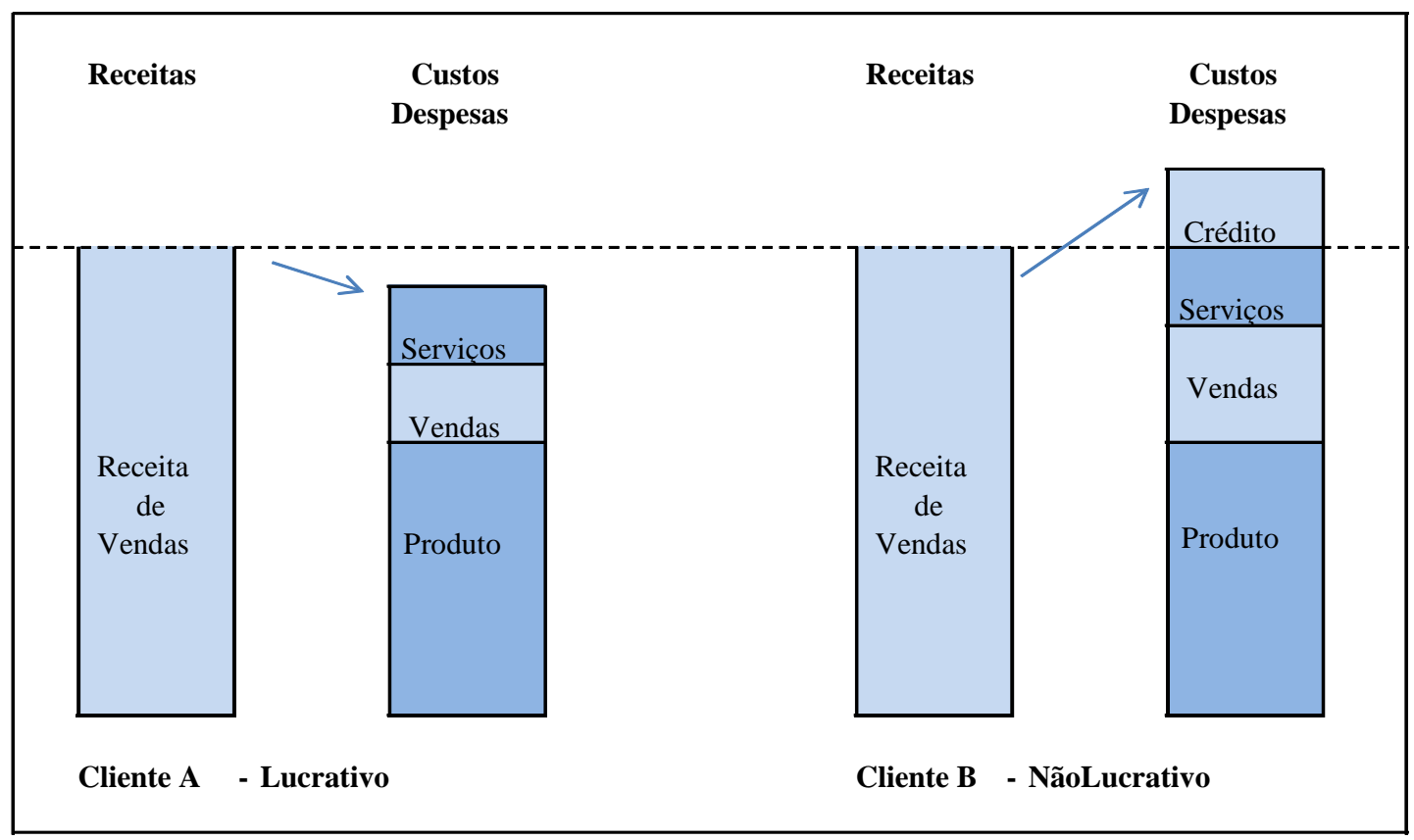

Figura 6 - Clientes com a mesma receita e características de custos desiguais FONTE: Adaptado de Van Raaij (2005, p. 375)

Uma consideração importante a partir dos resultados dessa análise é que os administradores terão acesso a informações sobre clientes que não são lucrativos e, dessa forma, poderão encontrar meios e adotar estratégias para reverter essa situação, sem que o cliente em particular diminua sua satisfação. Além disso, poderão rever os processos internos de modo a provocar mudanças nos resultados da lucratividade do cliente (GUERREIRO et al., 2008).

Van Raaij (2005) afirma que a análise da lucratividade do cliente tem uma orientação retrospectiva, já que se baseia em valores históricos da receita e do custo. Essa abordagem propicia relevantes considerações sobre dependência e manutenção na base de clientes. Contudo possui algumas limitações, sobretudo quando se deseja uma posição da base de clientes no longo prazo. Para uma transição do modo retrospectivo para prospectivo se faz necessário incluir na análise do valor do cliente estimativa de receitas e custos futuros.

\subsubsection{Valor vitalício do cliente ou Valor do relacionamento com o cliente (CustomerLifecycleValue)}

Uma definição amplamente aceita refere-se ao período compreendido entre o início e o fim do relacionamento do cliente com a empresa, ou seja, um modelo de ciclo de relacionamento de 
clientes que reflete o desenvolvimento da relação empresa-cliente ao longo do tempo (WANGENHEIM; LENTZ, 2006).

Para os autores Bolton, Lemon e Verhoef (2002), e Verhoef (2003), o valor do relacionamento com o cliente representa o valor atual líquido de todos os lucros, isto é, receitas menos custos, a partir de um cliente individual em que "todos os lucros" incluem múltiplos comportamentos dos clientes. Esses comportamentos abrangem tempo (retenção), profundidade (frequência da compra) e amplitude (compras cruzadas).

Na opinião de Gupta et al. (2006), o Valor Vitalício do Cliente (VVC) é o valor presente dos resultados esperados de um cliente durante todo o ciclo de vida de seu relacionamento com a empresa. Corroboram essa opinião Bauer e Hammerschmidt (2005) afirmando que, sob o ponto de vista do fornecedor, o valor do relacionamento com o cliente representa um profundo entendimento do valor do cliente, já que é capaz de mensurar os lucros sobre todo o ciclo de vida do cliente.

Estudos anteriores encontrados na literatura da contabilidade gerencial abordam o valor do relacionamento com o cliente, como meio de avaliar a influência desse relacionamento com o desempenho, dando foco especial na informação não financeira (MOURITSEN, 1997, VAIVIO, 1999; MALMI et al., 2004).

O valor do relacionamento com o cliente representa, portanto, uma aplicação dos princípios contemporâneos das finanças, para avaliar relações de negócios (DOYLE, 2000; BAUER; HAMMERSCHMIDT, 2005). O modelo procura determinar a lucratividade do cliente, baseado em todos os recebimentos e pagamentos que possam ser atribuíveis a estes, de uma forma prospectiva e direta.

O modelo para mensurar o valor do relacionamento com o cliente é similar à abordagem do fluxo de caixa descontado utilizado em finanças, exceto pelo fato de reconhecer que alguns clientes são mais importantes e mais lucrativos do que outros, além de incorporar a possibilidade da desistência de alguns clientes no futuro (GUPTA et al., 2006). Nessa mesma direção, Weir (2008) reitera a orientação voltada para o futuro e destaca seu fundamento em finanças, ao afirmar que o modelo emula um tipo de cálculo de valor presente líquido. 


\subsubsection{Componentes do valor vitalício do cliente}

A partir do exame de modelos básicos do valor do relacionamento com o cliente, Reinartz e Kumar (2000) verificaram que as variáveis incluídas no modelo podem, em geral, ser classificadas em três categorias: receitas, custos e taxa de retenção (BAUER; HAMMERSCHMIDT, 2005).

\subsection{Taxa de retenção}

Clientes não permanecem com a empresa para sempre. Eles trocam de empresas de telefonia, trocam de empresas de TV a cabo por satélite e cancelam assinaturas de revistas (GUPTA; LEHMANN, 2006). A permanência de um cliente junto à determinada empresa está associada ao grau de lealdade, portanto, à taxa de retenção de clientes pode ser inferida a partir de certas determinantes de lealdade, como satisfação do cliente, substituição de barreiras, redução de custos, comportamento instável e atração por alternativas (DWYER, 1997; KAPLAN; NARAYANAN, 2001; BAUER; HAMMERSCHMIDT, 2005).

De acordo com Bauer e Hammerschmidt (2005), a ideia de incluir a taxa de retenção no modelo consiste em refletir, de maneira aproximada, o comportamento do cliente. Considerase perdido o cliente que deixa de fazer negócios com o fornecedor e, por outro lado, é tratado como se fosse um cliente novo na ocasião que retoma o seu relacionamento com a empresa.

Atualmente existem inúmeras formas de estimar a retenção e migração de clientes em um determinado período. Vários pesquisadores têm utilizado modelos econométricos e probabilísticos, Gupta et al., (2006), e técnicas mais avançadas como a cadeia de Markov, Villanueva e Hanssens (2007), concluindo-se que métodos quantitativos vêm sendo normalmente utilizados para determinar as flutuações na base de clientes (WEIR, 2008). 


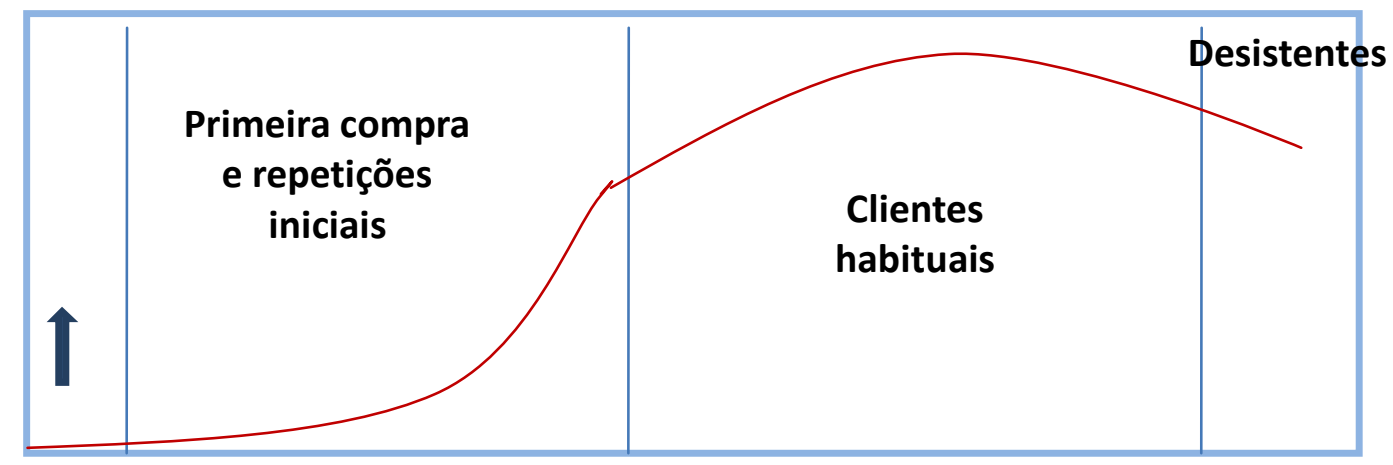

Potenciais

\section{Estágios no ciclo de vida do cliente}

Figura 7 -Ciclo de vida do cliente

FONTE: adaptado de Blattberget al. (2001, p.14)

\subsection{Receita de vendas}

Na opinião de Bauer e Hammerschmidt (2005), o grupo de receitas pode ser classificado em quatro subcategorias: i- vendas "normais"; ii- vendas adicionais; iii- vendas cruzadas e ivvalor de referência, representado pela margem de contribuição resultante das indicações feitas pelos clientes existentes. As primeiras três fontes de receita resultam de atividades efetuadas diretamente com os clientes das quais resultam valores de transações monetárias.

As vendas normais não são diretamente influenciadas pela empresa ou são afetadas apenas pelas ações padrões de marketing tal como a publicidade em televisão. Representa a venda básica, não incluindo o efeito do marketing direto de forma a aumentar as vendas adicionais e as vendas cruzadas.

Já as vendas adicionais são originadas pelas compras adicionais de um mesmo produto que são realizadas por clientes leais, trazendo como consequência um aumento na frequência ou intensidade durante o ciclo de relacionamento de longo prazo (maiores valores por compras e número maior de compras no período).

De outro lado, vendas cruzadas podem ser definidas como a venda de produtos ou categorias de produtos complementares, os quais não haviam sido ainda comercializados pelo fornecedor. Por último, o valor de referência deriva de novos clientes que foram atraídos através de indicações dos clientes existentes. 


\subsection{Custos para servir o cliente}

A primeira categoria de custos é constituída pelos custos de aquisição, isto é, os custos incorridos para conquistar clientes. O cálculo e a designação dos custos de aquisição dependem exclusivamente das práticas adotadas pela empresa, por exemplo: marketing direto versus marketing massivo. (JAIN; SINGH, 2002; BAUER; HAMMERSCHMIDT, 2005)

Os custos de marketing, por sua vez, representam custos associados a retenção e desenvolvimento do cliente, excluídos aqueles especificamente orientados no sentido da aquisição. Compreendem, por exemplo, gastos com promoções gerais, criação, elaboração e envio de catálogos de produtos, mensagens personalizadas etc. Os custos de recuperação também são incluídos nessa categoria. (RUST et al., 2000; BLATTBERG et al., 2001)

Por sua vez, os custos da venda relacionam-se aos custos de produção dos bens e serviços e todos os custos de servir o cliente, tais como: processamento do pedido, movimentação, estocagem e entrega. (PEPPERS; ROGERS, 2005)

Por último os custos de término do relacionamento também devem ser levados em consideração e computados como custos finais. Despesas administrativas incorridas no fechamento de uma conta ou custos de retorno de produtos vencidos são exemplos típicos de custos dessa natureza.

Finalmente cabe ressaltar que, dentre as categorias de custos, aqueles correspondentes ao custo fixo da empresa, que não puderem ser direcionados aos clientes, não devem ser incluídos na composição do modelo. (BAUER; HAMMERSCHMIDT, 2005)

\subsubsection{Valor econômico do cliente ou valor do ativo em cliente (Customer Equity)}

O Valor Econômico do Cliente (VEC) é comumente descrito como o somatório dos resultados individuais do relacionamento com o cliente (VVC) tanto para clientes atuais quanto para clientes potenciais. A apuração desses resultados leva em conta o período de tempo em que os clientes realizarão negócios com a empresa (BLATTBERG et al., 2001; RUST et al., 2000; WEIR, 2008). 
A premissa básica do valor do ativo em clientes é simples e direta: o cliente é um ativo financeiro que as organizações devem mensurar, gerenciar e maximizar assim como qualquer outro tipo de ativo (BLATTBERG et al., 2001; WIESEL et al., 2008). Concluem que o valor do ativo em clientes é mais do que um simples método para calcular o valor do relacionamento do cliente, pois se constitui num completo sistema de marketing que demanda estratégias integrativas de negócios.

Essa abordagem foi inicialmente proposta com uma medida para determinar o equilíbrio entre as variáveis: aquisição, retenção e realização de vendas cruzadas, de forma a alcançar o maior Valor Econômico do Cliente (VEC) possível e assim maximizar o valor do relacionamento com o cliente, durante todo o ciclo do seu relacionamento (BLATTBERG et al., 2001). Alguns estudos sobre VEC mostram sua utilização como um processo para aumentar retornos para o acionista como visto no trabalho de Doyle (2000)e ainda outros, mais recentemente, relacionam o VEC como uma Proxy para a avaliação do valor da empresa (BAUER; HAMMERSCHMIDT, 2005; GUPTA et al., 2006; SRIVASTAVA et al., 1998).

Quando se considera o Customer Equity (CE) de uma empresa deve-se levar em conta, na opinião de Bauer e Hammerschmidt (2005), dois aspectos fundamentais: i- o valor do relacionamento com clientes atuais e futuros (Customer Lifetime Value- CLV) e ii- agregação de todos os valores dos clientes individuais. 


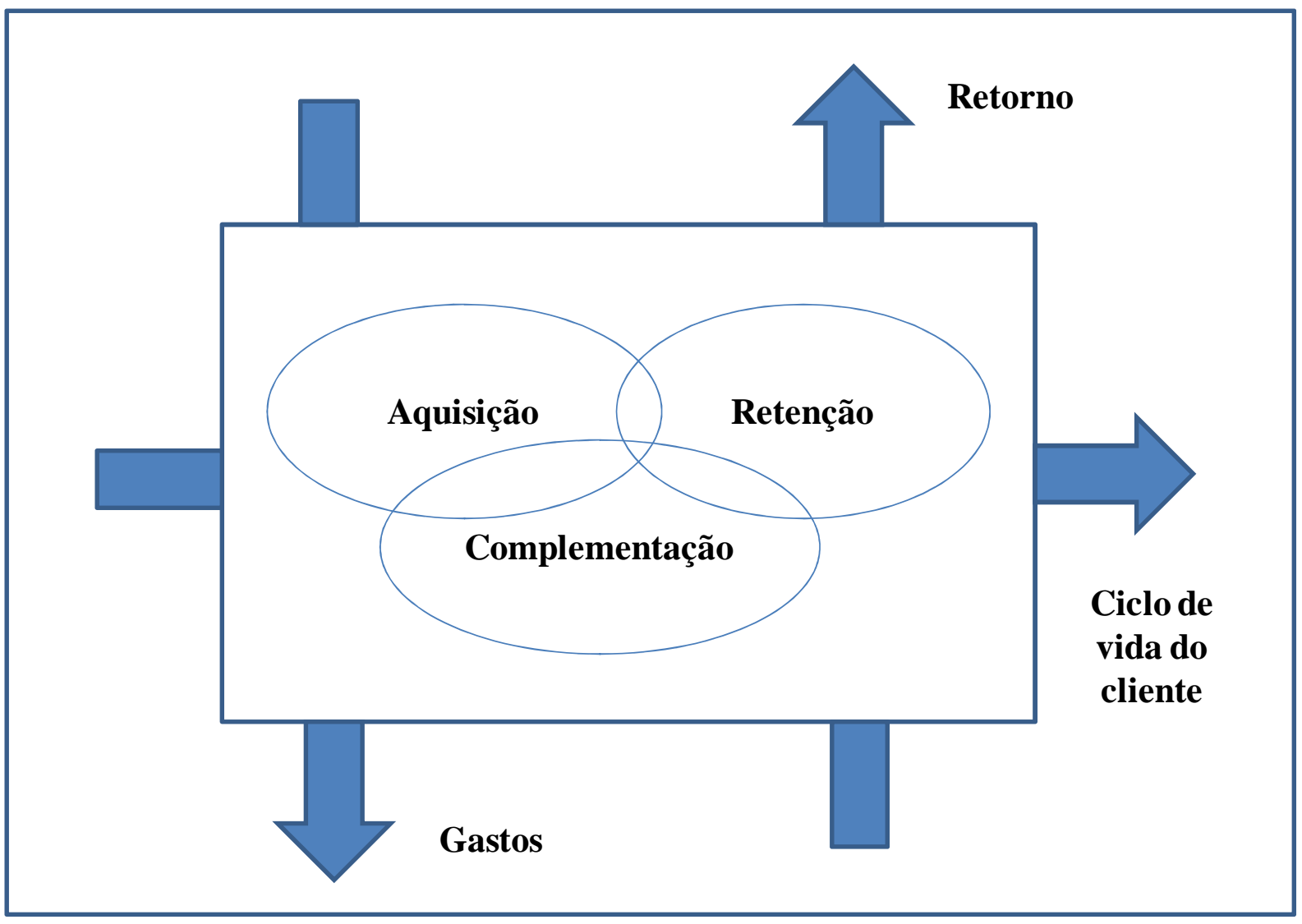

Figura 8 -Modelo de valor econômico do cliente

FONTE: Adaptado de Blattberget al. (2001, p.11)

Desse modo, deve-se considerar, além do valor descontado dos clientes atuais, o valor dos clientes potenciais (prospects) (RUST et al.; 2000; JAIN; SINGH, 2002).

Uma abordagem quantitativa, normalmente utilizada para determinar a taxa de aquisição de clientes, é sugerida por Blattberget al. (2001) representada pelo número de clientes potenciais conquistados sobre o número de clientes potenciais pretendidos. Essa constante expressa a efetividade das atividades de adquirir um cliente

O próximo passo consiste em determinar a lucratividade dos futuros clientes. Na opinião de Bauer e Hammerschmidt (2005), essa informação pode ser obtida utilizando dados históricos dos clientes e, a partir deles, determinar padrões de lucratividade. Projetando-se esses padrões em períodos futuros torna-se possível estimar lucratividades futuras.

Quando todas as variáveis forem identificadas, Bauer e Hammerschimdt (2005) sugerem a aplicação da seguinte formulação: 


$$
C E=\sum_{s=0}^{T} \frac{1}{(1+d)^{s}} \sum_{k=\left(v_{s-1}+1\right)}^{v_{s}} \sum_{t=s}^{T} r_{i}^{t} \frac{\left(R_{t i}-C_{t i}\right)}{(1+d)^{t}}
$$

Onde:

$\mathrm{T}=$ horizonte de tempo em anos

$\mathrm{i}=$ lista de clientes

$\mathrm{t}=$ período

$\mathrm{d}=$ taxa de desconto

$\mathrm{v}_{\mathrm{s}}=$ número de clientes que abandonam a empresa no final do período $\mathrm{s}$

$\mathrm{r}=$ taxa de retenção de cliente

$\mathrm{k}=$ lista de clientes de determinado segmento

$\mathrm{R}=$ receita do cliente

$\mathrm{C}=$ custos de servir o cliente.

Em adição à influência das finanças nos modelos de VEC, uma ideia atrelada a sua gestão sugere a utilização dessa métrica como base para cálculo do Return on Investment (ROI) de qualquer tipo de investimento estratégico (WEIR, 2008). Nesse sentido, corroboram Peppers e Rogers (2005) quando afirmam que o ativo em clientes VECé um recurso financeiro escasso com o qual uma empresa poderá gerar ainda mais valor.

Peppers e Rogers (2005) orientados nesse conceito criaram um indicador financeiro conhecido como ROC (Return on Customer), cuja finalidade é medir o desempenho da gestão do valor econômico do cliente. Assim, concluem que o indicador de retorno sobre clientes leva em consideração, de maneira explícita, as duas maneiras distintas pelas quais um cliente cria valor para o negócio: aumentando os fluxos de caixa atuais e ampliando os fluxos de caixa futuros.

\subsubsection{Estudos recentes sobre a contabilidade focada no cliente}

A análise levou em conta os trabalhos sobre a contabilidade focada no cliente que procuraram pesquisar temáticas normalmente inseridas no domínio do conhecimento da Contabilidade Gerencial. A análise não é exaustiva, contudo os trabalhos selecionados trazem as principais contribuições dessa linha de pesquisa dentro da literatura da contabilidade gerencial. 
2.3.4.1 MCMANUS, L.; GUILDING C. Exploring the potential of customer accounting: a synthesis of the accounting and marketing literatures. Journal of Marketing Management, v. 24, n. 7-8, p.771-795, 2008.

O trabalho teve como objetivo elaborar uma síntese da literatura sobre a contabilidade focada no cliente. Para isso, os autores desenvolveram uma ampla revisão da literatura em contabilidade e em marketing,destacando como aspectos relevantes as técnicas e os construtos que a contabilidade gerencial pode levar em consideração para implementar ou não a contabilidade focada no cliente.

Os autores iniciam suas análises considerando que a contabilidade focada no cliente representa um conjunto próprio de práticas que pode ser classificado na subcategoria da contabilidade chamada de "contabilidade gerencial estratégica" em função da necessidade em assumir uma postura mais orientada para a estratégia da empresa.

O exame do estado da arte sobre a contabilidade focada no cliente levou os autores a conduzir uma investigação sobre a não utilização de todo o seu potencial nas pesquisas em contabilidade. A argumentação baseia-se no fato de que alguns construtos, embora amplamente discutidos na literatura de marketing, têm merecido pouca atenção na literatura contábil, tais como: satisfação, lealdade e lucratividade do cliente.

Apresentam como resultado da pesquisa uma tabela trazendo os autores e as respectivas datas dos seus trabalhos, segregados segundo a natureza dos construtos da contabilidade focada no cliente e divididos, ainda, em literatura contábil e marketing. Nesse trabalho destacam-se a posição crítica que os autores assumem a respeito do estágio atual das pesquisas sobre o tema em contabilidade gerencial, além de valiosas sugestões, como oportunidades de novas pesquisas na área.

2.3.4.2 HELGESEN, O.Customer accounting and customer profitability analysis for the order handling industry. A managerial accounting approach. Industrial Marketing Management, v. 36, p. 757-769, 2007. 
Helgesen (2007) estudou um modelo próprio de artefato da contabilidade focada no cliente que chamou de estrutura contábil orientada para mercado. $\mathrm{O}$ desenho desse artefato permitia a identificação do lucro ou lucratividade em diversas camadas de análise: ao nível do pedido, do cliente e do mercado.

O modelo foi baseado numa forma hierárquica de atribuir custos às atividades. A estruturação atendia à apropriação dos custos para: i-unidades de negócio; ii- mercados; iii- clientes e ivpedidos. Nesse trabalho, o autor analisou o mercado norueguês de peixes para exportação, através de uma pesquisa com quatro empresas, cento e setenta e seis clientes e trinta e seis mercados.

A partir dos dados obtidos, Helgesen (2007) analisou os resultados de cada camada dessa estrutura a partir do peso relativo do seu resultado individual comparado com o acumulado de todos os demais itens. Os resultados encontrados revelaram que uma quantidade pequena de clientes é responsável por contribuir com a maior parte dos resultados. O autor utilizou a curva de Stobachoff para ilustrar os seus achados.

O destaque do trabalho de Helgesen (2007) pode ser atribuído à constatação da necessidade de uma contabilidade focada no cliente e o respectivo desenho dos seus artefatos se uma empresa pretende atender seus gestores com informação relevante para os diversos direcionadores de valor ao cliente, tais como: satisfação, lealdade, medidas de desempenho, além do ponto de vista dos gestores a respeito dos resultados dos clientes ao nível da unidade de negócios pelas quais são responsáveis.

\subsubsection{LIND, J.; STRÖMSTEN, T. When do firms use different types of customer} accounting? Journal of Business Research, v. 59, n. 12, p. 1257-1266, 2006.

Os autores desenvolveram uma estrutura conceitual para explicar a escolha dos artefatos da contabilidade focada no cliente, em função dos recursos empresariais, agrupados em técnicos e organizacionais, que são disponibilizados aos clientes. O grau de utilização desses recursos pelos clientes determina certo tipo de relacionamento. Nesse trabalho, os autores subdividem esses relacionamentos em quatro dimensões: transacional, facilitador, integrativo e conectivo. 
A metodologia utilizada foi um estudo de caso em duas empresas que atuam no mercado corporativo da Suécia (Ericsson e Holmen). Os resultados mostram as seguintes associações entre relacionamentos e artefatos: i- lucratividade do segmento de clientes com o tipo transacional; ii- análise da lucratividade do cliente com facilitador; iii- valor vitalício do cliente com integrativo e iv- análise do valor do cliente com o tipo conectivo.

Os autores observam que, nas duas empresas estudadas, a informação a respeito do valor vitalício da empresa era utilizada de maneira informal e somente em circunstâncias especiais (ad hoc) não havendo um sistema de informação que produzisse relatórios numa frequência regular. Outra importante constatação foi o emprego de uma mistura das técnicas da contabilidade focada no cliente para o mesmo tipo de relacionamento. O ponto forte do trabalho é o pioneirismo da pesquisa empírica que objetivou identificar relacionamentos entre os artefatos da contabilidade focada no cliente e o tipo de relacionamento.

\subsubsection{MCMANUS, L.An examination of customer accounting in an Australian}

Context. Dissertation submitted in fullfilment of the requirements of the degree of Doctor of Philosofy. Griffithy University. January. 2006.

A tese de doutorado diz respeito ao estudo da prática da contabilidade focada no cliente em empresas australianas. Seu objetivo principal reside em compreender o papel exercido pelas práticas da contabilidade focada no cliente em prover informações a respeito da base de clientes da empresa.

O trabalho levou em consideração três fases distintas nas pesquisas empíricas. A primeira fase compreendeu uma série de entrevistas exploratórias envolvendo profissionais da contabilidade e de marketing. Na segunda fase foi desenvolvido um estudo de caso para verificar a lucratividade de um segmento de clientes numa grande empresa de telecomunicações. A terceira fase envolveu a operacionalização de um questionário aplicado a gestores da área de contabilidade e marketing.

A autora buscou examinar o relacionamento existente entre os artefatos da contabilidade focada no cliente, fatores contingenciais como intensidade da competição, orientação para o mercado, tamanho da empresa e aspectos organizacionais e o desempenho econômico da 
empresa. Verificou também motivos pelos quais os artefatos da contabilidade focada no cliente não são utilizados.

A metodologia inclui a utilização de técnicas de modelagens estruturais para identificar os relacionamentos entre as variáveis. Os achados revelam relacionamentos entre as variáveis contingenciais e as práticas da contabilidade focada no cliente. Entre os resultados, curiosamente, o desempenho da empresa não revelou associação positiva entre as práticas da contabilidade focada no cliente.

A importância do trabalho destaca-se pelo seu caráter prospectivo e exploratório enquanto pesquisa empírica envolvendo construtos da contabilidade focada no cliente e também sob o aspecto do mérito e da profundidade das pesquisas de campo realizadas.

2.3.4.5 MALMI, T.; RAULAS, M.; SEHM, J.An empirical study on customer profitability accounting, customer strategies and corporate performance. Paper presented at the EAA Conference. Prague: April 2004.

O trabalho procurou explicar os efeitos provocados no desenho e uso dos artefatos da contabilidade focada no cliente quando a empresa adota a orientação do relacionamento com o cliente. Além disso, os autores buscaram ainda examinar o relacionamento existente entre a orientação para o relacionamento com o cliente, os artefatos da contabilidade focada no cliente e o desempenho econômico da empresa.

Os autores utilizaram uma pesquisa empírica do tipo surveyrealizada com 564 respondentes na Finlândia, para conduzirem o processo de investigação. Os resultados obtidos, a partir da modelagem de equações estruturais, sugerem que a orientação para o relacionamento tem efeitos diretos sobre as práticas da contabilidade focada no cliente e o desempenho da organização.

Os achados da pesquisa suportam a teoria de que o uso de artefatos sofisticados, no elenco das práticas adotadas pela contabilidade focada no cliente, ajuda as empresas a melhorar seu desempenho quando utilizam a competência da orientação com o relacionamento com o cliente. 
O trabalho se notabiliza pelo fato inédito de buscar explicações sobre o relacionamento existente entre o uso e forma de artefatos da contabilidade focada no cliente, estratégias de relacionamento com o cliente e o desempenho econômico da empresa.

2.3.4.6 GUILDING, Chris; MCMANUS,Lisa.The incidence, perceived merit and antecedents of customer accounting: an exploratory note. Accounting, Organizations and Society, v. 27, p. 45-59, 2002.

Os autores buscaram nesse trabalho estudar a incidência das práticas da contabilidade focada no cliente, a percepção dos seus usuários quanto ao mérito de reconhecê-la como um artefato da contabilidade gerencial e a associação entre fatores contingenciais que podem afetar o uso e a importância percebida da contabilidade focada no ciente.

Os autores desenvolveram uma estrutura conceitual que tipificou a contabilidade focada no cliente em cinco construtos teóricos, ou seja: i- análise da lucratividade do cliente, ii- análise da lucratividade de um segmento de clientes, iii- análise do valor vitalício do cliente, ivavaliação de um ou grupo de clientes como ativos e v- contabilidade focada no cliente como uma visão holística.

A partir de pesquisa survey realizada entre 300 empresas australianas, e empregando o modelo estatístico da regressão, os autores destacam os seguintes resultados: a- todas as cinco dimensões da contabilidade focada no cliente tiveram resultados acima da média no quesito importância percebida. Em relação ao uso, as duas dimensões orientadas para o futuro, ou a análise do valor vitalício do cliente, e a avaliação de um ou grupo de clientes como ativos foram os construtos que obtiveram resultados abaixo da média.

Em relação à associação entre as práticas da contabilidade focada no cliente e os fatores contingenciais, os resultados não suportaram a hipótese do teste $\mathrm{U}$ invertido para $\mathrm{o}$ relacionamento entre intensidade de competição e contabilidade focada no cliente. Por outro lado, a orientação para o mercado mostrou relacionamento positivo entre o uso e a importância percebida em três dos cinco construtos estudados. 
Este estudo representa, na literatura contábil, o primeiro trabalho acadêmico que abordou as dimensões formativas da contabilidade focada no cliente. Pelo seu aspecto inovador e didático, foi responsável pela introdução de uma tipologia que passou a servir de base para estudos posteriores, tornando-se um dos trabalhos mais referenciados nessa linha de pesquisa. 


\section{PROCEDIMENTOS METODOLÓGICOS}

Este capítulo tem como objetivo apresentar os fundamentos metodológicos que nortearam o desenvolvimento deste trabalho. A metodologia de uma pesquisa consiste na estruturação das etapas necessárias para se atingir os objetivos propostos, assim sendo, caracterizam-se a pesquisa, o universo e a amostra, o instrumento de coleta dos dados, as técnicas utilizadas para análise, contribuições e limitações.

\subsection{Teoria e hipóteses de pesquisa}

A teoria de base, pela qual este estudo foi orientado, é a teoria da contingência. Os fundamentos dessa teoria foram mencionados no referencial teórico e subsidiaram a definição dos construtos e a proposta de relacionamento entre as variáveis latentes. A esse respeito, Tilema (2005, p.101) afirma que a teoria da contingência é adequada para analisar os artefatos dos SCG nas circunstâncias em que estes são utilizados.

Na aplicação dos elementos dessa teoria, na análise dos atributos e usos dos SCG focados nos clientes, foi possível determinar as hipóteses que permitem construir e inferir relações entre as variáveis estudadas. As hipóteses formuladas são classificadas como explicativas, já que se revestem dessa função (LAKATOS; MARCONI, 1991) e são apresentadas na figura 9, a seguir: 


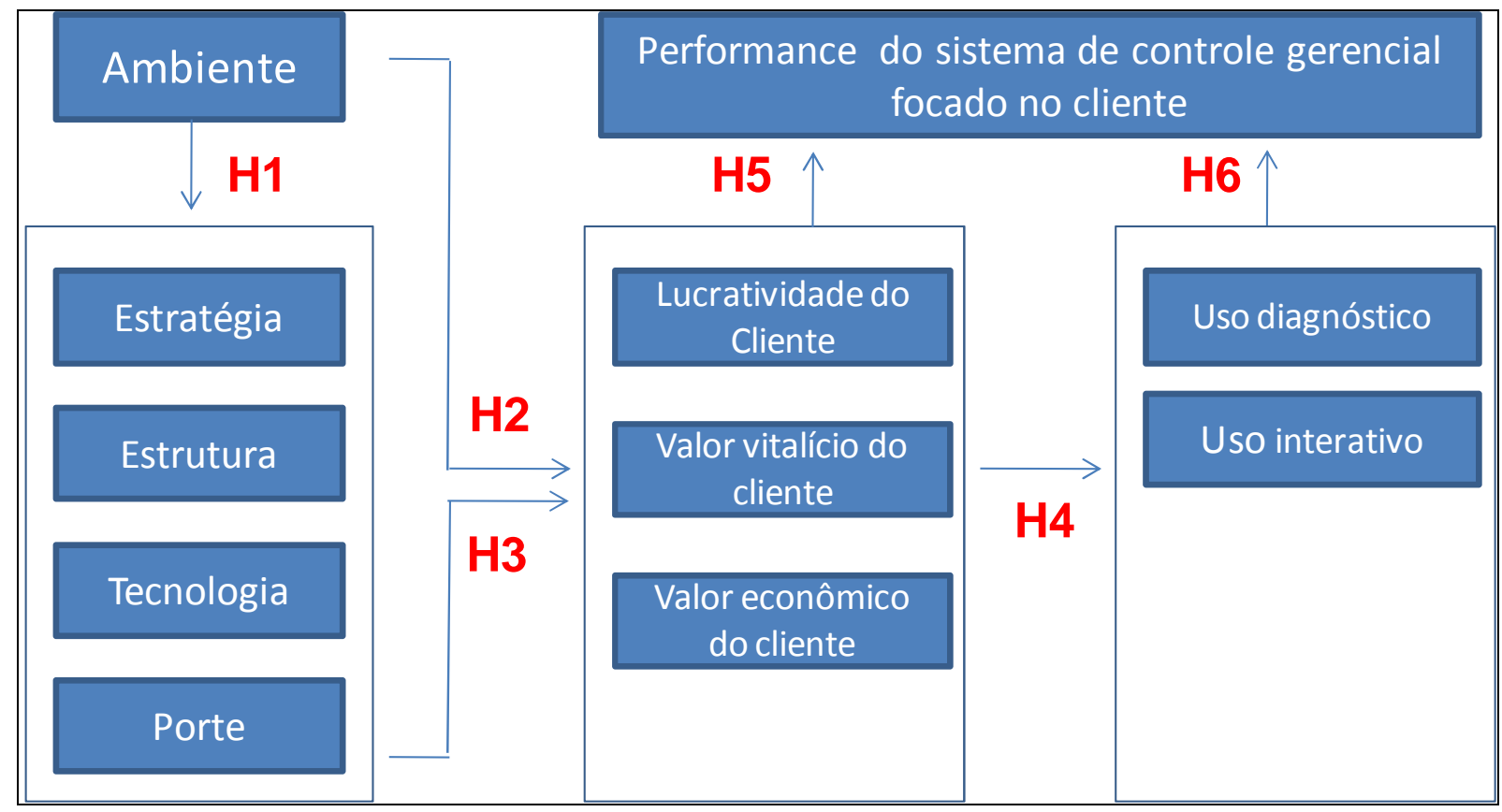

Figura 9 - Hipóteses de pesquisa - visão dimensional dos constructos

H1- O fator contingencial externo "ambiente" influencia os fatores contingenciais internos da organização.

H2- O fator contingencial externo "ambiente" influencia os atributos do sistema de controle gerencial focado nos clientes.

H3- Os "fatores contingenciais internos" influenciam os atributos do sistema de controle gerencial focado nos clientes.

H4- Os "atributos do sistema de controle gerencial focado nos clientes" influenciam o uso intensivo desses mesmos sistemas.

H5- Os "atributos do sistema de controle gerencial focado nos clientes" influenciam o desempenho desses sistemas.

H6- O uso "intensivo do sistema de controle gerencial focado nos clientes" influencia o desempenho desses sistemas.

\subsection{Caracterização da pesquisa}

Para a caracterização da pesquisa, adotou-se a tipologia proposta por Cooper e Schindler (2003) que classifica as pesquisas segundo sua categoria e as opções dadas para cada uma delas. Essa classificação é demonstrada no quadro 5: 
Quadro 5 - Classificação da pesquisa

\begin{tabular}{|l|l|}
\hline \multicolumn{1}{|c|}{ Categoria } & \multicolumn{1}{|c|}{ Opções } \\
\hline \hline O nível de elaboração da questão de pesquisa & $\begin{array}{l}\text { estudo exploratório } \\
\text { estudo formal }\end{array}$ \\
\hline \hline O método de coleta de dados & $\begin{array}{l}\text { monitoramento } \\
\text { interrogação/comunicação }\end{array}$ \\
\hline O poder do pesquisador em produzir efeitos nas variáveis & $\begin{array}{l}\text { lexperimental } \\
\text { que estão sendo estudadas }\end{array}$ \\
\hline \hline O objetivo do estudo & $\begin{array}{l}\text { escritivo } \\
\text { causal }\end{array}$ \\
\hline \hline A dimensão do tempo & $\begin{array}{l}\text { transversal } \\
\text { longitudinal }\end{array}$ \\
\hline \hline O escopo do tópico - amplitude e profundidade - do estudo & $\begin{array}{l}\text { estudo de caso } \\
\text { estudo estatístico }\end{array}$ \\
\hline \hline O ambiente de pesquisa & $\begin{array}{l}\text { ambiente de campo } \\
\text { pesquisa de laboratório } \\
\text { simulação }\end{array}$ \\
\hline
\end{tabular}

FONTE: Adaptado de Cooper e Schindler (2003)

Ao nível da elaboração da questão de pesquisa, o estudo classifica-se como formal, tendo em vista que o objetivo é testar hipóteses e responder uma questão formal de pesquisa. Quanto ao método de coleta de dados, a opção adotada foi a interrogação/comunicação, com a aplicação de um questionário para coleta de dados, onde o pesquisador não exerceu nenhum tipo de poder ou interferência, já que os dados foram disponibilizados ex-post facto.

O método da comunicação quanto à forma de aplicação compreende entrevistas e questionários autopreenchidos (MATTAR, 2005, p.184). Adotou-se, neste trabalho, o levantamento do tipo survey, eletrônico. Os respondentes foram convidados a participar da pesquisa, através de uma mensagem por email cujo texto indicava um link da rede mundial de computadores, conduzindo o usuário diretamente ao questionário eletrônico.

Em relação ao objetivo do estudo, situa-se como descritiva e causal. É descritiva à medida que descreve as características dos SCG focados nos clientes e causal, pois se busca compreender as relações entre as variáveis contingenciais e o desenho, uso e desempenho desses sistemas.

Certas condições de relacionamento entre fatores contingenciais, desenho e uso de SCG focados nos clientes são possíveis de ser analisadas graças ao emprego de técnicas e modelos 
estatísticos. Desse modo, o escopo desta pesquisa é estatístico, no qual se procurou priorizar a amplitude através da observação das características da amostra e inferindo sobre as hipóteses estudadas.

Trata-se de um estudo transversal, já que se limita a observar as características de fatores contingenciais e desenho e uso de SCG focados nos clientes de empresas brasileiras, num período específico de tempo. O ambiente é caracterizado como condições de campo, pois descreve as reais condições ambientais em que a organização está inserida.

\subsection{População e amostra}

Inicialmente, a população foi selecionada a partir do banco de dados das mil maiores empresas da revista Maiores e Melhores de 2008, publicada pela Editora Abril S.A. e elaborada pela equipe da Fundação Instituto de Pesquisas Contábeis, Atuariais e Financeiras (FIPECAFI). A empresa foi representada pelos analistas ou responsáveis das áreas de Controladoria ou afins.

Para o levantamento das empresas adotou-se o mesmo critério de Oyadomari (2008) e Junqueira (2010), ou seja, foram identificadas 691 empresas, que possuíam informações financeiras dos últimos três anos. Todos os representantes dessas empresas foram convidados a participar da pesquisa através de correspondência eletrônica.

Posteriormente, tendo em vista a estratégia de aumentar o índice de respostas, considerou-se a população formada pelas empresas representadas pelos alunos atendentes dos programas de pós-graduação em nível de mestrado profissional. Foram convidadas e aceitaram participar, duas instituições de ensino que oferecem esse tipo de formação acadêmica. Do Instituto Presbiteriano Mackenzie foram convidados 100 alunos e da Fundação Capixaba de Ensino outros 144 alunos.

De todas as empresas convidadas, foram retornados 93 questionários. Feita a análise de validação, 10 questionários não puderam ser aproveitados, ou por duplicidade nas respostas, ou por falta de dados sobre o porte ou ainda por falta de dados sobre o valor da receita. Não foi possível obter essas informações de outro modo, visto que o nome da empresa não era uma 
exigência no instrumento de coleta de dados. Os dados das respostas válidas são sumarizados na tabela 1 abaixo.

Tabela 1 - Índice de retorno por grupo de respondentes

\begin{tabular}{c|c|c|c|c|c|c}
\hline \multicolumn{1}{c}{ Indice de resposta por grupo de respondentes } \\
\hline & $\begin{array}{c}\text { População formada } \\
\text { pelas 1000 MM }\end{array}$ & $\begin{array}{c}\text { População formada } \\
\text { pelos programas de } \\
\text { pós }\end{array}$ & \multicolumn{3}{|c}{ Total } \\
\hline & $\mathbf{N}$ & $\%$ & $\mathbf{N}$ & $\%$ & $\mathbf{N}$ & \% \\
\cline { 2 - 8 } Convites & 691 & & 244 & & 935 & \\
\cline { 2 - 8 } $\begin{array}{c}\text { Respostas } \\
\text { Válidas }\end{array}$ & 57 & $8,2 \%$ & 26 & $10,7 \%$ & 83 & $8,9 \%$ \\
\hline
\end{tabular}

A validação da amostra foi obtida com o uso do software G*Power 3(Apêndice 3). Para o teste, adotaram-se os valores recomendados por Hair et al. (2005), ou seja, nível de significância de $5 \%$ e poder estatístico de $80 \%$, além da consideração de duas variáveis preditoras. Com esses parâmetros, o software retornou o tamanho da amostra igual a 68 . Assim sendo, a amostra obtida de 83 casos satisfaz as exigências do modelo estrutural e dá confiabilidade à análise dos resultados.

\subsection{Instrumento de pesquisa}

O plano de pesquisa considerou a utilização do questionário como instrumento de pesquisa (Apêndice 2), por duas razões: a primeira, pelo cumprimento da sua função básica que é descrever as características e medir determinadas variáveis de um grupo social (RICHARDSON, 1999) e a segunda, para dar continuidade e fazer comparações com resultados de pesquisas anteriores.

O questionário foi estruturado em blocos, no quais os respondentes eram solicitados para escolher, em cada uma das assertivas, uma opção que podia variar numa escala de 1 a 7 , sendo 1 para discordo totalmente e 7 para concordo plenamente. Exceto pela parte em que as questões são relacionadas ao perfil da empresa, ao perfil do respondente, empregados e 
receita, que eram abertas, todas as demais exigiam um posicionamento dos respondentes, caso contrário não poderiam completar e submeter o questionário.

\subsubsection{Bloco I - Ambiente}

No bloco I buscou-se identificar a intensidade do nível de competição. As cinco variáveis elencadas foram utilizadas em estudos anteriores e adaptadas à presente pesquisa. $\mathrm{O}$ quadro 6 , abaixo, demonstra o construto "Ambiente", as variáveis observadas e as principais referências.

Quadro 6 - Bloco I - Variáveis do construto "Ambiente"

\begin{tabular}{|c|c|l|l|c|c|c|}
\hline Bloco & Constructo & $\begin{array}{c}\text { Faceta do } \\
\text { constructo } \\
\text { pesquisada }\end{array}$ & Variáveis & No Itens & Escala & Referência \\
\hline 1 & Ambiente & $\begin{array}{l}\text { O nível de } \\
\text { lompetição no } \\
\text { ambiente da } \\
\text { empresa é intenso } \\
\text { emrelação: }\end{array}$ & $\begin{array}{l}\text { Vendas e distribuição; Qualidade e } \\
\text { variedade de produtos; Preço; } \\
\text { Participação de Mercado ( Market } \\
\text { Share); Serviçosaosclientes }\end{array}$ & 5 & Intervalar & $\begin{array}{l}\text { Narayanan (1984); Guilding e } \\
\text { McManus (2002) }\end{array}$ \\
\hline
\end{tabular}

\subsubsection{Bloco II - Fatores contingenciais}

O bloco II diz respeito aos fatores contingenciais. Os construtos pesquisados foram Estratégia, Estrutura, Tecnologia e Porte. A consideração desses construtos está alinhada a pesquisas internacionais sobre desenho e uso de sistemas de controle gerencial (FERREIRA; OTLEY, 2010) e estudos no Brasil (ESPEJO, 2008; JUNQUEIRA, 2010).

\subsubsection{Bloco II - Fatores contingenciais - Estratégia}

No fator contingencial "Estratégia" buscou-se identificar a postura adotada pela empresa em que se percebe destaque em relação aos seus concorrentes. As nove variáveis elencadas foram utilizadas em estudos anteriores e adaptadas à presente pesquisa. O quadro 7, a seguir, demonstra o construto "Estratégia", as variáveis observadas e as principais referências. 
Quadro 7 - Bloco II - Variáveis do construto "Estratégia"

\begin{tabular}{|c|c|c|c|c|c|c|}
\hline Bloco & Constructo & $\begin{array}{l}\text { Faceta do } \\
\text { constructo } \\
\text { pesquisada }\end{array}$ & Variáveis & $\mathbf{N}^{0}$ Itens & Escala & Referência \\
\hline 2 & Estratégia & $\begin{array}{l} \\
\text { A empresa se } \\
\text { destaca de seus } \\
\text { concorrentes por } \\
\text { adotar as seguintes } \\
\text { posturas: }\end{array}$ & \begin{tabular}{|l|} 
Fornecer produtos de alta qualidade; \\
Custos de procução baixos; Fornecer \\
produtos com características \\
únicas;Fornecer produtos de preço \\
baixo; Modificar o desenho e \\
introduzir novos produtos \\
rapidamente; Modificar o volume/mix \\
dos; produtos oferecidos; Fazer \\
entregas rápidas; Disponibilidade \\
imediata de produtos; Customização \\
de produtos e serviços as necessidades \\
do cliente
\end{tabular} & 9 & Intervalar & $\begin{array}{l}\text { Porter (1990); Chenhall e } \\
\text { Langfield-Smith (1998); } \\
\text { Chenhall (2005) }\end{array}$ \\
\hline
\end{tabular}

\subsubsection{Bloco II - Fatores contingenciais - Estrutura}

O fator contingencial "Estrutura" foi classificado em cinco facetas ou perspectivas, objetivando identificar as características do modelo de estrutura organizacional adotado pela empresa, a saber: i- são delegados amplos poderes para a alta gerência decidir sobre; ii- em relação ao desenho de cargos e tarefas; iii- em relação ao nível de formalidades; iv- em relação ao processo decisorial; v- em relação ao estilo gerencial pelo modo de tomar decisões. As treze variáveis elencadas foram utilizadas em estudos anteriores e adaptadas à presente pesquisa. O quadro 8 abaixo demonstra o construto "Estrutura", as variáveis observadas e as principais referências.

Quadro 8 - Bloco II - Variáveis do construto "Estrutura"

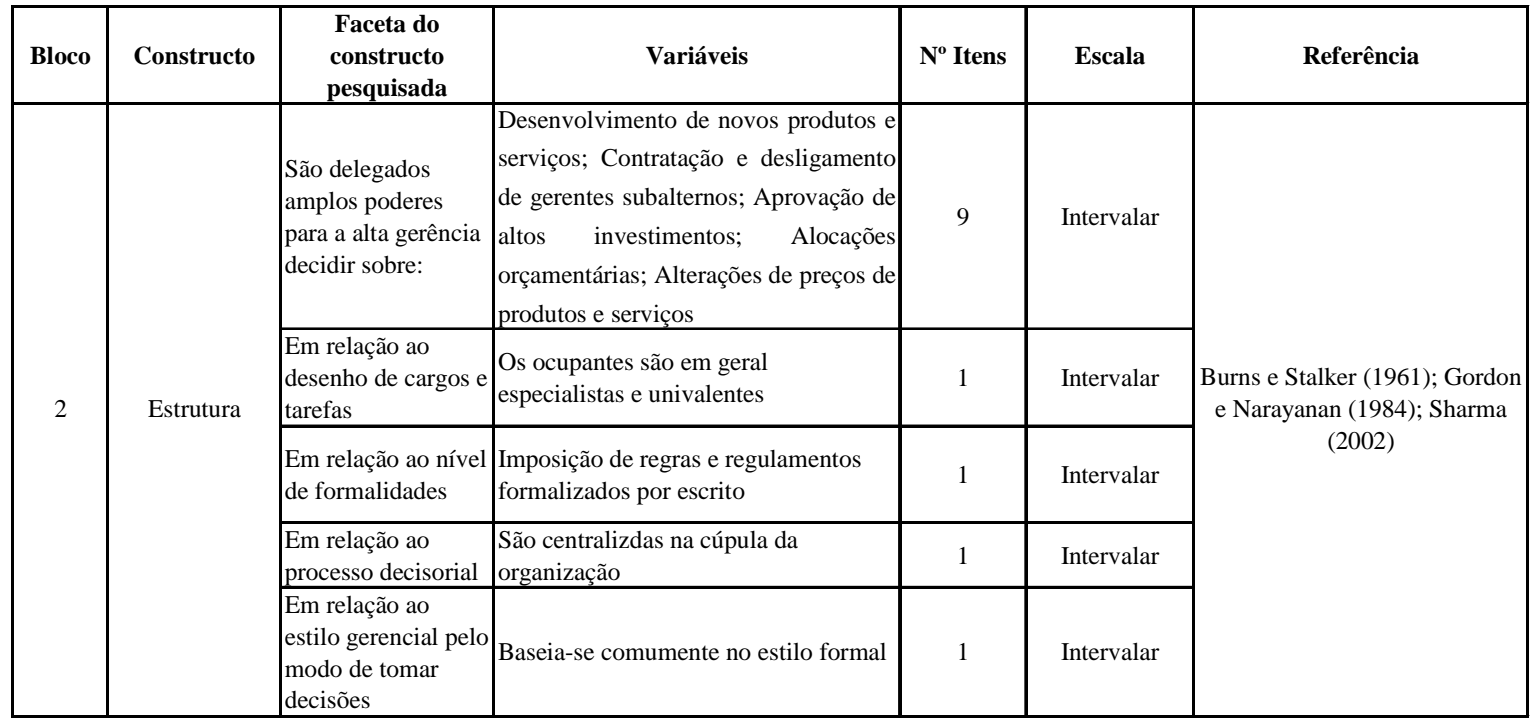




\subsubsection{Bloco II - Fatores contingenciais - Tecnologia}

No fator contingencial "Tecnologia" buscou-se identificar quais os sistemas que são intensamente utilizados para apoiar os processos de negócios. As sete variáveis elencadas foram utilizadas em estudos anteriores e adaptadas à presente pesquisa. O quadro 9 abaixo demonstra o construto "Tecnologia”, as variáveis observadas e as principais referências.

Quadro 9 - Bloco II - Variáveis do construto "Tecnologia"

\begin{tabular}{|c|c|c|l|c|c|c|}
\hline Bloco & Constructo & $\begin{array}{c}\text { Faceta do } \\
\text { constructo } \\
\text { pesquisada }\end{array}$ & Variáveis & No Itens & Escala & Referência \\
\hline 2 & Tecnologia & $\begin{array}{l}\text { Sistemasutilizados } \\
\text { intensamentepara } \\
\text { apoiarosprocessos } \\
\text { denegócios: }\end{array}$ & $\begin{array}{l}\text { E-commerce vendas de produtos e } \\
\text { serviçospela Internet; ERP-Sistemas } \\
\text { integrados de gestão; CRM-Gestão do } \\
\text { relacionamento com o cliente; SCM- } \\
\text { Gestão da cadeia de suprimentos; DW- } \\
\text { Armazém de dados; OLAP- } \\
\text { Processamentoanalítico on-line; BI- } \\
\text { Sistemas de inteligência de negócios }\end{array}$ & 7 & Intervalar \\
Hyvönen (2007)
\end{tabular}

\subsubsection{Bloco II - Fatores contingenciais - Porte da organização}

No fator contingencial "Porte" buscou-se identificar dois elementos que servem para comparar grandezas, neste caso foi adotado o número de funcionários e a receita bruta anual. As duas variáveis elencadas foram utilizadas em estudos anteriores e adaptadas à presente pesquisa. O quadro 10 abaixo demonstra o construto "Porte", as variáveis observadas e as principais referências.

Quadro 10 - Bloco II - Variáveis do construto "Porte"

\begin{tabular}{|c|c|c|c|c|c|c|}
\hline Bloco & Constructo & $\begin{array}{l}\text { Faceta do } \\
\text { constructo } \\
\text { pesquisada }\end{array}$ & Variáveis & $\mathbf{N}^{\mathbf{0}}$ Itens & Escala & Referência \\
\hline 2 & Porte & & $\begin{array}{l}\text { Número de funcionários; Receitabruta } \\
\text { anual }\end{array}$ & 2 & Categórica & $\begin{array}{l}\text { Abdel-Kader e Luther (2008); } \\
\text { Ferreira e Otley (2010) }\end{array}$ \\
\hline
\end{tabular}

\subsubsection{Bloco III - Atributos dos Sistemas de Controle Gerencial Focados nos}

\section{Clientes}

O bloco III do instrumento refere-se aos atributos dos sistemas de controle gerencial focados nos clientes. As variáveis observáveis foram operacionalizadas a partir dos estudos de Guilding e McManus (2002), McManus (2006), Weir (2008) e adaptadas à presente pesquisa. 
O construto de $2^{\circ}$ ordem "atributos" dos sistemas de controle gerencial focados nos clientes foi constituído a partir das variáveis observadas que compuseram os construtos de $1^{\circ}$ ordem; análise da lucratividade do cliente; valor vitalício do cliente e valor econômico do cliente.

\subsubsection{Bloco III - Atributos dos Sistemas de Controle Gerencial Focados nos}

\section{Clientes - Desenhos do sistema de informação}

No construto "atributos" dos SCG focados nos clientes, buscou-se identificar o tipo de artefato que os gestores utilizam para elaborar análises econômico financeiras relativas aos clientes da organização. Os respondentes eram solicitados a opinar sobre o uso das diversas análises elencadas nos 9 itens desse bloco.

As variáveis foram utilizadas em trabalhos anteriores e adaptadas à presente pesquisa. Os construtos de $1^{\mathrm{o}}$ ordem mensurados através desses 9 itens foram:i- análise da lucratividade do cliente; ii- valor vitalício do cliente e iii- valor econômico do cliente. O quadro 11 abaixo demonstra o construto "Atributos", as variáveis observadas e as principais referências.

Quadro 11 - Bloco II - Variáveis do construto "Atributos"

\begin{tabular}{|c|c|c|c|c|c|c|}
\hline Bloco & Constructo & $\begin{array}{c}\text { Faceta do } \\
\text { constructo } \\
\text { pesquisada }\end{array}$ & Variáveis & $\mathbf{N}^{o}$ Itens & Escala & Referência \\
\hline 3 & $\begin{array}{l}\text { Atributos do } \\
\text { sistema de } \\
\text { controle } \\
\text { gerencial } \\
\text { focadonos } \\
\text { clientes }\end{array}$ & $\begin{array}{l}\text { Osgestores no dia a } \\
\text { dia das suas } \\
\text { atribuiçõesfazem } \\
\text { usointenso das } \\
\text { seguintesanálises: }\end{array}$ & $\begin{array}{l}\text { Análise da receita de clientes; Análise } \\
\text { dos custos dos clientes; Análise da } \\
\text { rentabilidade dos clientes; Análise das } \\
\text { receitas durante o ciclo de vida do } \\
\text { cliente; Análise dos custos durante o } \\
\text { ciclo de vida do cliente; Análise da } \\
\text { lucratividade durante o ciclo de vida } \\
\text { docliente; Análise das receitas } \\
\text { potenciaisdevido a conquista de } \\
\text { futurosclientes; Análise dos custos } \\
\text { potenciaisdevido a conquista de } \\
\text { futurosclientes; Análise da receita } \\
\text { perdida devido ao abandono de futuros } \\
\text { clientes }\end{array}$ & 9 & Intervalar & $\begin{array}{l}\text { Guilding e McManus (2002); } \\
\text { Weir (2008) }\end{array}$ \\
\hline
\end{tabular}

\subsubsection{Bloco III - Atributos dos Sistemas de Controle Gerencial Focados nos}

\section{Clientes - Percepção sobre relevância e valor agregado}

Os nove itens que serviram para mensurar a percepção dos respondentes sobre a relevância e valor agregado desses atributos não foram utilizados na pesquisa. 


\subsubsection{Bloco IV - Uso dos Sistemas de Controle Gerencial Focados nos Clientes}

O bloco IV do instrumento refere-se ao tipo de uso dos sistemas de controle gerencial focados nos clientes. As variáveis observáveis foram operacionalizadas, a partir dos estudos de Simons (1995), Henri (2006); Ferreira e Otley (2010). Buscou-se identificar os objetivos para os quais os artefatos do SCG focados nos clientes eram utilizados.

O construto de $2^{\circ}$ ordem "uso" dos sistemas de controle gerencial focados nos clientes foi constituído a partir das 11 variáveis observadas que compuseram os construtos de $1^{\circ}$ ordem; uso diagnóstico e uso interativo. O quadro 12 abaixo demonstra o construto "Atributos", as variáveis observadas e as principais referências.

Quadro 12 - Bloco II - Variáveis do construto "Uso"

\begin{tabular}{|c|c|c|c|c|c|c|}
\hline Bloco & Construto & $\begin{array}{l}\text { Faceta do } \\
\text { construto } \\
\text { pesquisada }\end{array}$ & Variáveis & $\mathbf{N}^{o}$ Itens & Escala & Referência \\
\hline 4 & $\begin{array}{l}\text { Usointenso do } \\
\text { sistema de } \\
\text { controle } \\
\text { gerencial } \\
\text { focadonos } \\
\text { clientes }\end{array}$ & $\begin{array}{l} \\
\text { Osgestores } \\
\text { utilizam } \\
\text { intensamenteos } \\
\text { resultados das } \\
\text { análisesfocadas no } \\
\text { cliente, } \\
\text { objetivando: }\end{array}$ & $\begin{array}{l}\text { Acompanhar as metas com o que foi } \\
\text { planejado; Projetar (forecast) os } \\
\text { resultadosmaisprováveis; Corrigir } \\
\text { pequenosajustesquando da } \\
\text { comparação entre metas e resultados: } \\
\text { Analisarsomente as variações } \\
\text { significativas entre o orçado e o } \\
\text { realizado; Rever as principais metas; } \\
\text { Discutiroportunidades de melhorias } \\
\text { entre superiores, subordinados e pares; } \\
\text { Discutir a premissa e novos planos de } \\
\text { ações; Focar as questões críticas para o } \\
\text { sucesso da empresa: Unificar a visão } \\
\text { da organização sobre os problemas que } \\
\text { afetam o desempenho; Criaruma } \\
\text { linguagem comum a todos os gestores } \\
\text { edireção; Desenvolvernovas } \\
\text { estratégias e planos de ação }\end{array}$ & 11 & Intervalar & $\begin{array}{l}\text { Simons (1995); Widener } \\
\text { (2007); Ferreira e Otley (2010) }\end{array}$ \\
\hline
\end{tabular}

\subsubsection{Bloco V - Desempenho dos Sistemas de Controle Gerencial Focados nos}

\section{Clientes}

$\mathrm{O}$ bloco $\mathrm{V}$ do instrumento refere-se ao modo pela qual os sistemas de controle gerencial focados nos clientes contribuem para o processo de gestão empresarial. As variáveis observáveis foram operacionalizadas, a partir dos estudos Ferreira e Otley (2010). 
As cinco variáveis elencadas foram utilizadas em estudos anteriores e adaptadas à presente pesquisa. O quadro 13 abaixo demonstra o construto "Desempenho", as variáveis observadas e as principais referências.

Quadro 13 - Bloco II - Variáveis do construto "Desempenho"

\begin{tabular}{|c|c|l|l|c|c|c|}
\hline Bloco & Constructo & $\begin{array}{c}\text { Faceta do } \\
\text { constructo } \\
\text { pesquisada }\end{array}$ & Variáveis & No Itens & Escala & Referência \\
\hline 5 & Desempenho & $\begin{array}{l}\text { Os gestores sentem- } \\
\text { se plenamente } \\
\text { satisfeitos }\end{array}$ & $\begin{array}{l}\text { lerenciamento da empresa; Pela } \\
\text { contribuição para a tomada de decisão } \\
\text { contribuição a tomada de decisão } \\
\text { estratégica em longo prazo; Pela } \\
\text { contribuição pelo desempenho } \\
\text { econômico da empresa; Pela } \\
\text { contribuição pelo desempenho geral } \\
\text { do sistema }\end{array}$ & 5 & Intervalar & Ferreira e Otley (2010) \\
\hline
\end{tabular}

O último bloco refere-se aos dados da empresa, tais como: nome, setor econômico, e perfil do respondente. Nesse mérito, buscou-se identificar o nome, cargo, tempo de trabalho na empresa, faixa etária e endereço eletrônico. Na segunda fase, quando as instituições de ensino passaram a participar da pesquisa, um campo novo foi incluído com o propósito de identificar a instituição à qual o aluno ou egresso era ou estava vinculado.

\subsection{Coleta dos dados: vantagens e limitações}

A presente pesquisa foi realizada através de um levantamento do tipo survey utilizando-se o questionário como instrumento de coleta de dados. Adotou-se a correspondência eletrônica como forma de questionamento. A esse respeito, Mattar (2005) esclarece que devido ao fato de as opções de respostas serem padronizadas, o instrumento pode ser codificado, o que vem a facilitar extremamente o processo de digitação e processamento dos dados, tanto em termos de rapidez e economia quanto em termos de precisão.

Para os contatos selecionados, foram enviadas correspondências eletrônicas, mencionando a origem e as motivações do pesquisador e convidando essas pessoas a participaremda pesquisa. $\mathrm{O}$ texto da mensagem continha um link para acesso ao questionário (http://fs17.formsite.com/FlavioRobertoMantovani/form1/index.html) determinado pelo sistema de formulários para pesquisas online conhecido como Formsite Web Form Builder. 
As correspondências eletrônicas foram enviadas no início do mês de outubro de 2011 para a população formada pelas maiores e melhores empresas e início de novembro de 2011 para a população formada pelos alunos do mestrado profissional. Decorridas 4 semanas, aproximadamente, foi enviada nova correspondência, agradecendo aos participantes e destacando a importância da colaboração daqueles que ainda não haviam respondido. $\mathrm{O}$ processo de coleta foi dado como encerrado em 10 de dezembro de 2011.

Na opinião de Machado (2010), a principal vantagem da survey por correspondência, correio ou e-mail, é a possibilidade de obter informações de respondentes difíceis de se achar ou inacessíveis, bem como ser impessoal, garantir mais tempo para o respondente refletir sobre as perguntas e permitir maior cobertura demográfica.

De outro lado, de acordo com Mattar (2005, p.175), devem-se considerar algumas desvantagens na aplicação desse tipo de instrumento, tais como: depender da boa vontade do respondente, depender de o respondente dispor ou lembrar-se do dado solicitado, depender da sinceridade do respondente e o fato de que o instrumento de coleta ou forma de coleta pode influenciar as respostas.

\subsection{Pré-teste}

Durante o mês de agosto e setembro foi realizado um pré-teste do instrumento de coleta, visando corrigir as eventuais falhas e incorreções. A esse respeito, Richardson (1999) comenta: refere-se a aplicação prévia do questionário a um grupo que apresente as mesmas características da população incluída na pesquisa e tem por objetivo revisar e direcionar aspectos da investigação.

O questionário foi submetido para dois grupos distintos. $\mathrm{O}$ primeiro formado por docentes e pesquisadores na área da Contabilidade (dois professores doutores) e o outro formado por gestores de empresas (um do segmento de serviços e outro do segmento de comércio varejista). A devolutiva se deu através de entrevistas.

Atendendo as sugestões dos grupos, as seguintes alterações foram realizadas: i- para melhor compreensão das assertivas, foi padronizada, para todos os blocos, a categoria de resposta, de 
1 para discordo totalmente e 7 concordo plenamente; ii- o termo "desenho" foi substituído por "modelo"; iii- incluído o campo de e-mail do respondente, caso este tenha interesse em receber os resultados da pesquisa.

\subsection{Tratamento estatístico e critérios para a análise dos resultados}

Os dados foram exportados do ambiente Formsite, onde residiram até o encerramento da coleta dos dados, para uma planilha eletrônica, para verificação de inconsistências e conversão dos resultados das variáveis, $\mathrm{n}^{\circ}$ de funcionários e receita bruta para os seus correspondentes logaritmos. Realizada essa etapa, os dados numéricos e não numéricos foram armazenados numa matriz de dados.

Os dados foram analisados utilizando-se as técnicas da estatística descritiva e a modelagem de equações estruturais com estimação PLS-PM (Partial Least Squares - Path Modeling). Os softwares utilizados na análise dos dados foram o SPSS (Statistical Package for the Social Sciences) versão 16.0 e o Smart PLS versão 2.0.

O quadro 14 sumariza os procedimentos adotados para a análise dos dados. As técnicas da estatística descritiva foram utilizadas para as variáveis que dizem respeito ao perfil da empresa e do respondente. A estatística descritiva permite ao leitor uma melhor compreensão dos comportamentos dos dados por meio de tabelas, gráficos e medidas-resumo, identificando tendências, variabilidade e valores atípicos (FÁVERO et al., 2009, p.51).

No próximo passo, realizou-se a análise dos relacionamentos esperados entre as variáveis latentes, utilizando a Modelagem de Equações Estruturais (MEE) com estimação PLS. A modelagem de equações estruturais tem sido usada em várias áreas de estudo, sobretudo pelo interesse em: i- fornecer um método direto para lidar com múltiplas relações simultaneamente, enquanto fornece eficiência estatística e ii- habilidade para avaliar as relações de âmbito geral e fornecer uma transição da análise exploratória para a análise confirmatória (HAIR, 2005, p.466).

A escolha do método PLS-PM (Partial Least Square - Path Modeling) foi indicada pelo contexto da pesquisa, para verificar o relacionamento entre variáveis latentes. A esse respeito, 
Bido et al. (2010) esclarecem que esse método é apropriado quando se objetiva construir um modelo teórico no sentido mais exploratório do que confirmatório. Em adição, Chin et al. (2003) nos ensina, que o referido método possui a habilidade de modelar variáveis latentes sob condições de anormalidade e amostras pequenas e médias.

Quadro 14 - Tratamento estatístico

\begin{tabular}{|c|c|c|c|c|}
\hline Variáveis & \multicolumn{2}{|c|}{ Relacionamento entre as variáveis } & Hipótese & Tratamento \\
\hline $\begin{array}{c}\text { Fatorcontingencial } \\
\text { externo e fatores } \\
\text { contingenciaisinternos }\end{array}$ & Ambiente & $\begin{array}{l}\text { Estratégia; Estrutura; } \\
\text { Tecnologia e Porte }\end{array}$ & 1 & \multirow{6}{*}{$\begin{array}{l}\text { I-Avaliação do } \\
\text { modelo de } \\
\text { mensuração: } \\
\text { confiabilidade; } \\
\text { validade } \\
\text { convergente; } \\
\text { validade } \\
\text { discriminante. } \\
\text { II- Avaliaçãodo } \\
\text { modelo } \\
\text { estrutural: } \\
\text { coeficientes } \\
\text { estruturais, } \mathrm{R}^{2} \text {, } \\
\text { efeitosdiretos, } \\
\text { indiretos e totais }\end{array}$} \\
\hline $\begin{array}{l}\text { Fatorcontingencial } \\
\text { externo (ambiente) e } \\
\text { atributos dos SCG } \\
\text { focadosnosclientes }\end{array}$ & Ambiente & $\begin{array}{l}\text { Atributos dos SCG } \\
\text { focadosnosclientes }\end{array}$ & 2 & \\
\hline $\begin{array}{l}\text { Fatorescontingenciais } \\
\text { internos e atributos dos } \\
\text { SCG focadosnos } \\
\text { clientes }\end{array}$ & $\begin{array}{l}\text { Estratégia; Estrutura; } \\
\text { Tecnologia e Porte }\end{array}$ & $\begin{array}{l}\text { Atributos dos SCG } \\
\text { focadosnosclientes }\end{array}$ & 3 & \\
\hline $\begin{array}{c}\text { Atributos do SCG } \\
\text { focadosnosclientes e } \\
\text { uso dos SCG focados } \\
\text { nosclientes }\end{array}$ & $\begin{array}{l}\text { Atributos dos SCG } \\
\text { focadosnosclientes }\end{array}$ & $\begin{array}{c}\text { Uso dos SCG focados } \\
\text { nosclientes }\end{array}$ & 4 & \\
\hline $\begin{array}{l}\text { Atributos do SCG } \\
\text { focadosnosclientes e } \\
\text { desempenho dos SCG } \\
\text { focadosnosclientes }\end{array}$ & $\begin{array}{l}\text { Atributos dos SCG } \\
\text { focadosnosclientes }\end{array}$ & $\begin{array}{l}\text { Desempenho dos SCG } \\
\text { focadosnosclientes }\end{array}$ & 5 & \\
\hline $\begin{array}{l}\text { Uso do SCG focados } \\
\text { nosclientes e } \\
\text { desempenho dos SCG } \\
\text { focadosnosclientes }\end{array}$ & $\begin{array}{c}\text { Uso dos SCG focados } \\
\text { nosclientes }\end{array}$ & $\begin{array}{l}\text { Desempenho dos SCG } \\
\text { focadosnosclientes }\end{array}$ & 6 & \\
\hline $\begin{array}{c}\text { Perfil do respondente e } \\
\text { daempresa }\end{array}$ & \multicolumn{3}{|c|}{ Uso dos SCG focados nos clientes } & $\begin{array}{l}\text { Estatística } \\
\text { descritiva }\end{array}$ \\
\hline
\end{tabular}




\section{RESULTADOS DA PESQUISA}

O presente capítulo apresenta os resultados da pesquisa. O processo de análise dos dados obedeceu a seguinte estruturação: i- análise descritiva; ii- análise do modelo de mensuração; iii- análise do modelo estrutural e iv- análise das hipóteses de pesquisa.

\subsection{Análise descritiva dos dados}

A tabela 2 apresenta as análises de frequências das variáveis do construto ambiente. Considerando-se a soma dos percentuais dos itens de 5 a 7 , que revelam alto grau de concordância em relação à competitividade do ambiente, todas as variáveis indicaram, nessa faixa, resultados acima de $74,7 \%$.

Destacam-se das demais, o resultado alcançado pela variável preço $(81,9 \%)$ e vendas e distribuição $(80,7 \%)$ ensejando que o ambiente de atuação dessas empresas é considerado altamente competitivo e demanda maior exigência por sistemas de controle gerenciais.

Tabela 2 - Frequências para o construto ambiente

\begin{tabular}{lcccccccc}
\hline & $\mathbf{1}$ & $\mathbf{2}$ & $\mathbf{3}$ & $\mathbf{4}$ & $\mathbf{5}$ & $\mathbf{6}$ & $\mathbf{7}$ & Total \\
\hline Vendas e distribuição & 3,6 & - & 2,4 & 13,3 & 10,8 & 26,5 & 43,4 & 100,0 \\
Qualidade e variedade de produtos & 1,2 & 2,4 & 9,6 & 10,8 & 18,1 & 20,5 & 37,3 & 100,0 \\
Preço & 2,4 & 1,2 & 6,0 & 8,4 & 16,9 & 20,5 & 44,6 & 100,0 \\
Participação de mercardo (market-share) & 1,2 & 2,4 & 6,0 & 13,3 & 14,5 & 34,9 & 27,7 & 100,0 \\
Serviços ao cliente & 1,2 & - & 8,4 & 15,7 & 10,8 & 30,1 & 33,7 & 100,0 \\
\hline
\end{tabular}

A tabela 3 apresenta as análises de frequência das variáveis do construto estratégia. Pelos resultados dos extremos do nível de concordância em relação a postura da empresa frente seus concorrentes, tem-se que as empresas adotam estratégias de fornecer produtos de alta qualidade $(88,0 \%)$ e produtos e serviços customizados aos seus clientes $(74,7 \%)$.

As variáveis, custos de produção baixos $(59,0 \%)$ e fornecer produtos de preço baixo $(36,1 \%)$ indicam a tendência das empresas pesquisadas em adotar uma estratégia de diferenciação, 
focada em qualidade e produtos e serviços especiais, do que uma estratégia baseada em liderança de custos (PORTER, 1990).

Tabela 3 - Frequências para o construto estratégia

\begin{tabular}{|c|c|c|c|c|c|c|c|c|}
\hline & 1 & 2 & 3 & 4 & 5 & 6 & 7 & Total \\
\hline Fornecer produtos de alta qualidade & 1,2 & - & 1,2 & 9,6 & 9,6 & 24,1 & 54,2 & 100,0 \\
\hline Custos de produção baixos & 2,4 & 7,2 & 8,4 & 22,9 & 26,5 & 18,1 & 14,5 & 100,0 \\
\hline Fornecer produtos com características únicas & 4,8 & 6,0 & 9,6 & 12,0 & 13,3 & 32,5 & 21,7 & 100,0 \\
\hline Fornecer produtos de preço baixo & 10,8 & 13,3 & 14,5 & 25,3 & 19,3 & 10,8 & 6,0 & 100,0 \\
\hline $\begin{array}{l}\text { Modificar o desenho e introduzir novos } \\
\text { produtos rapidamente }\end{array}$ & 13,3 & 7,2 & 8,4 & 16,9 & 18,1 & 15,7 & 20,5 & 100,0 \\
\hline $\begin{array}{l}\text { Modificar o volume/mix dos produtos } \\
\text { oferecidos }\end{array}$ & 9,6 & 9,6 & 9,6 & 16,9 & 10,8 & 26,5 & 16,9 & 100,0 \\
\hline Fazer entregas rápidas & 7,2 & 1,2 & 6,0 & 12,0 & 18,1 & 24,1 & 31,3 & 100,0 \\
\hline Disponibilidade imediata de produtos & 6,0 & 2,4 & 4,8 & 13,3 & 14,5 & 24,1 & 34,9 & 100,0 \\
\hline $\begin{array}{l}\text { Customização de produtos e serviços às } \\
\text { necessidades dos clientes }\end{array}$ & 1,2 & 4,8 & 6,0 & 13,3 & 21,7 & 20,5 & 32,5 & 100,0 \\
\hline
\end{tabular}

A tabela 4 apresenta as análises de frequência das variáveis do construto estrutura. A variável que mensurou o processo decisorial, indicada por "são centralizadas na cúpula da organização" foi a que mais pontuou nos extremos do nível de concordância, ficando com 92,8\%. Mostrando certa coesão, a variável "as decisões são normalmente baseadas no estilo formal" foi, na sequência, a maior percentagem com $83,1 \%$.

Fica evidente que o perfil da estrutura organizacional das empresas é marcado por forte hierarquização e estilo decisório formal. A baixa contagem para a flexibilização na aprovação de altos investimentos $(36,1 \%)$, alterações nos preços de produtos e serviços $(59,0 \%)$ e alocações orçamentárias $(59,0 \%)$ comprovam a rigidez do desenho da estrutura organizacional dessas empresas. 
Tabela 4 - Frequências para o construto estrutura

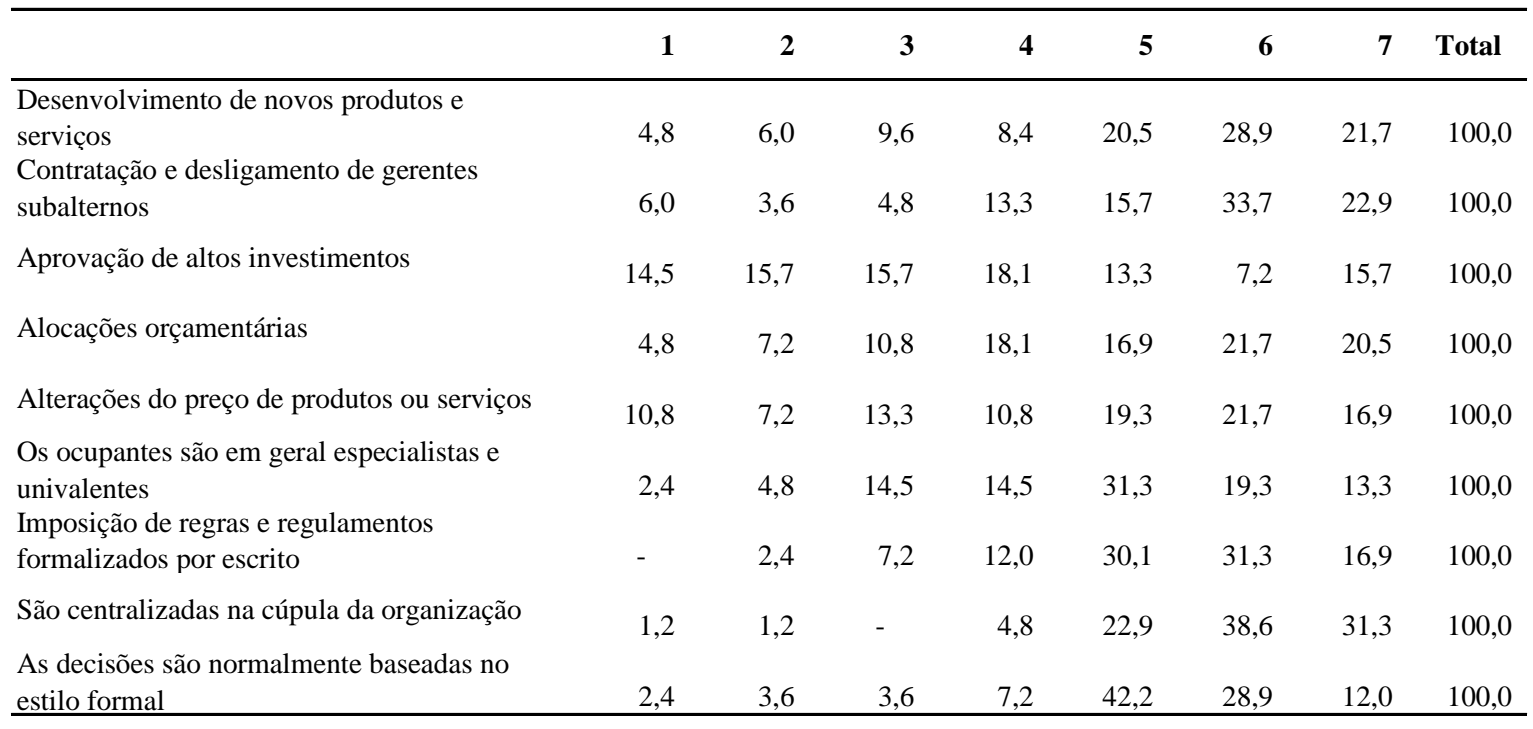

A tabela 5 apresenta as análises de frequência das variáveis do construto tecnologia. A expressiva contagem para a variável ERP - Sistemas integrados de gestão denota a preocupação que as empresas têm em melhorar seus processos e com isso tomar decisões mais rápidas e mais eficazes. As tecnologias conhecidas como analíticas e que contribuem para a gestão da cadeia de valor, como o CRM e SCM também ficaram evidentes pela análise.

As tecnologias OLAP-Processamento analítico on-line e E-Commerce-vendas de produtos e serviços pela Internet foram as tecnologias menos utilizadas. Ressalte-se que a opção de realizar vendas pela Internet é alternativa de apenas alguns segmentos econômicos específicos.

Tabela 5 - Frequências para o construto tecnologia

\begin{tabular}{|c|c|c|c|c|c|c|c|c|}
\hline $\begin{array}{l}\text { E-Commerce - vendas de produtos e serviços } \\
\text { pela Internet }\end{array}$ & 32,5 & 16,9 & 6,0 & 16,9 & 4,8 & 9,6 & 13,3 & 100,0 \\
\hline ERP - Sistemas integrados de gestão & 1,2 & 1,2 & 3,6 & 4,8 & 18,1 & 28,9 & 42,2 & 100,0 \\
\hline $\begin{array}{l}\text { CRM - Gestão do relacionamento com o } \\
\text { cliente }\end{array}$ & 4,8 & 6,0 & 10,8 & 15,7 & 13,3 & 22,9 & 26,5 & 100,0 \\
\hline SCM - Gestão da cadeia de suprimentos & 10,8 & 8,4 & 10,8 & 18,1 & 19,3 & 15,7 & 16,9 & 100,0 \\
\hline DW - Armazém de dados & 4,8 & 4,8 & 7,2 & 19,3 & 14,5 & 16,9 & 32,5 & 100,0 \\
\hline OLAP - Processamento analítico on-line & 13,3 & 10,8 & 8,4 & 20,5 & 16,9 & 13,3 & 16,9 & 100,0 \\
\hline
\end{tabular}

Nas estatísticas descritivas relativas ao desenho de sistemas de controle gerencial, exclusivamente, foi adotado o critério de analisar a média, mediana e desvio padrão, assim 
como o número mínimo e máximo obtido. Entende-se que esses tipos de medida podem ser de maior poder explicativo.

Na tabela 6 observam-se as variáveis do construto "Análise da lucratividade do cliente". Embora solicitadas individualmente, a receita e o custo constituem elementos de um único artefato de contabilidade gerencial chamado de "análise da lucratividade dos clientes".

A inclusão da variável "análise da lucratividade dos clientes" teve caráter confirmatório das suas precedentes, o que pode ser verificado pela diferença pouco significante existente entre as médias obtidas pelas duas variáveis que compõem basicamente o artefato.

Tabela 6 - Estatísticas descritivas do construto "análise da lucratividade dos clientes"

\begin{tabular}{lrrrrr}
\hline & Média & Mediana & $\begin{array}{l}\text { Desvio } \\
\text { Padrão }\end{array}$ & Mínimo & Máximo \\
\hline Análise da receita dos clientes & 5,41 & 6,00 & 1,61 & 1 & 7 \\
Análise dos custos dos clientes & 4,88 & 5,00 & 1,74 & 1 & 7 \\
Análise da lucratividade dos clientes & 5,28 & 6,00 & 1,61 & 1 & 7 \\
\hline
\end{tabular}

Na tabela 7 observam-se as variáveis do construto "Análise da lucratividade durante o ciclo de vida do cliente". Embora solicitadas individualmente, a receita e o custo constituem elementos de um único artefato de contabilidade gerencial chamado de "análise da lucratividade durante o ciclo de vida do cliente".

A diferença deste construto com o anterior reside na perspectiva de análise do usuário. Enquanto a anterior tem seu foco nas transações realizadas, ou passado, esta tem a orientação futura, ou seja, receita e custos envolvidos na relação atual e futura do cliente.

A inclusão da variável análise da lucratividade durante o ciclo de vida do cliente teve caráter confirmatório das suas precedentes, o que pode ser verificado pela diferença pouco significante existente entre as médias obtidas pelas duas variáveis que compõem basicamente o artefato. 
Tabela 7 - Estatísticas descritivas do construto "valor vitalício do cliente"

\begin{tabular}{lrrrrr}
\hline & Média & Mediana & $\begin{array}{c}\text { Desvio } \\
\text { Padrão }\end{array}$ & Mínimo & Máximo \\
\hline $\begin{array}{l}\text { Análise das receitas durante o ciclo de vida do } \\
\text { cliente }\end{array}$ & 4,80 & 5,00 & 1,79 & 1 & 7 \\
$\begin{array}{l}\text { Análise dos custos durante o ciclo de vida do } \\
\text { cliente }\end{array}$ & 4,47 & 5,00 & 1,82 & 1 & 7 \\
$\begin{array}{l}\text { Análise da lucratividade durante o ciclo de } \\
\text { vida do cliente }\end{array}$ & 4,86 & 5,00 & 1,79 & 1 & 7 \\
\hline
\end{tabular}

Na tabela 8 observam-se as variáveis do construto "Análise do valor econômico do cliente". A orientação básica também é o futuro, já que no contexto desse construto levam-se em conta receitas e custos potenciais, adquiridos de clientes novos e perdidos por aqueles que optaram por outro fornecedor.

Embora solicitadas individualmente, a receita e o custo potenciais e a receita potencial perdida constituem elementos de um único artefato de contabilidade gerencial chamado de "análise do valor econômico do cliente".

Tabela 8 - Estatísticas descritivas do construto "valor econômico do cliente"

\begin{tabular}{|c|c|c|c|c|c|}
\hline & Média & Mediana & $\begin{array}{l}\text { Desvio } \\
\text { Padrão }\end{array}$ & Mínimo & Máximo \\
\hline $\begin{array}{l}\text { Análise das receitas potenciais devido à } \\
\text { conquista de futuros clientes }\end{array}$ & 5,01 & 6,00 & 1,68 & 1 & 7 \\
\hline $\begin{array}{l}\text { Análise dos custos potenciais devido à } \\
\text { conquista de futuros clientes }\end{array}$ & 4,84 & 5,00 & 1,68 & 1 & 7 \\
\hline $\begin{array}{l}\text { Análise da receita potencial perdida devido ao } \\
\text { abandono dos clientes }\end{array}$ & 4,77 & 5,00 & 1,66 & 1 & 7 \\
\hline
\end{tabular}

Na tabela 9 observam-se as variáveis do construto "Uso diagnóstico". Todas as variáveis mostraram-se bastante aderentes à opinião favorável dos respondentes. O processo do planejamento e controle de metas fica evidente pelo nível de respostas nos extremos de concordância.

As variáveis "acompanhar as metas com o que foi planejado", "projetar os resultados mais prováveis" e "corrigir pequenos ajustes quando da comparação entre metas e resultados", mostraram o mesmo resultado, ou seja, 79,5\% nesse intervalo de respostas. A variável "rever principais metas" com 78,3\% e, finalmente, "analisar somente variações significativas" com percentual de $69,9 \%$. 
Tabela 9 - Estatísticas descritivas do construto "uso diagnóstico"

\begin{tabular}{|c|c|c|c|c|c|c|c|c|}
\hline & 1 & 2 & 3 & 4 & 5 & 6 & 7 & Total \\
\hline Acompanhar as metas com o que foi planejado & - & 4,8 & 3,6 & 12,0 & 14,5 & 26,5 & 38,6 & 100,0 \\
\hline $\begin{array}{l}\text { Projetar (forecast) os resultados mais } \\
\text { prováveis }\end{array}$ & 2,4 & 3,6 & 7,2 & 7,2 & 18,1 & 26,5 & 34,9 & 100,0 \\
\hline $\begin{array}{l}\text { Corrigir pequenos ajustes, quando da } \\
\text { comparação entre metas e resultados }\end{array}$ & 1,2 & 6,0 & 4,8 & 8,4 & 24,1 & 26,5 & 28,9 & 100,0 \\
\hline $\begin{array}{l}\text { Analisar somente as variações significativas } \\
\text { entre o orçado e o realizado }\end{array}$ & 2,4 & 4,8 & 3,6 & 19,3 & 26,5 & 25,3 & 18,1 & 100,0 \\
\hline Rever as principais metas & 2,4 & 6,0 & 2,4 & 10,8 & 16,9 & 33,7 & 27,7 & 100,0 \\
\hline
\end{tabular}

Na tabela 10 observam-se as variáveis do constructo "Uso interativo". A variável focar as questões críticas para o sucesso da empresa foi a que mais recebeu pontuação no extremo das avaliações, ficando com 79,5\% das respostas. Na sequência, as variáveis discutir as premissas e novos planos de ação $(78,3 \%)$ e desenvolver novas estratégias e planos de ação $(77,1 \%)$ evidenciando a contribuição do uso interativo de sistemas de controle gerencial focados nos clientes na formulação de novos planos e estratégias.

Tabela 10 - Estatísticas descritivas do construto "uso interativo"

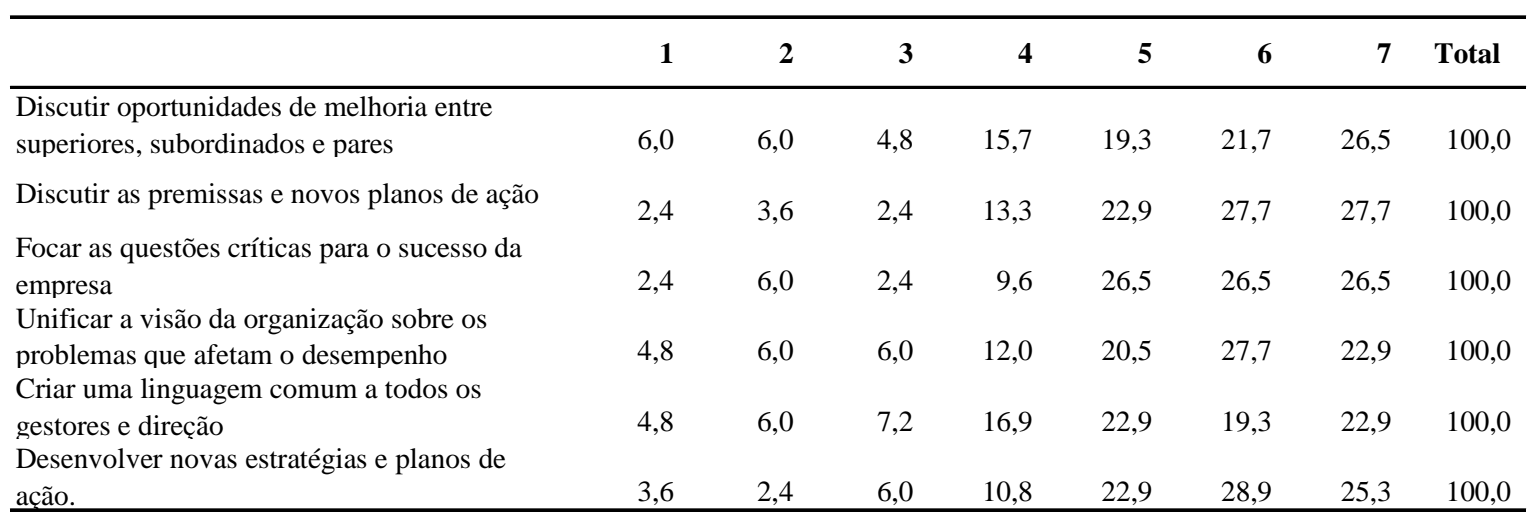

Na tabela 11 observam-se as variáveis do construto "Desempenho". Na percepção dos respondentes, a variável "Pela contribuição para o desempenho econômico da empresa" foi a que mais pontuou, ficando com 78,3\% no intervalo extremo de concordância. Na sequência e ordem de importância, a variável: "Pelo desempenho do sistema em geral" (75,9\%)e "Pela contribuição para a tomada de decisão operacional a curto prazo" $(74,7 \%)$. 
Tabela 11 - Estatísticas descritivas do construto "Desempenho"

\begin{tabular}{|c|c|c|c|c|c|c|c|c|}
\hline $\begin{array}{l}\text { Pela contribuição para o gerenciamento da } \\
\text { empresa }\end{array}$ & - & 3,6 & 7,2 & 15,7 & 24,1 & 30,1 & 19,3 & 100,0 \\
\hline $\begin{array}{l}\text { Pela contribuição para a tomada de decisão } \\
\text { operacional a curto prazo }\end{array}$ & - & 3,6 & 8,4 & 13,3 & 25,3 & 31,3 & 18,1 & 100,0 \\
\hline $\begin{array}{l}\text { Pela contribuição para a tomada de decisão } \\
\text { estratégica em longo prazo }\end{array}$ & 2,4 & 8,4 & 10,8 & 13,3 & 22,9 & 22,9 & 19,3 & 100,0 \\
\hline Pelo desempenho do sistema em geral & - & 6,0 & 7,2 & 10,8 & 22,9 & 32,5 & 20,5 & 100,0 \\
\hline
\end{tabular}

Os dados da tabela 12 demonstram as atividades econômicas das empresas participantes da pesquisa. Observa-se que a atividade serviços participa com $26,5 \%$ do total dos respondentes. Isso se deve, principalmente, ao fato do perfil da empresa à qual o aluno ou egresso das instituições de ensino está vinculado. Do total de 26 respondentes desse grupo, 17 anotaram estar trabalhando em empresas de serviços.

Tabela 12 - Empresas por atividade econômica

\begin{tabular}{|c|c|c|c|}
\hline Atividade & Frequência & $\%$ & $\begin{array}{c}\text { Frequência } \\
\text { Acumulada }(\%)\end{array}$ \\
\hline Serviços & 22,0 & 26,5 & 26,5 \\
\hline Outrasindústrias de transformação & 13,0 & 15,7 & 42,2 \\
\hline Agricultura, Pecuária, Floresta e Pesca & 9,0 & 10,8 & 53,0 \\
\hline Químico, Petroquímico, Papel e Celulose & 7,0 & 8,4 & 61,4 \\
\hline Comércio & 7,0 & 8,4 & 69,9 \\
\hline Transporte & 4,0 & 4,8 & 74,7 \\
\hline Carvão, Petróleo e Minerais & 3,0 & 3,6 & 78,3 \\
\hline Automotivo & 3,0 & 3,6 & 81,9 \\
\hline Máquinas, Equipamentos e MateriaisElétricos & 3,0 & 3,6 & 85,5 \\
\hline Eletricidade, Gás, outras & 3,0 & 3,6 & 89,2 \\
\hline Têxtil e Confecções & 2,0 & 2,4 & 91,6 \\
\hline Madeira, Móveis & 2,0 & 2,4 & 94,0 \\
\hline Farmacêutico & 1,0 & 1,2 & 95,2 \\
\hline Água, Esgoto, outras & 1,0 & 1,2 & 96,4 \\
\hline Hotéis e Restaurantes & 1,0 & 1,2 & 97,6 \\
\hline AtividadesImobiliárias & 1,0 & 1,2 & 98,8 \\
\hline Telecomunicações & 1,0 & 1,2 & 100,0 \\
\hline TOTAL & 83,0 & & 100,0 \\
\hline
\end{tabular}

Observa-se, pela tabela 13, que a grande maioria dos respondentes está em posição ou condição de usuário de sistemas de controle gerencial. Apenas 8,4\% do total representam outras posições, tais como: auditor, sócio-proprietário, etc. 
Como esse campo no questionário não tinha o seu preenchimento obrigatório, alguns respondentes optaram por omitir suas posições. Nesse caso, esta opção representou $14,5 \%$ do total dos respondentes.

Tabela 13 - Perfil dos respondentes

\begin{tabular}{l|r|r|r}
\hline \multicolumn{1}{c|}{ Cargo Ocupado } & Frequência & $\%$ & $\begin{array}{c}\text { Frequência } \\
\text { Acumulada (\%) }\end{array}$ \\
\hline Gerente & 25,0 & 30,1 & 30,1 \\
Nãoinformado & 12,0 & 14,5 & 44,6 \\
Contador & 9,0 & 10,8 & 55,4 \\
Supervisor/Coordenador & 8,0 & 9,6 & 65,1 \\
Analista & 8,0 & 9,6 & 74,7 \\
Controller & 7,0 & 8,4 & 83,1 \\
Outros & 7,0 & 8,4 & 91,6 \\
Diretor & 5,0 & 6,0 & 97,6 \\
Consultor & 2,0 & 2,4 & 100,0 \\
\hline TOTAL & 83,0 & & 100,00 \\
\hline
\end{tabular}

\subsection{Modelagem de equações estruturais}

No conceito de Hair et al. (2005, p. 468), a modelagem de equações estruturais é uma técnica multivariada que combina aspectos de regressão múltipla (examinando relações de dependência) e análise fatorial (representando conceitos não medidos - fatores - com múltiplas variáveis) para estimar uma série de relações de dependência inter-relacionadas simultaneamente.

Como a modelagem em equações estruturais (MEE) permite a avaliaçãode relações entre construtos não mensuráveis diretamente (VL - variáveislatentes) é natural que elaseja muito adequada a pesquisas empíricas em todas as áreas da Administração (BIDO et al., 2010, p.246).

A figura 10 demonstra o diagrama de caminhos que, segundo Hair et al. (2005), representa graficamente o conjunto completo de relações entre os construtos do modelo. No modelo proposto, os relacionamentos esperados entre os construtos são descritos a seguir. 
O ambiente é uma variável independente que possui relacionamento positivo com as variáveis "Fatores contingenciais internos" e "Atributos do SCGFC".

A variável "Fatores contingenciais internos" é dependente em relação à variável "ambiente" e independente no relacionamento com a variável "Atributos do SCGFC".

A variável "Atributos do SCGFC" é dependente em relação às variáveis "Ambiente" e "Fatores contingenciais internos" e independente no relacionamento com as variáveis "Uso intenso de SCGFC" e "Desempenho dos SCGFC".

A variável "Uso intenso de SCGFC" é dependente em relação à variável "Atributos do SCGFC" e independente no relacionamento com a variável "Desempenho dos SCGFC".

A variável "Desempenho dos SCGFC" é dependente em relação às variáveis "Atributos do SCGFC" e "Uso intenso dos SCGFC".

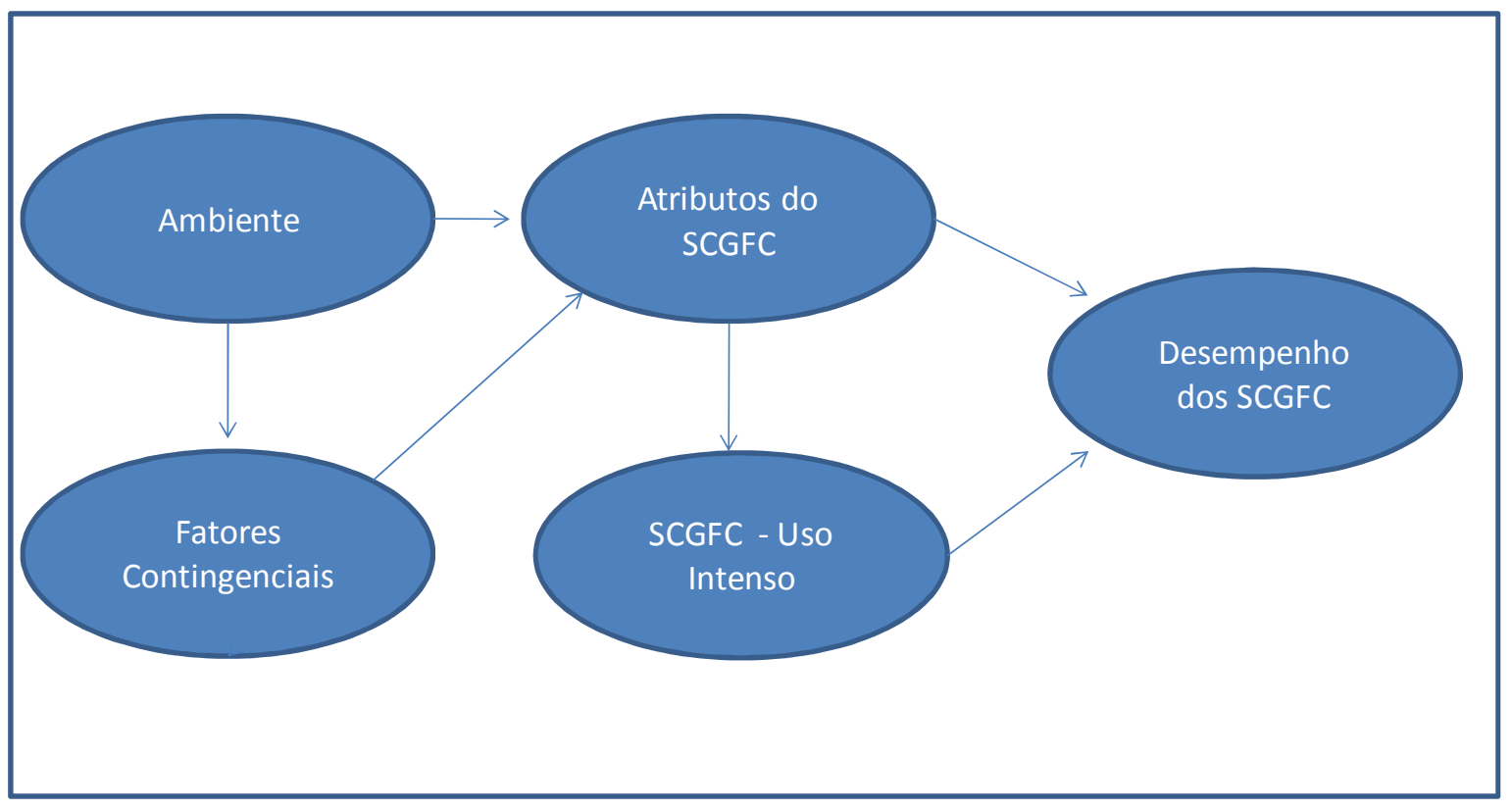

Figura 10 - Diagrama de caminhos

\subsubsection{Análise do modelo de mensuração}

Para a análise do modelo de mensuração e do modelo estrutural foi utilizado o software SmartPls 2.0. Esse software tem sido ultimamente bastante utilizado por pesquisadores da linha de contabilidade gerencial (OYADOMARI, 2008; ESPEJO 2008; JUNQUEIRA, 2010) 
e permite a estimação dos indicadores pelo método PLS-PM (Partial Least Squares - Path Modeling), o que, segundo Bidoet al. (2010), é um dos motivos para se usar o PLS-PM em detrimento de outros métodos, é a possibilidade de se modelar variáveis latentes (VL) como indicadores formativos.

Durante a análise do modelo de mensuração foram desenvolvidos certos procedimentos e testes que dão validade estatística para a pesquisa. Nesta etapa é realizada: i- a análise de correlação das variáveis; ii- a análise da confiabilidade composta,; iii- a verificação da variância média explicada; iv- a validação discriminante; e v- a validade convergente.

A figura 11 ilustra os resultados do processamento da mensuração do modelo original. Os retângulos representam os indicadores, ou as variáveis observadas que são manifestações dos construtos de $1^{\circ}$ ordem ou variável latente que, por sua vez, estão graficamente, representadas nas esferas.

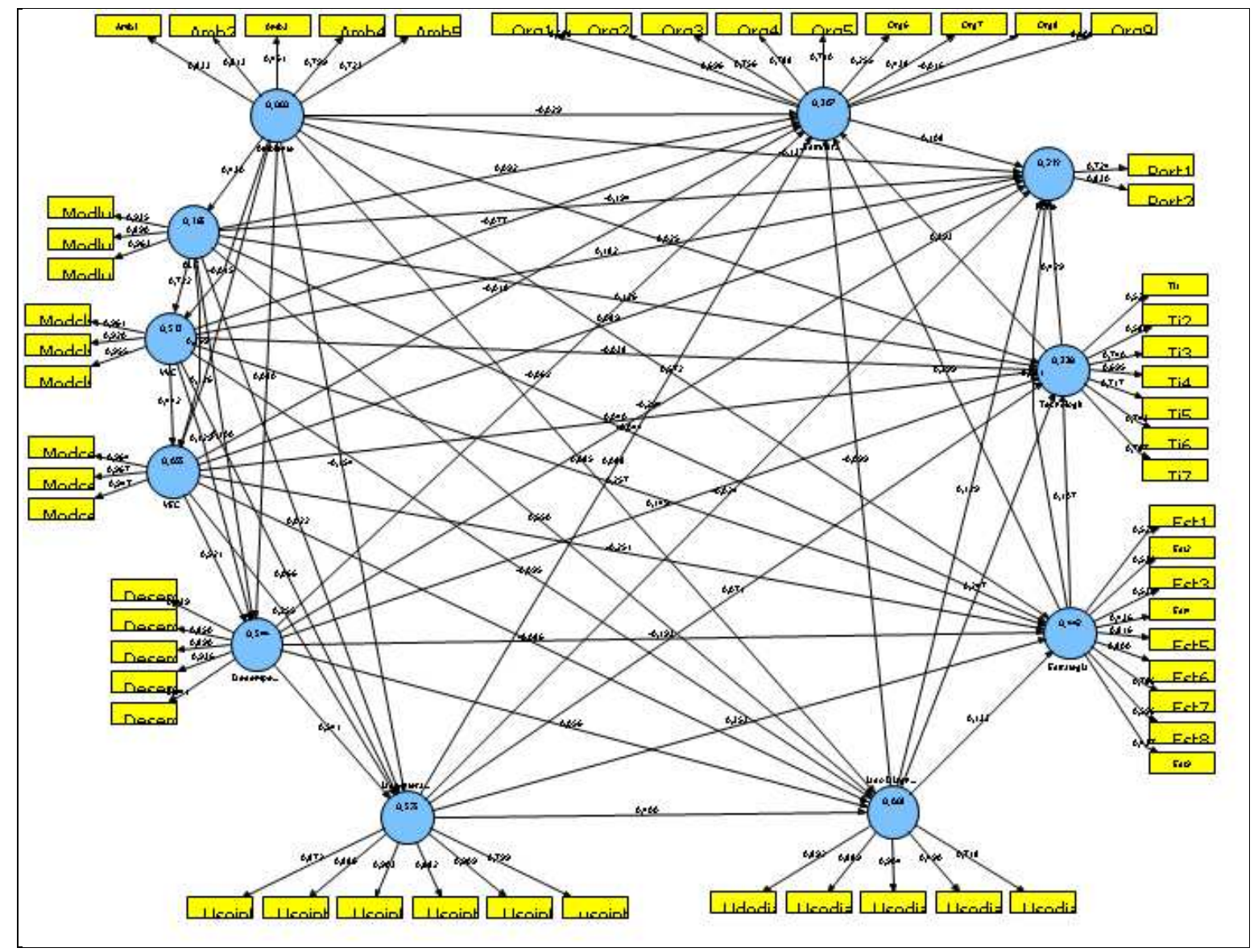

Figura 11 - Ilustração da etapa de mensuração do modelo original 
Os resultados numéricos junto às setas que chegam aos indicadores representam as cargas fatoriais. Os resultados numéricos junto às setas que ligam os construtos representam o coeficiente da equação e, por último, o resultado numérico dentro das esferas representa o $\mathrm{R}^{2}$ que é o coeficiente de relação múltipla, que indica a proporção em que uma variação na variável dependente é explicada pela variação nas variáveis independentes.

A seguir são apresentados os resultados da mensuração do modelo original.

Tabela 14 - Resultados do modelo original

\begin{tabular}{|c|c|c|c|c|}
\hline Modelo Original & VME & $\begin{array}{c}\text { Confiabilidade } \\
\text { composta }\end{array}$ & $\mathbf{R}^{2}$ & Alpha de Cronbach \\
\hline ALC & $\overline{0,86}$ & 0,95 & 0,19 & 0,92 \\
\hline Ambiente & 0,55 & 0,85 & - & 0,78 \\
\hline Desempenho & 0,83 & 0,96 & 0,54 & 0,95 \\
\hline Estratégia & 0,39 & 0,85 & 0,44 & 0,79 \\
\hline Estrutura & 0,35 & 0,80 & 0,37 & 0,72 \\
\hline Porte & 0,61 & 0,75 & 0,22 & 0,36 \\
\hline Tecnologia & 0,48 & 0,86 & 0,34 & 0,81 \\
\hline UsoDiagnóstico & 0,63 & 0,89 & 0,60 & 0,85 \\
\hline UsoInterativo & 0,77 & 0,95 & 0,57 & 0,94 \\
\hline VEC & 0,92 & 0,97 & 0,65 & 0,96 \\
\hline VVC & 0,89 & 0,96 & 0,51 & 0,94 \\
\hline
\end{tabular}

Na tabela 14, os construtos são avaliados pela Variância média explicada, pela Confiabilidade composta, pelo Coeficiente de relação múltipla $\mathrm{R}^{2}$ e o Alpha de Cronbach. No contexto das equações estruturais, Chin (1998, p.320) recomenda que a avaliação da confiabilidade do construto seja feita pela Confiabilidade composta e não pelo Alpha de Cronbach.Observa-se que todas as VL possuem confiabilidade igual ou superior ao valor de 0,70 .

O primeiro passo da análise residiu em verificar a Variância Média Explicada (VME) de cada construto. Tomando-se como base o valor de 50\% recomendado por Chin (1998, p.321), os componentes dos construtos Estratégia, Estrutura e Tecnologia foram revisados sob a análise de componentes principais e excluídas as variáveis que apresentaram cargas fatoriais abaixo de 0,50 .

O apêndice 4 demonstra as cargas fatoriais calculadas para cada uma das variáveis observadas. As variáveis cujas linhas estão demarcadas foram excluídas do processo de 
mensuração do modelo. Adicionalmente, visando o adequado ajuste do modelo, foi excluída também a variável Est2, embora sua carga fatorial inicial indicasse 0,54.

Tabela 15 - Matriz de correlações entre as variáveis do modelo original

\begin{tabular}{|c|c|c|c|c|c|c|c|c|c|c|c|}
\hline & ALC & Ambiente & Desemp. & Estratégia & Estrutura & Porte & Tecnologi & soDiagn & UsoInterat & VEC & VVC \\
\hline Ambiente & 0,43 & 0,74 & & & & & & & & & \\
\hline Estratégia & 0,36 & 0,56 & 0,31 & 0,62 & & & & & & & \\
\hline Estrutura & 0,29 & 0,29 & 0,24 & 0,49 & 0,59 & & & & & & \\
\hline Porte & 0,05 & $(0,08)$ & $(0,03)$ & 0,01 & 0,20 & 0,78 & & & & & \\
\hline UsoInterativo & 0,52 & 0,19 & 0,72 & 0,36 & 0,30 & 0,07 & 0,45 & 0,63 & $\mathbf{0 , 8 8}$ & & \\
\hline VEC & 0,74 & 0,42 & 0,72 & 0,31 & 0,24 & 0,06 & 0,45 & 0,58 & 0,65 & 0,96 & \\
\hline VVC & 0,72 & 0,30 & 0,61 & 0,36 & 0,23 & 0,10 & 0,38 & 0,52 & 0,56 & 0,74 & 0,95 \\
\hline
\end{tabular}

Através da matriz de correlações entre as variáveis, observa-se a ausência de multicolinearidade, já que não existe correlação entre os construtos acima de 0,74. Desse modo, não é necessário tomar nenhuma ação corretiva, tais como: modificações nas variáveis ou fazer uso de procedimentos especializados de estimação (HAIR et al., 2005).

A raiz quadrada da VME é evidenciada nas colunas transversais em negrito e apresenta resultado superior à correlação calculada de cada variável, tanto na vertical quanto na horizontal, indicando que os construtos estão adequadamente discriminados.

Após a exclusão das variáveis observáveis que possuíam carga fatorial insuficientemente explicativas do construto a que se referiam, foi realizado o processamento do novo conjunto, agora denominado modelo modificado. A figura 12 ilustra os resultados do processamento da mensuração do modelo modificado. 


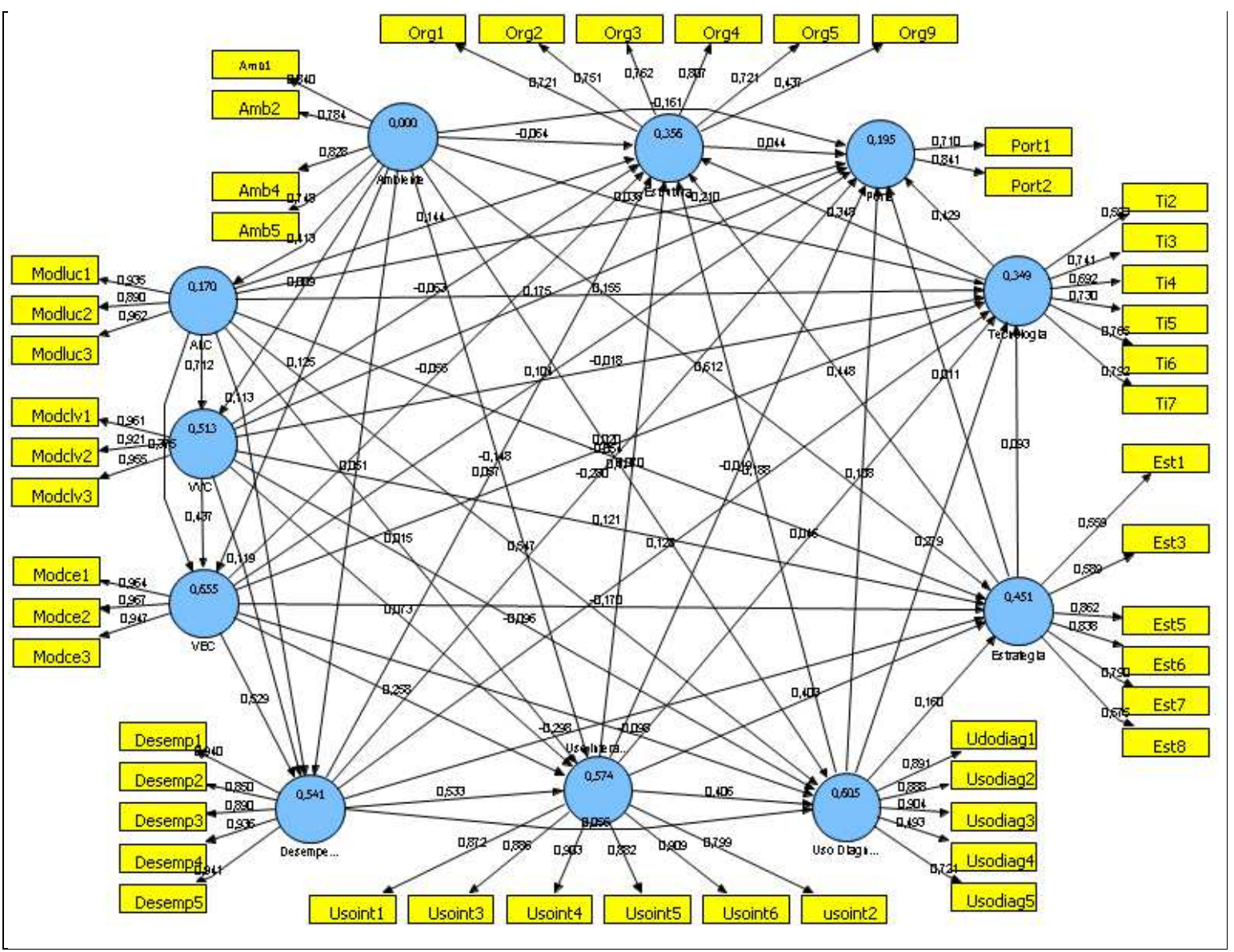

Figura 12 - Ilustração da etapa de mensuração do modelo modificado

Os resultados do processo de mensuração do modelo modificado podem ser resumidos através da tabela 16 abaixo.

Tabela 16 - Resultados do modelo modificado

\begin{tabular}{l|r|r|r|r}
\hline ModeloModificado & VME & $\begin{array}{c}\text { Confiabilidade } \\
\text { composta }\end{array}$ & $\mathbf{R}^{2}$ & Alpha de Cronbach \\
\hline ALC & 0,86 & 0,95 & 0,17 \\
Ambiente & 0,64 & 0,88 & - & 0,81 \\
Desempenho & 0,83 & 0,96 & 0,54 & 0,95 \\
Estratégia & 0,51 & 0,86 & 0,45 & 0,80 \\
Estrutura & 0,50 & 0,86 & 0,36 & 0,80 \\
Porte & 0,61 & 0,75 & 0,20 & 0,36 \\
Tecnologia & 0,52 & 0,87 & 0,35 & 0,81 \\
UsoDiagnóstico & 0,63 & 0,89 & 0,60 & 0,85 \\
UsoInterativo & 0,77 & 0,95 & 0,57 & 0,94 \\
VEC & 0,92 & 0,97 & 0,65 & 0,96 \\
VVC & 0,89 & 0,96 & 0,51 & 0,94 \\
\hline \multicolumn{2}{c}{}
\end{tabular}

A VME que indica a variância média explicada pelo construto ficou com todos os resultados acima de 0,50. A confiabilidade composta, que indica o nível de adequação na medição da 
variável pelos seus indicadores, também mostrou resultados expressivos. Exceto pelo Alpha de Cronbach da variável latente "porte" indicando 0,36 todas as demais receberam resultados acima de 0,80 .

No teste de validade discriminante, o resultado da raiz quadrada da VME, destacada em negrito na tabela 17 , indica que os construtos foram adequadamente discriminados.

Tabela 17 - Matriz de correlações entre as variáveis do modelo modificado

\begin{tabular}{|c|c|c|c|c|c|c|c|c|c|c|c|}
\hline & ALC & Ambiente & esemp & Estratégia & trutura & Porte & Tecnologia & oDiag & UsoInterat & VEC & VVC \\
\hline ALC & $\mathbf{0 , 9 3}$ & & & & & & & & & & \\
\hline Ambiente & 0,41 & $\mathbf{0 , 8 0}$ & & & & & & & & & \\
\hline Desempenho & 0,61 & 0,35 & 0,91 & & & & & & & & \\
\hline Estratégia & 0,30 & 0,58 & 0,22 & 0,71 & & & & & & & \\
\hline Estrutura & 0,28 & 0,29 & 0,24 & 0,49 & 0,71 & & & & & & \\
\hline Porte & 0,05 & $(0,06)$ & $(0,02)$ & 0,06 & 0,15 & $\mathbf{0 , 7 8}$ & & & & & \\
\hline Tecnologia & 0,50 & 0,31 & 0,46 & 0,31 & 0,44 & 0,33 & 0,72 & & & & \\
\hline UsoDiagnóstico & 0,70 & 0,36 & 0,59 & 0,38 & 0,26 & 0,13 & 0,54 & $\mathbf{0 , 8 0}$ & & & \\
\hline UsoInterativo & 0,52 & 0,17 & 0,72 & 0,33 & 0,28 & 0,08 & 0,44 & 0,63 & $\mathbf{0 , 8 8}$ & & \\
\hline VEC & 0,74 & 0,41 & 0,72 & 0,27 & 0,23 & 0,06 & 0,45 & 0,58 & 0,65 & 0,96 & \\
\hline VVC & 0,72 & 0,30 & 0,61 & 0,27 & 0,21 & 0,11 & 0,39 & 0,52 & 0,56 & 0,74 & 0,95 \\
\hline
\end{tabular}

Pela análise das correlações, observa-se alta correlação entre os construtos "ALC"; "VVC" e "VEC" o que evidencia que esses construtos, na verdade, são complementares, constituindo dimensões ou modelos de desenho de sistemas de controle gerencial focados nos clientes.

Semelhante aos construtos formativos do desenho de SCGFC, observa-se alta correlação entre os construtos Uso diagnóstico e Uso Interativo, o que torna patente sua complementaridade, na constituição do uso de sistemas de controle gerencial focados nos clientes.

Igualmente notável é a alta correlação entre a variável "Desempenho" e "ALC"; "VVC"; "VEC"; Uso diagnóstico e Uso interativo, demonstrando a forte relação de dependência dessas variáveis para se obter altos níveis de satisfação pelo uso desses sistemas, assim como a sua contribuição pelo desempenho da organização.

\subsubsection{Análise do modelo estrutural}

Na figura 13 são identificados coeficientes estruturais e os $\mathrm{R}^{2}$ das variáveis de $1^{\circ}$ ordem, "Ambiente" e "Desempenho" e das variáveis de $2^{\circ}$ ordem, "Fatores contingenciais internos", "Desenho dos SCGFC" e "Uso dos SCGFC". 
Para a análise dos coeficientes estruturais foi seguida a orientação de Hair et al. (2006) que sugerem uma classificação de significância estatística para os coeficientes de correlação, de acordo com o quadro abaixo:

Quadro 15 - Classificação dos coeficientes de correlação

\begin{tabular}{|lllll|}
\hline Leve quase imperceptível & $\rightarrow$ & 0,01 & a & 0,20 \\
Pequena, mas definida & $\rightarrow$ & 0,21 & a & 0,40 \\
Moderada & $\rightarrow$ & 0,41 & a & 0,70 \\
Alta & $\rightarrow$ & 0,71 & a & 0,90 \\
Muito Forte & $\rightarrow$ & 0,91 & a & 1,00 \\
\hline
\end{tabular}

FONTE: Hair et al., 2006, p. 312

Para a análise dos $R^{2}$ foi seguida a orientação de Cohen (1977) que sugere uma classificação do efeito explicativo de uma variável latente na regressão múltipla ou em PLS, de acordo com o quadro abaixo:

Quadro 16 - Classificação do efeito explicativo de uma variável latente

\begin{tabular}{|llllll|}
\hline Efeito pequeno & $\rightarrow$ & $\mathrm{f}^{2}$ & $=0,02$ & $\rightarrow$ & $\mathrm{R}^{2}=2 \%$ \\
Efeito médio & $\rightarrow$ & $\mathrm{f}^{2}$ & $=0,15$ & $\rightarrow$ & $\mathrm{R}^{2}=13 \%$ \\
Efeito grande & $\rightarrow$ & $\mathrm{f}^{2}$ & $=0,35$ & $\rightarrow$ & $\mathrm{R}^{2}=26 \%$ \\
& & & & &
\end{tabular}

FONTE: Cohen, 1977 


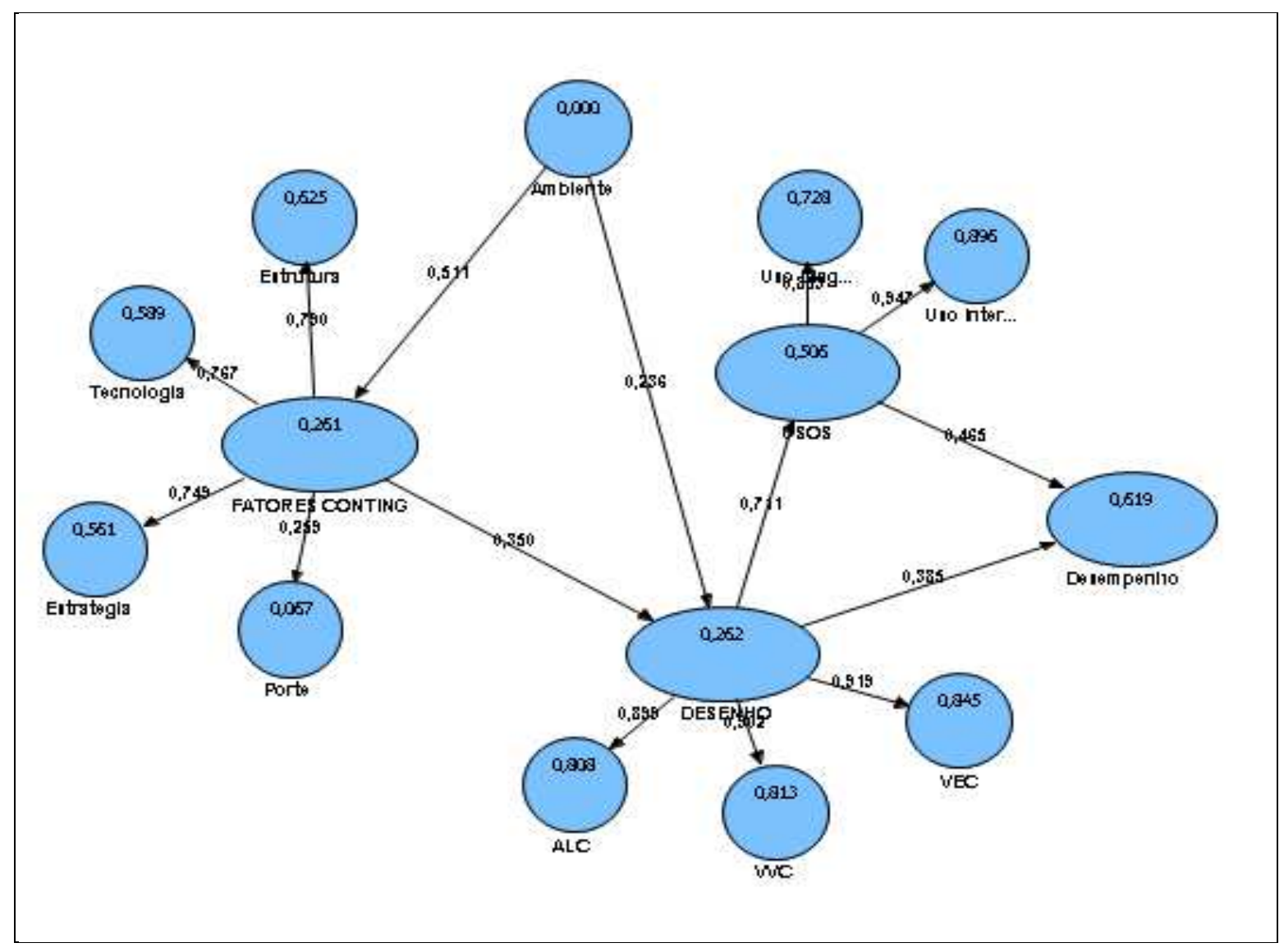

Figura 13 - Ilustração dos resultados do modelo estrutural

Para análise do resultado dos testes $\mathbf{t}$ de student tomou-se, como base, a tabela de valores críticos da distribuição t de student elaborada por Fávero et al. (2009, p. 597). Considerando o parâmetro de $\mathrm{z}$ graus de liberdade e probabilidade associada na cauda superior de 0,05 podese encontrar nessa tabela o resultado de 1,645. 


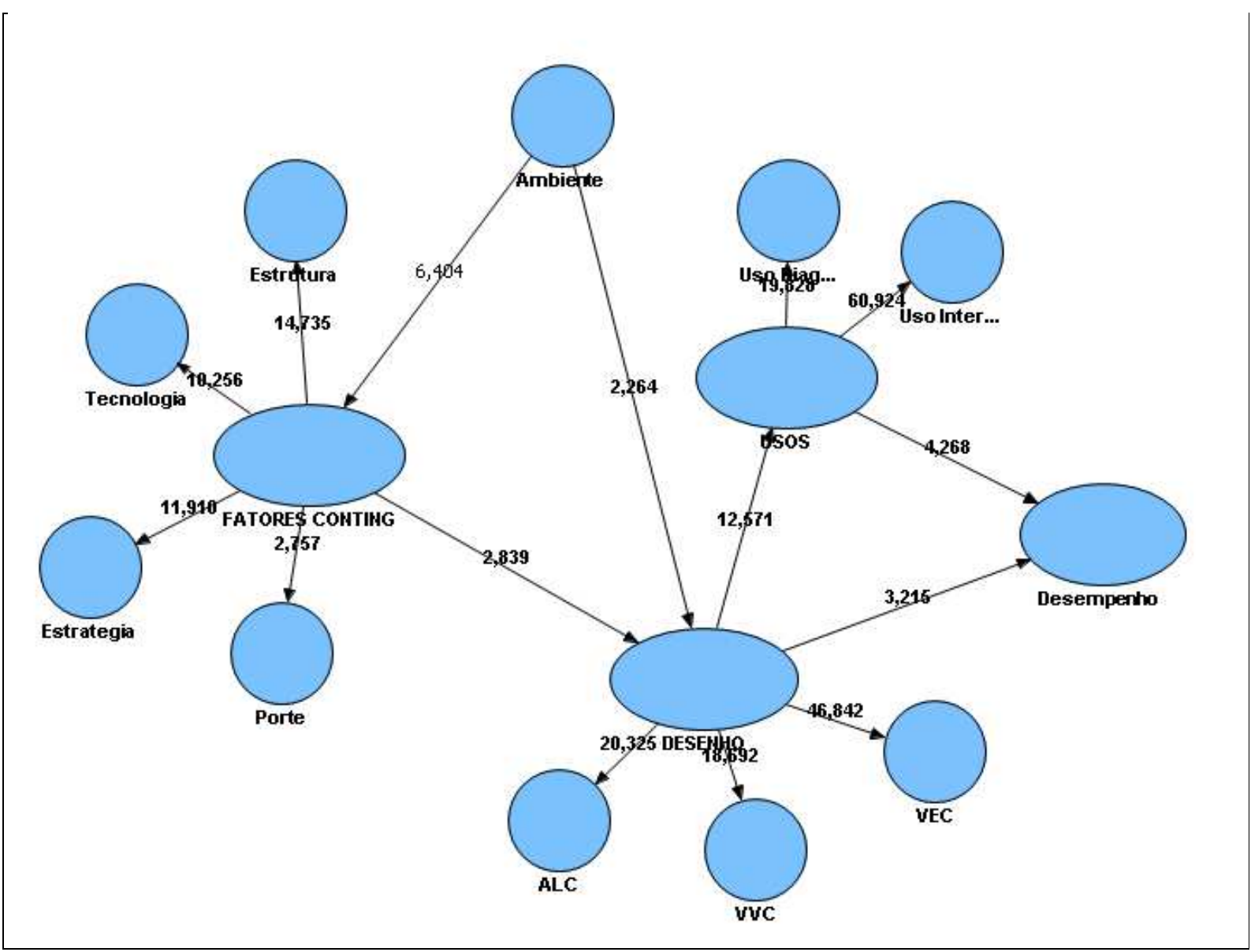

Figura 14 - Ilustração do modelo estrutural - Estatísticas t de student

Para obter os resultados da estatística t de student, foi utilizado o software SmartPls 3 usando a opção de cálculo bootstrapping com n $=83$ e 1000 iterações. Um resumo dos resultados pode ser observado na tabela 18 abaixo:

Tabela 18 - Modelo estrutural - relacionamentos entre os construtos

\begin{tabular}{c|r|r|r|r|r|r}
\hline Relacionamento entre os constructos & $\begin{array}{c}\text { Coeficiente } \\
\text { Estrutural } \\
\text { (a) }\end{array}$ & $\begin{array}{c}\text { Média do } \\
\text { coeficiente } \\
\text { estrutural } \\
\text { (b) }\end{array}$ & $\begin{array}{c}\text { Desvio } \\
\text { Padrão (c) })\end{array}$ & $\begin{array}{c}\text { Erro } \\
\text { Padrão (d) }\end{array}$ & $\begin{array}{c}\text { Estatistica t } \\
\text { (a) / (d) }\end{array}$ & Valor p \\
\hline AMBIENTE -> DESENHO & 0,236 & 0,236 & 0,107 & 0,107 & 2,264 & 0,02 \\
AMBIENTE -> FATORES CONTING & 0,511 & 0,526 & 0,080 & 0,080 & 6,404 & 0,00 \\
DESENHO -> DESEMPENHO & 0,386 & 0,378 & 0,124 & 0,124 & 3,215 & 0,00 \\
DESENHO -> USO & 0,712 & 0,715 & 0,059 & 0,059 & 12,571 & 0,00 \\
FATORES CONTING -> DESENHO & 0,350 & 0,348 & 0,122 & 0,122 & 2,839 & 0,00 \\
USO -> DESEMPENHO & 0,465 & 0,472 & 0,111 & 0,111 & 4,268 & 0,00 \\
\hline
\end{tabular}

Em relação à análise da significância estatística, todos os coeficientes estruturais mostraramse relevantes. O relacionamento entre ambiente e atributos dos SCGFC, o menor entre todos os demais, de acordo com a classificação de Hair et al. (2006), é pequena mas definida. O 
mais importante, pelos resultados, o relacionamento entre desenho e uso de SCGFC apresenta o mais alto grau de coeficiente estrutural.

Na tabela 18, observam-se também os valores da estatística t para cada relacionamento entre os construtos. O resultado que dá validade estatística é 1,645, ou seja, se o resultado for acima desse parâmetro o valor da estatística não pertence a região crítica e, portanto, leva à rejeição da hipótese nula $\mathrm{H}_{0} \mathrm{e}$ permite concluir que há diferença entre as médias das variáveis.

Todas as combinações entre as variáveis estudadas indicaram resultados superiores ao t crítico de 1,645 e significância estatística ao nível de 0,05. Assim, obteve-se validade de todos os relacionamentos do modelo estrutural. O quadro 17 apresenta as hipóteses de pesquisa e os resultados alcançados.

Quadro 17 - Hipóteses de pesquisa e resultados alcançados

\begin{tabular}{|c|c|c|}
\hline Hipóteses & Resultado & $\begin{array}{l}\text { Téc } \\
\text { Estat }\end{array}$ \\
\hline $\begin{array}{l}\text { H1- O fator contingencial externo "ambiente" possui } \\
\text { associação com os fatores contingenciais internos da } \\
\text { organização. }\end{array}$ & Comprovada & \multirow{6}{*}{$\begin{array}{c}\text { Avaliação do } \\
\text { modelo de } \\
\text { mensuração: } \\
\text { confiabilidade, } \\
\text { validade convergente, } \\
\text { validade } \\
\text { discriminante. } \\
\text { Análise do modelo } \\
\text { estrutural: } \\
\text { coeficientes } \\
\text { estruturais, } \mathrm{R}^{2 ;} \text { efeitos } \\
\text { diretos e indiretos e } \\
\text { totais }\end{array}$} \\
\hline $\begin{array}{l}\text { H2- O fator contingencial externo "ambiente" possui } \\
\text { associação com os atributos do sistema de controle gerencial } \\
\text { focado nos clientes. }\end{array}$ & Comprovada & \\
\hline $\begin{array}{l}\text { H3- Os "fatores contingenciais internos" possuem associação } \\
\text { com atributos do sistema de controle gerencial focado nos } \\
\text { clientes. }\end{array}$ & Comprovada & \\
\hline $\begin{array}{l}\text { H4- Os "atributos do sistema de controle gerencial focado nos } \\
\text { clientes" possuem associação com o uso intensivo desses } \\
\text { mesmos sistemas. }\end{array}$ & Comprovada & \\
\hline $\begin{array}{l}\text { H5- Os "atributos do sistema de controle gerencial focado nos } \\
\text { clientes" possuem associação com o desempenho desses } \\
\text { sistemas. }\end{array}$ & Comprovada & \\
\hline $\begin{array}{l}\text { H6- O uso "intensivo do sistema de controle gerencial focado } \\
\text { nos clientes" possui associação com o desempenho desses } \\
\text { sistemas. }\end{array}$ & Comprovada & \\
\hline
\end{tabular}

\subsection{Considerações finais sobre os resultados da pesquisa}

Nesta seção, passa-se a interpretar os resultados obtidos pelas variáveis latentes de $1^{\mathrm{a}}$ ordem e os coeficientes estruturais e $\mathrm{R}^{2}$ das variáveis de $2^{\mathrm{a}}$ ordem. Com base na literatura, faz-se uma análise baseada em resultados verificados em pesquisas anteriores. 
A primeira hipótese de pesquisa (H1) considera que o ambiente possui associação com os fatores contingenciais internos da organização. Os dados da tabela 19 abaixo demonstram as cargas fatoriais das variáveis observáveis, o $\mathrm{R}^{2}$ e o coeficiente estrutural da variável formativa. As variáveis foram operacionalizadas baseadas nos trabalhos de Kandwalla (1972), Gordon e Narayanan (1984) e Guilding e McManus (2002).

O coeficiente estrutural de 0,511 indica o efeito direto que a variável ambiente exerce sobre a variável fatores contingenciais internos revelando a importância dessa associação. Sob a análise do relacionamento entre essas variáveis, o resultado do teste $t$ de 6,404 comprova a diferença das médias das duas variáveis.

Os resultados encontrados estão em conformidade com as pesquisas internacionais realizadas por Kandwala (1972), Gordon e Narayanan (1984), Chenhall e Morris (1986) e pesquisas nacionais desenvolvidas por Espejo (2008) e Junqueira (2010). Esse quadro sugere a proposição citada por Chenhall (2003) de que, quanto mais incerto o ambiente, mais abertos e mais externamente focados são os SCG.

Tabela 19 - Resultados da VL ambiente e os efeitos na VL Fatores Contingenciais Internos

\begin{tabular}{|c|c|c|c|c|}
\hline Variáveis Observáveis & $\begin{array}{c}\text { Cargas } \\
\text { Fatoriais }\end{array}$ & $\begin{array}{c}\mathrm{R}^{2} \text { VL de } 1^{\mathrm{o}} \\
\text { ordem }\end{array}$ & $\begin{array}{l}\text { Coeficientes } \\
\text { estruturais }\end{array}$ & $\begin{array}{c}\text { VL de } 2^{\circ} \\
\text { ordem - t test }\end{array}$ \\
\hline Vendas & 0,852 & \multirow{4}{*}{$\begin{array}{c}\text { Ambiente } \\
0,00\end{array}$} & \multirow{4}{*}{$\mathbf{0 , 5 1 1}$} & \multirow{4}{*}{\begin{tabular}{|c} 
Fatores \\
Contingenciais \\
Internos $\quad \mathbf{6 , 4 0 4}$
\end{tabular}} \\
\hline Qualidade & 0,770 & & & \\
\hline Preço & 0,840 & & & \\
\hline Serviços & 0,733 & & & \\
\hline
\end{tabular}

A segunda hipótese (H2) estabelece que o fator contingencial externo ambiente possui associação com os atributos (desenho) dos sistemas de controle gerencial focados nos clientes. Os dados da tabela 20, a seguir, demonstram as cargas fatoriais das variáveis observáveis, o $\mathrm{R}^{2}$ e o coeficiente estrutural da variável formativa.

Diferentemente dos achados de Espejo (2008) e parcialmente dos resultados encontrados por Junqueira (2010), o coeficiente estrutural de 0,236 indica o efeito, ainda que relativamente discreto, que a variável ambiente exerce sobre a variável atributos (desenho) dos SCGFC revelando a importância dessa associação. Sob a análise do relacionamento entre essas variáveis, o resultado do teste t de 2,264comprova a diferença das médias das duas variáveis. 
Tabela 20 - Resultados da VL ambiente e os efeitos nos atributos dos SCGFC

\begin{tabular}{|c|c|c|c|c|}
\hline Variáveis Observáveis & $\begin{array}{c}\text { Cargas } \\
\text { Fatoriais } \\
\end{array}$ & $\begin{array}{c}\mathrm{R}^{2} \text { VL de } 1^{o} \\
\text { ordem }\end{array}$ & $\begin{array}{l}\text { Coeficientes } \\
\text { estruturais }\end{array}$ & $\begin{array}{c}\text { Teste t de } \\
\text { student }\end{array}$ \\
\hline Vendas & 0,852 & \multirow{4}{*}{$\begin{array}{c}\text { Ambiente } \\
0,00\end{array}$} & \multirow{4}{*}{0,236} & \multirow{4}{*}{$\begin{array}{c}\text { Influência na } \\
\text { variável } \\
\text { desenho dos }\end{array}$} \\
\hline Qualidade & 0,770 & & & \\
\hline Preço & 0,840 & & & \\
\hline Serviços & 0,733 & & & \\
\hline
\end{tabular}

A terceira hipótese de pesquisa (H3) verifica a associação entre os fatores contingenciais internos e os atributos do sistema de controle gerencial focado nos clientes. Os dados da tabela 21 abaixo demonstram as cargas fatoriais das variáveis observáveis e o $\mathrm{R}^{2}$ da variável formativa. As variáveis foram operacionalizadas baseadas nos trabalhos de Gordon e Narayanan (1984), Porter (1990),Sharma (2002),Laudon e Laudon (2007),Hyvönen (2007), Abdel-Kader e Luther (2008) e Ferreira e Otley (2010).

Tabela 21 - Resultados da VL Fatores Contingenciais Internos e os efeitos nos atributos dos SCGFC

\begin{tabular}{|c|c|c|c|c|}
\hline $\begin{array}{c}\text { Variáveis } \\
\text { Observáveis }\end{array}$ & $\begin{array}{c}\text { Cargas } \\
\text { Fatoriais }\end{array}$ & $\begin{array}{c}R^{2} \text { VL de } 1^{o} \\
\text { ordem }\end{array}$ & $\begin{array}{c}\mathrm{R}^{2} \mathrm{VL} \text { de } 2^{\mathrm{o}} \\
\text { ordem }\end{array}$ & $\begin{array}{c}\text { Teste t de } \\
\text { student }\end{array}$ \\
\hline Prod alta qualidade & 0,490 & \multirow{6}{*}{$\begin{array}{c}\text { Estratégia } \\
\mathbf{0 , 5 6 1}\end{array}$} & \multirow{19}{*}{\begin{tabular}{|c|} 
Fatores \\
contingenciais \\
internos \\
$\mathbf{0 , 2 6 1}$
\end{tabular}} & \multirow{19}{*}{$\begin{array}{l}\text { Influência na } \\
\text { variável } \\
\text { "desenho dos } \\
\text { SCGFC" } \\
\mathbf{2 , 8 3 9}\end{array}$} \\
\hline Prod caract. Únicas & 0,578 & & & \\
\hline Flex desenho & 0,874 & & & \\
\hline Mod volume/mix & 0,858 & & & \\
\hline Entrega rápida & 0,799 & & & \\
\hline Disponibilidade & 0,590 & & & \\
\hline Novos prod/servs & 0,722 & \multirow{5}{*}{$\begin{array}{c}\text { Estrutura } \\
\mathbf{0 , 6 2 5}\end{array}$} & & \\
\hline Contratar gerentes & 0,724 & & & \\
\hline Aprov investimentos & 0,764 & & & \\
\hline Aloc. Orçamentárias & 0,849 & & & \\
\hline Alterar preços & 0,755 & & & \\
\hline ERP & 0,576 & \multirow{6}{*}{$\begin{array}{c}\text { Tecnologia } \\
\mathbf{0 , 5 8 9}\end{array}$} & & \\
\hline CRM & 0,749 & & & \\
\hline SCM & 0,683 & & & \\
\hline DW & 0,728 & & & \\
\hline OLAP & 0,776 & & & \\
\hline $\mathrm{BI}$ & 0,800 & & & \\
\hline Funcionarios & 0,628 & \multirow{2}{*}{ Porte $\mathbf{0 , 0 6 7}$} & & \\
\hline Receita Bruta & 0,895 & & & \\
\hline
\end{tabular}

As cargas fatoriais das variáveis observáveis mostram-se representativas de cada variável de $1^{\mathrm{a}}$ ordem às quais se relacionam. Os resultados de $\mathrm{R}^{2}$ das variáveis latentes estratégia $56 \%$, estrutura $62 \%$, tecnologia $59 \%$ denotam forte poder explicativo no relacionamento entre as 
suas variáveis reflexivas. A VL porte apresentou um baixo $\mathrm{R}^{2}$ devido principalmente ao seu número limitado de indicadores.

$\mathrm{O}$ resultado de $\mathrm{R}^{2}$ de $26 \%$ na variável latente de $2^{\mathrm{a}}$ ordem "fatores contingenciais internos" mostra um efeito grande, Cohen (1977), das variáveis: estratégia, estrutura, tecnologia e porte sobre a VL de $2^{\mathrm{a}}$ ordem "fatores contingenciais internos". O coeficiente estrutural de 0,350 mostra a significância dessa VL como preditora da variável "atributos dos SCGFC". Sob a análise do relacionamento entre essas variáveis, o resultado do teste t de 2,839comprova a diferença das médias das duas variáveis.

Evidências de relacionamento entre fatores contingenciais internos e atributos do sistema orçamentário foram achadas no trabalho de Espejo (2008) e relacionamento entre fatores contingenciais internos e artefatos do SCG no estudo de Junqueira (2010). Guilding e McManus (2002) e McManus (2006) identificaram a influência de fatores contingenciais internos sobre os atributos de SCG focados nos clientes.

A quarta hipótese de pesquisa (H4) considera a associação entre os atributos do sistema de controle gerencial focados nos clientes com o uso intensivo desses mesmos sistemas. Os dados da tabela 22 abaixo demonstram as cargas fatoriais das variáveis observáveis, o $\mathrm{R}^{2}$ e o coeficiente estrutural da variável formativa. As variáveis foram operacionalizadas baseadas nos trabalhos de Guilding e McManus (2002), McManus (2006) e Weir (2008).

Tabela 22 - Resultados da VL Atributos dos SCGFC e os efeitos no uso intensivo dos SCGFC

\begin{tabular}{|c|c|c|c|c|}
\hline $\begin{array}{c}\text { Variáveis } \\
\text { Observáveis }\end{array}$ & $\begin{array}{c}\text { Cargas } \\
\text { Fatoriais }\end{array}$ & \begin{tabular}{|c|}
$\mathrm{R}^{2}$ VL de $1^{\circ}$ \\
ordem
\end{tabular} & $\begin{array}{c}\mathrm{R}^{2} \text { VL de } 2^{o} \\
\text { ordem }\end{array}$ & Teste t de student \\
\hline Receita & 0,941 & \multirow{3}{*}{ ALC } & \multirow{9}{*}{$\begin{array}{l}\text { Desenho do } \\
\text { SCG focados } \\
\text { nos clientes } \\
\mathbf{0 , 2 6 2}\end{array}$} & \multirow{9}{*}{$\begin{array}{c}\text { Influência na } \\
\text { variável desenho do } \\
\text { SCG focados nos } \\
\text { clientes } \mathbf{1 2 , 5 7 1}\end{array}$} \\
\hline Custo & 0,881 & & & \\
\hline Lucratividade & 0,966 & & & \\
\hline Receita & 0,963 & \multirow{3}{*}{ VVC $\mathbf{0 , 8 1 3}$} & & \\
\hline Custo & 0,916 & & & \\
\hline Lucratividade & 0,957 & & & \\
\hline Receita & 0,963 & \multirow{3}{*}{ VEC $\mathbf{0 , 8 4 5}$} & & \\
\hline Custo & 0,966 & & & \\
\hline Receita Perdida & 0,948 & & & \\
\hline
\end{tabular}

O resultado de $\mathrm{R}^{2}$ de $26 \%$ na variável latente de $2^{\mathrm{a}}$ ordem “desenho dos SCGFC" mostra um efeito grande, Cohen (1977), que as variáveis de $1^{\text {a }}$ ordem ALC, VVC e VEC exercem sobre 
essa VL. O coeficiente estrutural de 0,711 mostra a significância dessa VL como preditora da variável "uso intensivo dos SCGFC". Sob a análise do relacionamento entre essas variáveis, o resultado do teste t de 12,571 comprova a diferença das médias das duas variáveis.

A quinta (H5) e a sexta (H6) hipóteses de pesquisa verificam a influência dos atributos e do uso intenso de SCGFC no desempenho desses sistemas. Os dados da tabela 23 abaixo demonstram as cargas fatoriais das variáveis observáveis, o $\mathrm{R}^{2}$ e o coeficiente estrutural das variáveis formativas.

A variável desempenho dos SCGFC foi operacionalizada baseada no estudo de Ferreira e Otley (2010), no qual a ênfase sobre o desempenho é atribuída ao sistema em si, ao invés de ao desempenho da organização. As variáveis observáveis visaram capturar a satisfação dos usuários do sistema, a contribuição dos SCGFC no desempenho da organização e o desempenho do sistema como um todo. A ideia baseia-se na abordagem da interação onde se espera que a interação entre variáveis contextuais e variáveis organizacionais possa influenciar o desempenho (FERREIRA; OTLEY, 2010).

Tabela 23: Resultados da VL Atributos dos SCGFC e os efeitos no uso intensivo dos SCGFC

\begin{tabular}{|c|c|c|c|c|}
\hline VariáveisObserváveis & $\begin{array}{c}\text { Cargas } \\
\text { Fatoriais }\end{array}$ & $\begin{array}{c}\mathbf{R}^{2} \text { VL de } 1^{o} \\
\text { ordem }\end{array}$ & $\begin{array}{c}\mathbf{R}^{2} \text { VL de } 2^{o} \\
\text { ordem }\end{array}$ & $\begin{array}{c}\text { Teste t de } \\
\text { student }\end{array}$ \\
\hline Receita & 0,941 & \multirow{3}{*}{ ALC $\quad \mathbf{0 , 8 0 8}$} & \multirow{9}{*}{$\begin{array}{l}\text { Desenho do } \\
\text { SCG focados } \\
\text { nosclientes } \\
\mathbf{0 , 2 6 2}\end{array}$} & \multirow{9}{*}{$\begin{array}{l}\text { Influênciana } \\
\text { variável } \\
\text { desempenho do } \\
\text { SCG focados } \\
\text { nosclientes } \\
\mathbf{3 , 2 1 6}\end{array}$} \\
\hline Custo & 0,881 & & & \\
\hline Lucratividade & 0,966 & & & \\
\hline Receita & 0,963 & \multirow{3}{*}{ VVC $\mathbf{0 , 8 1 3}$} & & \\
\hline Custo & 0,916 & & & \\
\hline Lucratividade & 0,957 & & & \\
\hline Receita & 0,963 & \multirow{3}{*}{ VEC $\mathbf{0 , 8 4 5}$} & & \\
\hline Custo & 0,966 & & & \\
\hline ReceitaPerdida & 0,948 & & & \\
\hline Acompmetas & 0,904 & \multirow{4}{*}{$\begin{array}{c}\text { Uso } \\
\text { diagnóstico } \\
\mathbf{0 , 7 2 8}\end{array}$} & \multirow{10}{*}{$\begin{array}{l}\text { Usointensivo } \\
\text { de SCG } \\
\text { focadosnos } \\
\text { clientes } \\
\mathbf{0 , 5 0 6}\end{array}$} & \multirow{10}{*}{$\begin{array}{l}\text { Influênciana } \\
\text { variável } \\
\text { desempenho do } \\
\text { SCG focados } \\
\text { nosclientes } \\
\mathbf{4 , 2 6 8}\end{array}$} \\
\hline Forecast & 0,901 & & & \\
\hline Ajustes & 0,918 & & & \\
\hline Revermetas & 0,686 & & & \\
\hline Oportunidades & 0,877 & \multirow{6}{*}{$\begin{array}{c}\text { UsoInterativo } \\
\mathbf{0 , 8 9 6}\end{array}$} & & \\
\hline Planos de ação & 0,799 & & & \\
\hline Questõescriticas & 0,884 & & & \\
\hline Unificarvisão & 0,903 & & & \\
\hline Linguagemcomum & 0,881 & & & \\
\hline Novasestratégias & 0,908 & & & \\
\hline
\end{tabular}


O resultado de $\mathrm{R}^{2}$ de $26 \%$ na variável latente de $2^{\mathrm{a}}$ ordem "desenho dos SCGFC" e de $51 \%$ na variável latente de $2^{a}$ ordem "uso intensivo dos SCGFC" mostram a percentagem relativa de explicação que as VL de $1^{\mathrm{a}}$ ordem têm sobre as suas correspondentes VL de $2^{\mathrm{a}}$ ordem. Sob a análise do relacionamento entre essas variáveis, o resultado do teste t de 3,105 para a variável "desenho" e 4,187 para a variável "uso"comprova a diferença das médias das duas variáveis.

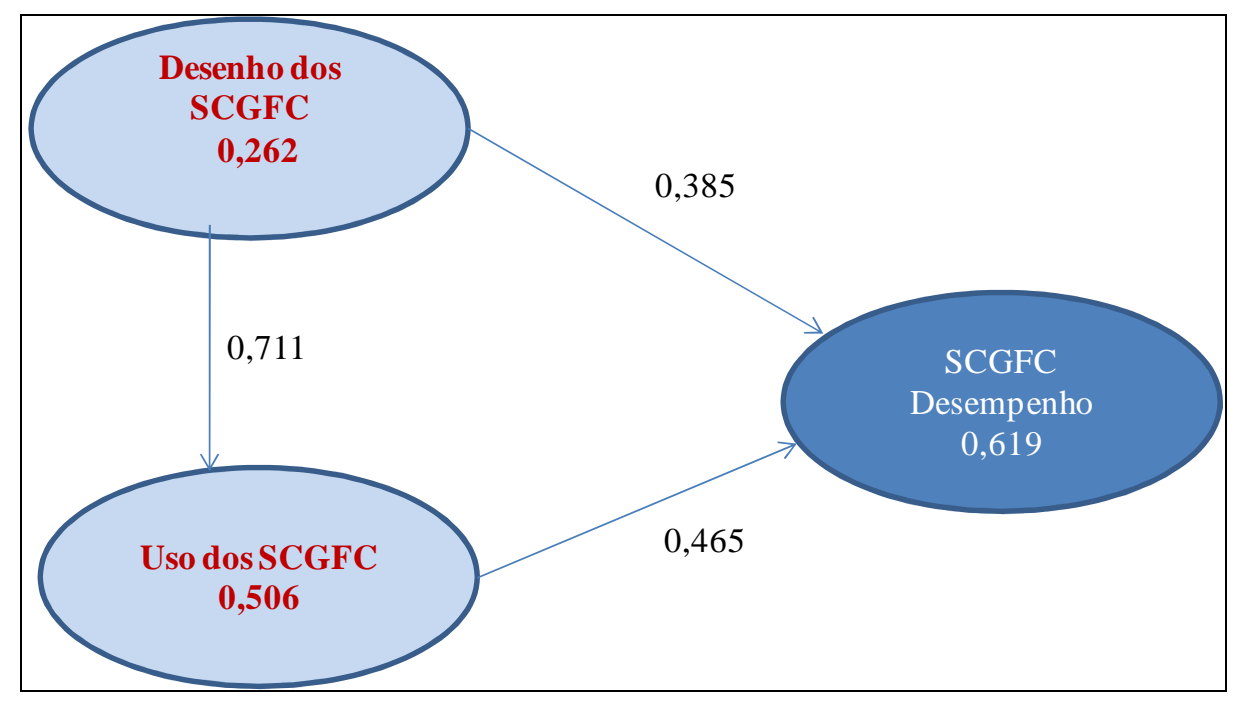

Figura 15 - Coeficientes estruturais na variável desempenho dos SCGFC

A figura 15 demonstra o resultado dos coeficientes estruturais de cada uma das variáveis preditoras da variável desempenho dos SCGFC. O coeficiente da variável desenho mostra seu efeito direto na variável desempenho de 0,385 , assim como o coeficiente da variável uso mostra o efeito direto na variável desempenho de 0,465. Destaca-se a importância da variável desenho quando se combina o seu efeito direto de 0,385 e mais o efeito indireto mediado pela variável uso de 0,330 correspondendo a um efeito total de 0,715 sobre a variável desempenho. 


\section{CONCLUSÕES}

O estudo procurou compreender, no ambiente empresarial brasileiro, a influência de fatores contingenciais externos e internos, no desenho e uso de sistemas de controle gerenciais focados nos clientes e se ambos, na prática, podem contribuir para a melhoria do desempenho desses sistemas nas organizações.

Nesse contexto, a pesquisa objetivou investigar a existência de associações entre os atributos e uso intenso do sistema de controle gerencial focado nos clientes, com fatores contingenciais externos (ambiente) e internos (estratégia, estrutura organizacional, tecnologia e porte) e seus efeitos no desempenho do sistema. A pesquisa foi desenvolvida com 83 empresas brasileiras cujos respondentes pertencem, na sua maioria, a cargos geralmente atribuídos à área de Controladoria.

Para a análise multivariada dos dados da pesquisa foi utilizada a técnica estatística modelagem de equações estruturais com o método de estimação Partial Least Squares. Esse modelo de estimação permite averiguar relacionamentos entre variáveis latentes que se caracterizam tanto por serem formativas, quanto reflexivas.Além disso, adéqua-se bem ao tratamento estatístico de amostras pequenas.

O trabalho foi conduzido levando-se em conta os atributos dos sistemas de controle gerencial focados nos clientes, baseado nos estudos de Guilding e McManus (2002), e uso intenso e desempenho baseado nos estudos de Ferreira e Otley (2010). Os resultados da pesquisa atendem o objetivo da pesquisa e todas as hipóteses foram testadas e comprovadas.

H1- O fator contingencial externo "ambiente" influencia os fatores contingenciais internos da organização: constatou-se que o ambiente exerce influência significativa sobre os fatores contingenciais internos (estratégia, estrutura organizacional, tecnologia e porte). Conclui-se, então, que as características do ambiente participam sobremaneira nas decisões que envolvem a configuração dos fatores contingenciais internos. 
H2- O fator contingencial externo "ambiente" influencia os atributos do sistema de controle gerencial focados nos clientes: ainda que de maneira discreta, o ambiente exerce influência nos atributos do SCG focados nos clientes.

H3- Os "fatores contingenciais internos" influenciam os atributos do sistema de controle gerencial focado nos clientes: foi constatada a influência dos fatores contingenciais internos no desenho dos SCG focados nos clientes, de forma semelhante ao ambiente, a presença do relacionamento se verifica de forma branda.

H4- Os "atributos do sistema de controle gerencial focado nos clientes" influenciam o uso intensivo desses mesmos sistemas: o desenho dos SCG focados nos clientes representa, entre as hipóteses de pesquisa estudadas, aquela que se revelou mais forte em termos de associação com o uso intensivo desses mesmos sistemas.

H5- Os "atributos do sistema de controle gerencial focado nos clientes" influenciam o desempenho desses sistemas: o desenho dos SCG focados nos clientes tem papel fundamental na satisfação pelo uso desses sistemas. Os atributos, considerados na forma de artefatos, representados pela Análise da lucratividade do cliente; Valor vitalício do cliente e Valor econômico do cliente podem, inclusive, contribuir para o desempenho econômico da organização.

H6- O uso "intensivo do sistema de controle gerencial focado nos clientes" influencia o desempenho desses sistemas: de forma análoga, a hipótese anterior, o uso intensivo, representado pelo uso diagnóstico e interativo de forma conjunta, contribui para o desempenho do próprio sistema e para o desempenho econômico da organização.

Em relação à contribuição da pesquisa para a literatura da contabilidade gerencial, podem-se destacar os seguintes aspectos: i- permite que os resultados da presente pesquisa sejam comparados com resultados encontrados em ambientes distintos; ii- constata a influência entre os fatores contingenciais e atributos dos sistemas de controle gerencial focados nos clientes: iii- constata a influência dos atributos dos SCG focados nos clientes no seu uso intensivo; e iv- constata a influência do desenho e uso de SCG focados nos clientes exercida, no desempenho desses próprios sistemas nas organizações. 
Do ponto de vista pragmático, entende-se que a pesquisa possa contribuir para: i- alertar os administradores quanto à influência exercida pelos fatores contingenciais internos e externos na composição do desenho de sistemas de controle gerencial, em especial naqueles focados nos clientes; ii- enfatizar aos administradores que o uso de sistemas de controle gerencial, quer na forma de diagnóstico, quer na forma interativa e tanto melhor no seu conjunto, podem gerar benefícios pela plena utilização dos artefatos, alcançando o desempenho desejado.

Atenção merece ser dada no que se refere às limitações dos achados da pesquisa: i- os respondentes são, na sua maioria, representantes da área de Controladoria. E esse público, de fato, constituía o alvo da pesquisa. Entretanto, não se pode julgar que os representantes da área de Marketing, por exemplo, tivessem o mesmo perfil de resposta; ii- a amostra, constituída por 83 empresas foi intencional, é pequena e tem forte concentração da atividade de serviços, embora não sejam objetos de inviabilização da pesquisa, uma nova estratégia adequada ao convencimento na participação dos respondentes deve ser introduzida; iii- a operacionalização dos construtos, visou contemplar estudos anteriores e, por conta disso, pode ter deixado de capturar algum elemento importante na realidade das empresas brasileiras.

Diante da realidade exposta, sugerem-se algumas oportunidades de novos estudos, que podem ser elencados: i- verificar a possibilidade de estabelecer um arranjo (fit) entre fatores contingenciais, desenho, uso de SCG focados nos clientes e desempenho; ii- realizar este modelo de pesquisa com outro público alvo; iii- realizar a presente pesquisa em empresas que adotam o artefato Balanced Scorecard, pois supostamente utilizam SCGFC de forma mais intensiva; iv- verificar o impacto de variáveis como "satisfação do cliente"; "lealdade do cliente" e "retenção do cliente" no desempenho econômico da organização. 


\section{REFERÊNCIAS}

ABDEL-KADER, M.; LUTHER, R.The impact of firm characteristics on management accounting practices: a UK-based empirical analysis. British Accounting Review, v. 40, n. 1, p. 2-27, 2008.

AGUIAR, A. B.; PACE, E. S. U.; FREZATTI, F. Análise do inter-relacionamento das dimensões da estrutura de sistemas de controle gerencial: um estudo piloto. RAC Eletrônica, Curitiba, v.3, art.1, p. 1-21, 2009.

ANDRADE, M. M. de. Introdução à metodologia do trabalho científico. 6. ed. São Paulo: Atlas, 2002.

ANTHONY, R. N.; GOVINDARAJAN, V. Sistemas de controle gerencial. São Paulo: McGraw-Hill, 2008.

ARMSTRONG, C.E.; SHIMIZU, K.A.Review of approaches to empirical research on the resource-based view of the firm.Journal of Management, v. 33,n. 6, p. 959-986, 2007.

ATKINSON, A.A.; BANKER, R.D; KAPLAN, R.S.; YOUNG, S.M. Contabilidade gerencial.São Paulo: Atlas, 2000.

BARNEY, J. Firm resources and sustained competitive advantage.Journal of Management, v. 17, n. 1, p.99-120, 1991.

BAUER, H.; HAMMERSCHMIDT.Customer-based corporate valuation.Integrating the concepts of customer equity and shareholder value.Marketing Decision, v. 43, n. 3, p. 331$348,2005$.

BELLIS-JONES, R. Customer profitability analysis.Management Accounting, v.67, n. 2; p. 26-28, 1989.

BIDO, D.S.; SILVA, D.; SOUZA, C.A.; GODOY, A.S. Mensuração com indicadores formativos nas pesquisas em administração de empresas: como lidar com a multicolinearidade entre eles?Administração: Ensino e Pesquisa. Rio de Janeiro, v. 11, n. 2, p. 245-269, 2010.

BLATTBERG, Robert C.; GETZ, Gary; THOMAS, Jacquelyn S. Customer equity.Building and managing relationships as valuable assets.New York:HBS Press, 2001.

BOLTON, R.N.; LEMON, K.N.; VERHOEF, P.C.The theoretical underpinnings of customer asset management: a framework and propositions for future research. Erin Report Series Research in Management, 2002. 
BOURNE, M.;NEELY, A.;MILLS, J.;PLATTS, K. Implementing performance measurement systems: a literature review. Int. J. Business Performance Management, v. 5, n. 1, p.1-24, 2003.

BURNS, J.; VAIVIO, J. Management accounting change.Management Accounting Research, v. 12, n. 4, p. 389-402, 2001.

CADEZ, S.; GUILDING, C.An exploratory investigation of an integrated contingency model of strategic management accounting. Accounting, Organizations and Society, v. 33, p. 836863, 2008.

CARDOSO, R.L.; MÁRIO, P. C.; AQUINO, A.C.B. Contabilidade gerencial. Mensuração, monitoramento e incentivos. São Paulo: Atlas, 2007.

CATELlI, A. (Coord.). Controladoria. Uma abordagem da gestão econômica Gecon. São Paulo: Atlas, 1999.

CHENHALL, R. H. Integrative strategic performance management systems, strategic alignment of manufacturing learning and strategic outcomes: an exploratory study. Accounting, Organizations and Society, v. 30, p. 395-422, 2005.

CHENHALL, R. H. Management control systems design within its organizational context: findings from contingency-based research and directions for the future. Accounting Organizations and Society, v. 28, p. 127-168, 2003.

CHENHALL, R.H.; LANGFIELD-SMITH, K. Multiple Perspectives of Performance Measures.European Management Journal, v. 25, n. 4, p. 266-282, 2007.

CHENHALL, R. H.; LANGFIELD-SMITH, K.The relationship between strategic priorities management techniques and management accounting.An empirical investigation using systems approach.Accounting, Organizations and Society, v. 23, n. 3, p. 243-264, 1998.

CHENHALL, R. H.; MORRIS, D.The impact of structure, envinroment, and interdependence on the perceived usefulness of the management accounting systems.The Accounting Review, v. LXI, n. 1, 1986.

CHIAVENATO, I. Introdução à teoria geral da administração. 7. ed. Rio de Janeiro: Elsevier, 2004. 
CHIN,W. W. The partial least squares approach to structural equation modeling. In: MARCOULIDES, G. A. (Ed.). Modern methods for business research. New Jersey: Laurence Eribaum Associates, Publisher, 1998. p. 295-336.

CHIN, W. W.; NEWSTED, P. R. Structural equation modeling analysis with small samples using partial least squares. In: HOYLE, R. H.Statistical strategies for small sample research. California: Sage Publications, Inc., 1999. p.307-341.

CHONG, V. K.; CHONG K. M. Strategic choices environment uncertainty and SBU performance.A note on the intervening role of accounting management systems.Accounting and Business Research, v. 27, n. 4, p. 268-276, 1997.

COHEN, J. Statistical power analysis for the behavioral sciences (revised edition). New York: Academic Press, 1977.

COLLIER, P.M. Entrepreneurial control and the construction of a relevant accounting.Management AccountingResearch, v. 16, p. 321-339, 2005.

COOPER, D. R.; SCHINDLER, P. S. Métodos de pesquisa em administração. 7. ed. Porto Alegre: Bookman, 2003.

DAY,G.S. The capabilities of market-driven organizations.Journal of Marketing,v. 58, p. 37-52, 1994.

DECHOW, N.; GRANLUND, M.; MORITSEN, J. (org. Chapman, C.; Hoopwood; Shields). Management control of the complex organization: relationships between management accounting and information technology.Handbook of Management Accounting Research, v. 2, 2007.

DESARBO, W.S; JEDIDI, K.; SINHA, I. Customer value analysis in a heterogeneous market.Strategic Management Journal,v. 22, p. 845-857, 2001.

DONALDSON, L. The contingency theory of organizations.Foundations for organizational science.London: Sage, 2001.

DOYLE, P. Value-based marketing.Journal of Strategic Marketing,v. 8, n. 4, p.299-311, 2000.

DWYER, F. R. Customer lifetime valuation to support marketing decision making. Journal of Direct Marketing, v. 11, n. 4, p. 8-15, 1997.

ESPEJO, M.M.S. B.Perfil dos atributos do sistema orçamentário sob a perspectiva contingencial: uma abordagem multivariada. São Paulo, 2008. Tese (Doutorado) - Faculdade de Economia, Administração e Contabilidade da Universidade de São Paulo. 
FÁVERO, L.P.; BELFIORE, P.; SILVA, F.L.; CHAN, S.L. Análise de dados: modelagem multivariada para tomada de decisões. Rio de Janeiro: Campus, 2009.

FERNANDES, B.H.R. Competências e performance organizacional: um estudo empírico. São Paulo, 2004. Tese (Doutorado) - Faculdade de Economia, Administração e Contabilidade da Universidade de São Paulo.

FERREIRA, A.; OTLEY, D.The design and use of performance management systems: an extended framework for analysis. Management Accounting Research, n. 20, p. 263-282, 2009.

FERREIRA, A.; OTLEY, D. Design and use of management control systems: an analysis of the interaction between design misfit and intensity of use. Draft Paper. Aug. 2010.

FOSTER, G.; GUPTA, M. Marketing, cost management and management accounting and management accounting.Journal of Management Accounting Research,v. 6, p. 43-77, 1994.

FOSTER, G.; GUPTA, M.; SJOBLOM, L. Customer profitability analysis: challenges and new directions. Cost Management, p. 5-17, 1996.

FREZATTI, F. et al. Controle gerencial: uma abordagem da contabilidade gerencial no contexto econômico, comportamental e sociológico. São Paulo: Atlas, 2009.

GIRAU, F. et al. Fundamental of management control. Pearson education France. Ebook. Disponível em: <http://www.pearson.fr/livre/?GCOI=27440100959280>. Acesso em: 22/10/2011.

GORDON, A.L.; NARAYANAN, V.K. Management accounting systems, perceived environmental uncertainty and organization structure: an empirical investigation. Accounting, Organizations and Society,v. 9, n. 1, p. 33-47, 1984.

GRANLUND, M. On the interface between management accounting and modern information technology.A literature review and some empirical evidence. Working Paper, 2007.

GRANT, R.M. Contemporary strategy analysis.Oxford: Blackwell, 2008.

GUERRA, A. R. Arranjos entre fatores situacionais e sistema de contabilidade gerencial sob a ótica da teoria contingencial. São Paulo, 2007. Dissertação (Mestrado) - Faculdade de Economia, Administração e Contabilidade da Universidade de São Paulo. 
GUERREIRO, Reinaldo; MERSCHMANN, Elvira Vazquez Villamor; BIO, Sergio Rodrigues. Mensuração do custo para servir e análise de rentabilidade de cliente: uma aplicação em indústria de alimentos no Brasil. RAUSP-e Revista de Administração Eletrônica, São Paulo, v. 1, p. 6, 2008.

GUILDING, C.; MCMANUS, L.The incidence, perceived merit and antecedents of customer accounting: an exploratory note. Accounting, Organizations and Society, v. 27,p.45-59, 2002.

GUPTA, S.; LEHMANN.D.R.Customer lifetime value and firm valuation.Journal of Relationship Marketing, v. 5, n. 2/3, 2006.

GUPTA, S.; HANSSENS, D.; HARDIE B.; KAHN W.; KUMAR V.; LIN. N.; RAVISHANKER, N.; SRIRAM, S. Modeling Customer Lifetime Value. Journal of Service Research, v. 9, p. 139-155, 2006.

HAIR, J.F.et al. Análise multivariada de dados.Porto Alegre: Bookman, 2005.

HAIR, J. F. et al. Fundamentos de métodos de pesquisa em administração.Porto Alegre: Bookman, 2006.

HELGESEN, O. Customer accounting and customer profitability analysis for the order handling industry - a managerial accounting approach.Industrial Marketing Management, v. 36, n. 6, p. 757-769, 2007.

HENRI, J.F. Management control systems and strategy: a resource-based perspective. Accounting.Organization and Society, v. 31, p.529-558, 2006.

HOQUE, Z.; JAMES, W. Linking balanced scorecard measures to size and market factors.Impact on organizational performance.Journal of Management Accounting Research, v. 12, 2000.

HORNGREN, C.T.; SUNDEM, G.L.; STRATTON, W.O. Introduction to management accounting.10. ed.New Jersey: Prentice Hall, 1996.

HUNGER, D.; WHEELEN, T. L. Gestão estratégica: princípios e práticas. Rio de Janeiro: Reichmann \& Affonso Editores, 2002.

HURLEY, R. F.; HULT, G. T. M. Inovation, market orientation, and organizational learning: an integration and empirical examination. Journal of Marketing, v. 62, p. 42-54, 1998. 
HULT, G.T.M.; KETCHEN, D.J.Does market orientation matter?: a test of the relationship between positional advantage and performance. Strategic Management Journal, v.22, p. 899-906, 2001.

HYVÖNEN, J. Strategy, performance measurement techniques and information technology of the firm and their links to organizational performance.Management Accounting Research, v. 18, p.343-366, 2007.

ITTNER, C.D.; LARCKER, D.F. Assessing empirical research in managerial accounting: a value based management perspective. Journal of Accounting and Economics, v. 32, p. 349410, 2001.

JAIN, D; SINGH, S. S. Customer lifetime value research in marketing: a review and future directions.Journal of Interactive Marketing, v. 16, n. 2, p. 34-46, 2002.

JAWORSKI, B. J.; KOHLI, A. K. Market orientation: antecedents and consequences. Journal of Marketing,v. 57, p. 53-70, 1993.

JUNQUEIRA, E.R. Perfil do sistema de controle gerencial. Sob a perspectiva da teoria da contingência. São Paulo, 2010. Tese (Doutorado) - Faculdade de Economia, Administração e Contabilidade da Universidade de São Paulo.

KANDWALLA, P. N. The effect of different types of competition on the use of management controls. Journal of Accounting Research, Autumn. 1972.

KAPLAN, R. S.; COOPER, R. Custo e desempenho: administre seus custos para ser mais competitivo. São Paulo: Futura, 1998.

KAPLAN, R. S.; NARAYANAN, V. G. Measuring and managing customer profitability.Journal of Cost Management, p. 5-15, Sept./Oct. 2001.

KOHLI, A.K.; JAWORSKI, B.J. Market orientation: the construct, research propositions and managerial implications. Journal of Marketing,v. 54, p 1-19, 1990.

LAKATOS, E. M.; MARCONI, M. A. Fundamentos de metodologia científica. 3. ed. São Paulo: Atlas, 1991.

LANGFIELD-SMITH, K. (org. Chapman, C.; Hoopwood; Shields) A review of quantitative research in management control systems and strategy.Handbook of Management Accounting Research, v. 2, 2007.

LAUDON, K. C.; LAUDON, J. P. Sistemas de informação gerenciais. 7. ed. São Paulo: Pearson Prentice Hall, 2007. 
LIN, J. A.Consumer support architecture for enhancing customer relationships.Wseas Transactions on Information Science and Applications, v.6, p. 384-396, 2009.

LIND, J.; STRÖMSTEN, T.When do firms use different types of customer accounting.Journal of Business Research, v. 59, n. 12, p.1257-1266, 2006.

LORD, B. R.; SHANAHAN, I. P.; NOLAN, B. M. The use and perceived merit of customer accounting in New Zealand. Accounting Research Journal, v. 20, n.1, 2007.

MACHADO, M. R. As informações sociais e ambientais evidenciadas nos relatórios anuais das empresas: a percepção dos usuários. São Paulo, 2010. Tese (Doutorado) Faculdade de Economia, Administração e Contabilidade da Universidade de São Paulo.

MALMI, T.; RAULAS, M.; SEHM J.An empirical study on customer profitability accounting, customer strategies and corporate performance. Paper presented at the EAA Conference.Prague: April. 2004.

MATTAR, F. N. Pesquisa de marketing: metodologia, planejamento. 6. ed. São Paulo: Atlas, 2005.

MCMANUS, L. An examination of customer accounting in an Australian context. Dissertation submitted in fulfillment of the requirements of the degree of Doctor in Philosophy. Department of Accounting, Finance and Economics, Griffith Business School, Griffith University, 2006.Disponível em:<http://www4.gu.edu.au:8080/adt-root/public/adtQGU20070111.145255/index.html>. Acessoem: 07/12/2009.

MCMANUS, L.; GUILDING, C.Exploring the potential of customer accounting: a synthesis of the accounting and marketing literatures.Journal of Marketing Management, v. 24, n. 78, p.771-795, 2008.

MERCHANT, K. A. Influences on departmental budgeting: an empirical examination of a contingency model. Accounting, Organizations and Society, v. 3-4, p. 291-307, 1984.

MERCHANT, K. A.; OTLEY, D. T. (org. Chapman, C.; Hoopwood; Shields) A review of the literature on control and accountability.Handbook of Management Accounting Research, v. 2, 2007.

MERCHANT, K. A.; VAN DER STEDE, W. Management control systems.performance measurement, evaluation and incentives. Harlow: Prentice Hall England, 2007.

MOURITSEN, J. Marginalizing the customer: customer orientation, quality and accounting performance.Scandinavian Journal of Management, v. 13, n. 1, p. 5-18, 1997. 
MULHERN, F. Customer profitability analysis: measurement, concentration and research directions. Journal of Interactive Marketing,v.13, p. 25-40,1999.

NASCIMENTO, A. M.; REGINATO, L. (Orgs.). Controladoria: um enfoque na eficácia organizacional. São Paulo: Atlas, 2007.

NARVER, J.C.; SLATER, S.F.The effect of a market orientation on business profitability.Journal of Marketing, 1990.

NEWBERT, S. L. Empirical research on the resource based view of the firm: an assessment and suggestions for future research. Strategic Management Journal, v.28, n. 2, p. 121-146, 2007.

OLIVEIRA, D. P. R. Teoria geral da administração. São Paulo: Atlas, 2008.

OTLEY, D. Performance management: a framework for management control systems research. Management Accounting Research,v. 10, p.363-382, 1999.

OYADOMARI, J. C. T. et al. Análise dos trabalhos que usaram o modelo levers of control de Simons na literatura internacional no período de 1995 a 2007. RCO - Revista de Contabilidade e Organizações, FEA-RP/USP, Ribeirão Preto, v. 3, n. 7, p. 25-42, 2009.

OYADOMARI, J.C.T. Uso do sistema de controle gerencial e desempenho: um estudo em empresas brasileiras sob a ótica da VBR (Visão Baseada em Recursos). São Paulo, 2008. Tese (Doutorado) - Faculdade de Economia, Administração e Contabilidade da Universidade de São Paulo.

PEPPERS, Don; ROGERS, Martha. Retorno sobre clientes. Return on customer. um modo revolucionário de medir e fortalecer seu negócio. Rio de Janeiro: Elsevier, 2005.

PFEIFER, P. E.; HASKINS, M. E.;CONROY R. M. Customer lifetime value, customer profitability, and the treatment of acquisition spending. Journal of Managerial Issues, v. 17, n. 1, p. 11-25, 2005.

PORTER, M. E. Vantagem competitiva: criando e sustentando um desempenho superior. Rio de Janeiro: Campus, 1990.

RAAIJ VAN, E.M.; STOELHORST, J.W.The implementation of a market orientation.A review and integration of the contributions to date.European Journal of Marketing, v. 42, n. 11/12, p. 1265-1293, 2008.

RAO, S.; FRAZER, L.The use of internet-based technologies in Australian franchise systems A preliminary study. Journal of Internet Business, v. 1, n. 2, p. 231-246, 2005. 
REINARTZ, W.; THOMAS, J. S.; KUMAR, V. Balancing acquisition and retention resources to maximize customer profitability. Journal of Marketing, v. 69, p. 63-79, 2005.

RICHARDSON, R. J. Pesquisa social: métodos e técnicas. São Paulo: Atlas, 1999.

ROSLENDER, R.; HART, S.Taking the customer into account: transcending the construction of the customer through the promotion of self-accounting. Critical Perspectives on Accounting, 2010.

RUST, Roland T.; ZEITHAML, Valarie A.; LEMON, Katherine N. Driving customer equit.how customer lifetime value is reshaping corporate strategy. New York: The Free Press, 2000.

SHARMA, D. S. The differential effect of environmental dimensionality, size, and structure on budget system characteristics in hotels.Management Accounting Research, 2002.

SIMONS, R. Accounting control systems and business strategy: an empirical analysis. Accounting, Organizations and Society, v. 12,n.4, p. 357-374,1987.

SIMONS, R. Levers of control. Boston:HarvardBusinessSchool Publishing, 1995.

SIMONS, R. Performance measurement \& control systems for implementing strategy. New Jersey: Prentice-Hall, 2000.

SLATER,S.F.; NARVER, J.C. Market orientation and the learning organization.Journal of Marketing, v. 59, p.63-74, 1995.

SMITH, M.; DIKOLLI, S. Customer profitability: an activity-based costing approach. Management Accounting Journal, v. 10, n.7, p.3-7, 1995.

SOUTES, Dione Olesczuk. Uma investigação do uso de artefatos da contabilidade gerencial por empresas brasileiras. São Paulo, 2006. Dissertação (Mestrado) - Faculdade de Economia, Administração e Contabilidade da Universidade de São Paulo.

SRIVASTAVA, R.K.; SHERVANI, T.A.; FAHEY, L. Market based assets and shareholder value: a framework for analysis. Journal of Marketing,v. 62, p. 2-18, 1998.

TILLEMA, S. Towards an integrated contingency framework for MAS sophistication case studies on the scope of accounting instruments in Dutch power and gas companies. Management Accounting Research, v. 16, p. 101-129, 2005.

VAIVIO, J. Examining “The Quantified Customer".Accounting, Organizations and Society, v. 24, n. 8, p. $689-715,1999$. 
VAN RAAIJ, E. M. The strategic value of the customer profitability analysis.Marketing Intelligence \& Planning, v. 4/5; p. 372, 2005.

VAN TRIEST, S. Customer size and profitability.Journal of Business and Industrial Marketing, v. 20, n. 3, p. 148-155, 2005.

VASCONCELOS, F. C; CYRINO, A. B. Vantagem competitiva: os modelos teóricos atuais e a convergência entre estratégia e teoria organizacional. $\boldsymbol{R A} \boldsymbol{E}$ - Revista de Administração de Empresas, São Paulo, v. 40, n. 4, Out./Dez. 2000.

VERHOEF, P. C. Understanding the effect of customer relationship management efforts on customer retention and customer share development.Journal of Marketing, v. 67, n. 1, p.3045, 2003.

VILLANUEVA, J.; HANSSENS, D.M. Customer equity: measurement, management and research opportunities. Foundations and Trends in Marketing, v. 1, n. 1, p. 1-95, 2007.

WANGENHEIM, Florian V.; LENTZ, Patrick.Understanding your customer portfolio: a simple approach to customer segmentation according to lifecycle dynamics.Disponível em:<http: www.wiso.uni-dortmund.de/ white_paper.pdf>. Acesso em: 01/02/2006.

WEIR, K. Examining the theoretical influences of customer valuation metrics. Journal of Marketing Management,v. 24, n. 7-8, p.797-824, 2008.

WERNERFELT, B. A resource based view of the firm. Strategic Management Journal, v. 5, p. 171-180, 1984.

WIESEL, T.; SKIERA, B.; VILLANUEVA, J. Customer equit: an integral part of financial reporting. Journal of Marketing, v. 72, p 1-14, 2008.

WRIGT, P.; KROLL, M. J.; PARNELL J. Administração estratégica: conceitos. São Paulo: Atlas, 2000. 


\section{APÊNDICES}

APÊNDICE 1 - CARTA DE APRESENTAÇÃO

APÊNDICE 2 - QUESTIONÁRIO

APÊNDICE 3 - RELATÓRIO DE ESTATÍSTICAS - SOFTWARE G3 POWER

APÊNDICE 4 - CARGAS FATORIAIS DOS CONSTRUTOS DE PESQUISA 


\section{APÊNDICE 1 - CARTA DE APRESENTAÇÃO}

\section{CARTA DE APRESENTAÇÃO}

São Paulo, julho de 2011

Prezados Senhores:

Compreender a influência que os fatores contingenciais exercem sobre os sistemas de controle gerenciais focados nos clientes, pode contribuir, indiretamente, para a melhoria do desempenho das empresas brasileiras. Essa temática representa a base da minha pesquisa para desenvolver a tese de doutorado na FEA/USP sob orientação do Prof. Dr. Carlos Alberto Pereira.

Para atingir esse objetivo, peço a sua gentileza para responder ao questionário, bastando acessar o link: http://fs17.formsite.com/FlavioRobertoMantovani/form1/index.html. O seu preenchimento demandará aproximadamente 15 minutos e as respostas serão tratadas de forma consolidada, afim de manter o sigilo sobre a identidade das empresas e dos seus administradores pesquisados.

Como forma de retribuir sua colaboração, as empresas respondentes serão convidadas a participar de um workshop liderado pelo pesquisador, abordando o tema: Aspectos econômicos e financeiros na gestão do relacionamento com o cliente, a ser realizada na sede da FIPECAFIno dia 18 de dezembro de 2011.

No caso de persistir alguma dúvida no preenchimento, ou eventual esclarecimento, peço entrar em contato com Flavio Mantovani pelo email: flavio.mantovani@usp.br ou através do telefone 11-5523-4283.

Desde já agradecemos pela sua atenção e valiosa contribuição.

Prof. Msc. Flavio Roberto Mantovani Prof. Dr. Carlos Alberto Pereira

Doutorando FEA/ USP Professor orientador FEA/USP 


\section{APÊNDICE 2 - QUESTIONÁRIO}

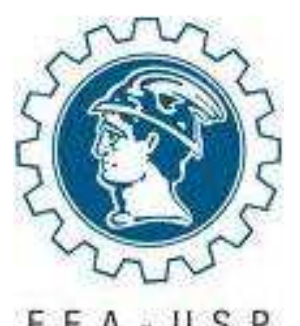

FEA - US P

Esta pesquisa visa compreender a influência de fatores contingenciais nos modelos e usos de sistemas de controle gerenciais focados nos clientes. O objetivo é identificar os relacionamentos entre esses elementos e os seus efeitos no desempenho do sistema. $\mathrm{O}$ tempo médio de resposta é de 10 a 15 minutos. Um glossário de termos específicos é apresentado ao final deste questionário.

* O nível de competição no ambiente de atuação da empresa é intenso em relação:

$\begin{array}{llllllll} & \mathbf{1} & \mathbf{2} & \mathbf{3} & \mathbf{4} & \mathbf{5} & \mathbf{6} & \mathbf{7} \\ \text { Vendas e distribuição } & \mathbf{C} & \mathbf{C} & \mathbf{C} & \mathbf{C} & \mathbf{C} & \mathbf{C} & \mathbf{C} \\ \text { Qualidade e variedade de produtos } & \mathbf{C} & \mathbf{C} & \mathbf{C} & \mathbf{C} & \mathbf{C} & \mathbf{C} & \mathbf{C} \\ \text { Preço } & \mathbb{C} & \mathbf{C} & \mathbf{C} & \mathbf{C} & \mathbf{C} & \mathbf{C} & \mathbf{C} \\ \text { Participação de mercado (market-share) } & \mathbf{C} & \mathbf{C} & \mathbf{C} & \mathbf{C} & \mathbf{C} & \mathbf{C} & \mathbf{C} \\ \text { Serviços ao cliente } & \mathbf{C} & \mathbf{C} & \mathbf{C} & \mathbf{C} & \mathbf{C} & \mathbf{C} & \mathbf{C}\end{array}$

* A empresa se destaca de seus concorrentes por adotar as seguintes posturas:

Fornecer produtos de alta qualidade

$\begin{array}{lllllll}1 & 2 & 3 & 4 & 5 & 6 & 7\end{array}$

Custos de produção baixos

C $C \subset \subset \subset C D C$

Fornecer produtos com características únicas

C $\subset \subset \subset \subset C E C$

Fornecer produtos de preço baixo

$\mathbb{C} \square \square \square \square \square$

$\square \square \square \square \square \square \square$ 
Modificar o desenho e introduzir novos produtos rapidamente

$C \square \square \square C \square \square$

Modificar o volume/mix dos produtos oferecidos

C $C \subset \subset \subset \subset C D$

Fazer entregas rápidas

C $\subset \subset \subset \subset C D E$

Disponibilidade imediata de produtos

C $C \square \subset \square C D$

Customização de produtos e serviços às necessidades dos clientes

$C \square \square \square \square \square \square$

* São delegados amplos poderes para a alta gerência decidir sobre:

$\begin{array}{llllllll} & \mathbf{1} & \mathbf{2} & \mathbf{3} & \mathbf{4} & \mathbf{5} & \mathbf{6} & \mathbf{7} \\ \text { Desenvolvimento de novos produtos e serviços } & \mathbf{C} & \mathbf{C} & \mathbf{C} & \mathbf{C} & \mathbf{C} & \mathbf{C} & \mathbf{C} \\ \text { Contratação e desligamento de gerentes subalternos } & \mathbf{C} & \mathbf{C} & \mathbf{C} & \mathbf{C} & \mathbf{C} & \mathbf{C} & \mathbf{C} \\ \text { Aprovação de altos investimentos } & \mathbf{C} & \mathbf{C} & \mathbf{C} & \mathbf{C} & \mathbf{C} & \mathbf{C} & \mathbf{C} \\ \text { Alocações orçamentárias } & \mathbf{C} & \mathbf{C} & \mathbf{C} & \mathbf{C} & \mathbf{C} & \mathbf{C} & \mathbf{C} \\ \text { Alterações do preço de produtos ou serviços } & \mathbf{C} & \mathbf{C} & \mathbf{C} & \mathbf{C} & \mathbf{C} & \mathbf{C} & \mathbf{C}\end{array}$

* Em relação a estruturação de cargos e tarefas

$\begin{array}{rrrrrrrrr} & \mathbf{1} & \mathbf{2} & \mathbf{3} & \mathbf{4} & \mathbf{5} & \mathbf{6} & \mathbf{7} \\ \text { Os ocupantes são em geral especialistas e univalentes } & \mathbf{C} & \mathbf{C} & \mathbf{C} & \mathbf{C} & \mathbf{C} & \mathbf{C} & \mathbf{C}\end{array}$

* Em relação ao nível de formalidades:

$\begin{array}{lllllll}1 & 2 & 3 & 4 & 5 & 6 & 7\end{array}$

Imposição de regras e regulamentos formalizados por escrito

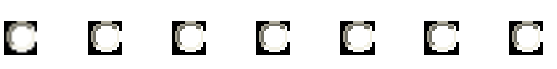


* Em relação ao processo decisorial:

$\begin{array}{rlllllll} & 1 & 2 & 3 & 4 & 5 & 6 & 7 \\ \text { São centralizadas na cúpula da organização } & \mathbb{C} & \mathbb{C} & \mathbb{C} & \mathbb{C} & \mathbb{C} & \mathbb{C} & \mathbb{C}\end{array}$

* Em relação ao estilo gerencial representado pelo modo de tomar decisões:

$\begin{array}{llllllll}1 & 2 & 3 & 4 & 5 & 6 & 7\end{array}$

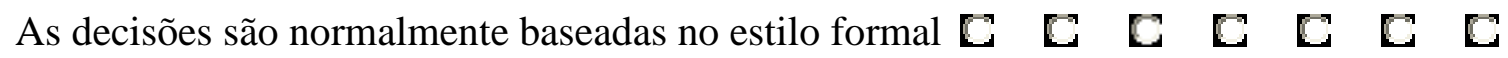

* Sistemas utilizados intensamente para apoiar os processos de negócios:
$\begin{array}{lllllll}1 & 2 & 3 & 4 & 5 & 6 & 7\end{array}$

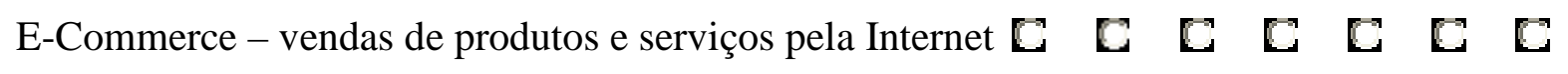
ERP - Sistemas integrados de gestão
$\begin{array}{lllllll} & C & \mathrm{C} & \mathrm{C} & \mathrm{C} & \mathrm{C} & \mathrm{C}\end{array}$
CRM - Gestão do relacionamento com o cliente

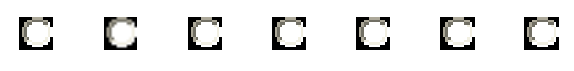
SCM - Gestão da cadeia de suprimentos
C E E E E E E
DW - Armazém de dados
C E E E E E E
OLAP - Processamento analítico on-line
$\square \square \square \square \square \square \square$
BI - Sistemas de inteligência de negócios
$\square \square \square \square \square \square \square$

* Independente de fazer uso ou não, os gestores compreendem a relevância e o elevado valor agregado das seguintes análises.

Análise da receita dos clientes

Análise dos custos dos clientes

Análise da lucratividade dos clientes

Análise das receitas durante o ciclo de vida do cliente $\begin{array}{lllllll}1 & 2 & 3 & 4 & 5 & 6 & 7\end{array}$

$\mathbb{C} \subset \square \subset \square \square \square$

$\square \square \square \square \square \square \square$

$C \square \square \square C \square C$

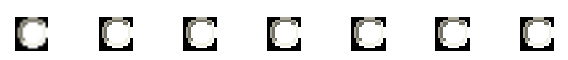


Análise dos custos durante o ciclo de vida do cliente

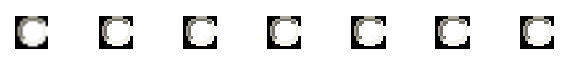

Análise da lucratividade durante o ciclo de vida do cliente

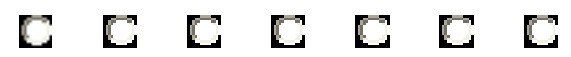

Análise das receitas potenciais devido à conquista de futuros clientes

$\mathbb{C} \subset \subset \subset \subset \subset \square$

Análise dos custos potenciais devido à conquista de futuros clientes

C $\mathbb{C} \subset \subset \subset \subset \subset E$

Análise da receita potencial perdida devido ao abandono dos clientes

C $\mathbb{C} \subset \mathbb{E} \subset \mathbb{C}$

* Os gestores, no dia a dia das suas atribuições, fazem uso intenso das seguintes análises.

Análise da receita dos clientes

Análise dos custos dos clientes

Análise da lucratividade dos clientes

Análise das receitas durante o ciclo de vida do cliente

Análise dos custos durante o ciclo de vida do cliente

Análise da lucratividade durante o ciclo de vida do cliente

Análise das receitas potenciais devido à conquista de futuros clientes

Análise dos custos potenciais devido à conquista de futuros clientes

Análise da receita potencial perdida devido ao abandono dos clientes

\section{$\begin{array}{lllllll}1 & 2 & 3 & 4 & 5 & 6 & 7\end{array}$}

$C \square \square \square C \square \square$

$C \square \square \square \square \square \square$

C $C \square \subset \subset \subset \square$

$\square \square \square \square \square \square \square$

$\square \square \square \square \square \square \square$

$C \square \square \square \square \square \square$

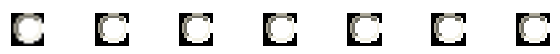

C $\subset \subset \subset \subset \subset \subset \square$

$\mathbb{C} \subset \subset \subset \subset \subset \subset$ 
* Os gestores utilizam intensamente os resultados das análises focadas nos clientes, objetivando:

\begin{tabular}{|c|c|c|c|c|c|c|c|}
\hline & 1 & 2 & 3 & 4 & 5 & 6 & 7 \\
\hline Acompanhar as metas com o que foi planejado & $\mathrm{C}$ & $\mathrm{C}$ & $\mathrm{C}$ & $\mathrm{C}$ & $\mathrm{C}$ & $\mathrm{C}$ & 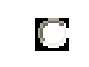 \\
\hline Projetar (forecast) os resultados mais prováveis & $\mathbb{C}$ & $\mathbb{E}$ & $\mathbb{C}$ & $\mathbb{C}$ & $\mathbb{C}$ & C & \\
\hline $\begin{array}{l}\text { Corrigir pequenos ajustes, quando da comparação entre } \\
\text { metas e resultados }\end{array}$ & C & $\mathbb{C}$ & $\mathbf{C}$ & $\mathbb{C}$ & $\mathbb{C}$ & C & \\
\hline $\begin{array}{l}\text { Analisar somente as variações significativas entre o orçado } \\
\text { e o realizado }\end{array}$ & $\mathbb{C}$ & $\mathbf{C}$ & $\mathbf{C}$ & $\mathbb{C}$ & $\mathbf{C}$ & $\mathbb{C}$ & \\
\hline Rever as principais metas & $\mathrm{C}$ & $\mathbb{C}$ & $\mathbb{C}$ & $\mathrm{C}$ & $\mathbf{C}$ & $\mathbb{C}$ & \\
\hline $\begin{array}{l}\text { Discutir oportunidades de melhoria entre superiores, } \\
\text { subordinados e pares }\end{array}$ & $\mathbb{C}$ & $\mathbb{C}$ & $\mathbb{C}$ & $\mathbb{C}$ & $\mathbb{C}$ & $\mathbb{E}$ & \\
\hline Discutir as premissas e novos planos de ação & $\boldsymbol{C}$ & $\square$ & $\mathrm{C}$ & $\mathbb{C}$ & $\mathrm{C}$ & $\mathbb{C}$ & \\
\hline Focar as questões críticas para o sucesso da empresa & $\mathrm{C}$ & $\mathbb{C}$ & $\mathbb{C}$ & $\mathbb{C}$ & $\mathbb{C}$ & $\mathrm{C}$ & \\
\hline $\begin{array}{l}\text { Unificar a visão da organização sobre os problemas que } \\
\text { afetam o desempenho }\end{array}$ & C & $\mathbb{C}$ & $\mathrm{C}$ & $\mathbb{C}$ & $\mathbb{C}$ & C & \\
\hline Criar uma linguagem comum a todos os gestores e direção & $\mathbf{C}$ & $\mathbb{C}$ & $\mathbb{C}$ & $\mathrm{C}$ & $\mathrm{C}$ & $\mathrm{C}$ & \\
\hline Desenvolver novas estratégias e planos de ação. & $\mathrm{C}$ & $\mathbb{C}$ & $\mathbb{C}$ & $\mathrm{C}$ & $\mathrm{C}$ & $\mathrm{C}$ & \\
\hline
\end{tabular}

* Os gestores sentem-se plenamente satisfeitos:
$\begin{array}{lllllll}1 & 2 & 3 & 4 & 5 & 6 & 7\end{array}$
Pela contribuição para o gerenciamento da empresa

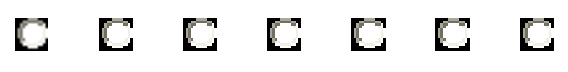
Pela contribuição para a tomada de decisão operacional a curto prazo

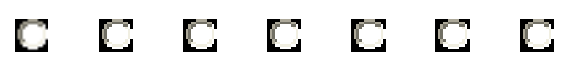
Pela contribuição para a tomada de decisão estratégica em longo prazo

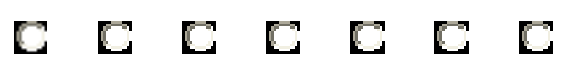
Pela contribuição para o desempenho econômico da empresa

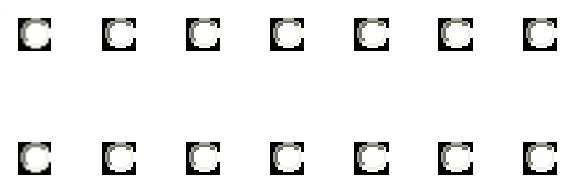
Pelo desempenho do sistema em geral 
Nome da empresa

* Atividade econômica principal

* No de funcionários (dados da última Demonstração Contábil publicada)

* Receita bruta em mil R \$ (dados da última Demonstração Contábil publicada)

Nome do respondente

Cargo

Tempo de trabalho na empresa

Faixa etária

* Instituição de ensino a que está ou esteve vinculado

Endereço eletrônico - email (opcional - se desejar receber os resultados da pesquisa e participar do workshop)

Análise da receita dos clientes: Corresponde ao cálculo e a identificação de toda a receita gerada pela venda para cada cliente ou segmento de clientes.

Análise dos custos dos clientes: Corresponde ao cálculo e a identificação de todo o custo, incluindo os custos de servir de cada cliente ou segmento de clientes.

Análise da lucratividade dos clientes: Corresponde ao cálculo do lucro obtido do cliente. O lucro resulta das vendas diminuídas dos custos identificados de cada cliente ou segmento de clientes.

Análise das receitas durante o ciclo de vida dos clientes: 0 mesmo conceito da análise da receita dos clientes, mas realizada num horizonte de tempo maior (ciclo de vida dos clientes existentes) objetivando incluir as receitas esperadas no futuro.

Análise dos custos durante o ciclo de vida dos clientes: 0 mesmo conceito da análise dos custos dos clientes, mas realizada num horizonte de tempo maior (ciclo de vida dos clientes existentes) objetivando incluir todos os custos esperados no futuro.

Análise da lucratividade durante o ciclo de vida dos clientes: 0 mesmo conceito da análise da lucratividade dos clientes, mas realizada num horizonte de tempo maior (ciclo de vida dos clientes existentes) objetivando incluir todas as receitas e todos os custos esperados no futuro.

Análise das receitas potenciais devido à conquista de futuros clientes: $O$ mesmo conceito da análise da receita dos clientes, mas realizada num horizonte de tempo maior objetivando incluir as receitas oriundas de novos clientes que são esperadas no futuro.

Análise dos custos potenciais devido à conquista de futuros clientes: $\mathrm{O}$ mesmo conceito da análise dos custos dos clientes, mas realizada num horizonte de tempo maior objetivando incluir todos os custos oriundos de novos clientes que são esperados no futuro. 
Análise da receita potencial perdida devida ao abandono de clientes: Corresponde ao cálculo da receita que deixaria de ser ganha sob a perspectiva da perda de clientes que são esperadas no futuro.

*Indicates Response Required

Submit 1

Poweredby FormSite.com 
APÊNDICE 3 - RELATÓRIO DE ESTATÍSTICAS - SOFTWARE G3 POWER

\section{GPOWER}

F tests - Linear multiple regression: Fixed model, $\mathrm{R}^{2}$ deviation from zero

Analysis:

A priori: Compute required sample

size

Input: $\quad$ Effect size $f^{2} \quad=0.15$

$\alpha$ err prob $\quad=0.05$

Power $(1-\beta$ err prob $)=0.8$

Number of predictors $=\quad 2$

Output: Noncentrality parameter $\lambda \quad=10.2000000$

Critical F $\quad=3.1381419$

Numerator df $\quad=2$

Denominator $\mathrm{df} \quad=65$

Total sample size $\quad=68$

Actualpower $\quad=0.8044183$ 


\section{APÊNDICE 4 -CARGAS FATORIAIS DO MODELO DE MENSURAÇÃO}

\begin{tabular}{ccccccc} 
1A RODADA - AFC & AVE & Composite & R & \multicolumn{2}{c}{ Cronbachs } & \\
& & Reliability & Square & Alpha & Communality & Redundancy \\
Ambiente & 0,55060 & 0,85540 & 0,00000 & 0,78790 & 0,55060 & 0,00000 \\
CLV & 0,89310 & 0,96160 & 0,51230 & 0,94000 & 0,89310 & $-0,00940$ \\
Desempenho & 0,82930 & 0,96040 & 0,54500 & 0,94810 & 0,82930 & 0,04540 \\
Estratégia & 0,39070 & 0,84470 & 0,44790 & 0,78790 & 0,39070 & 0,12540 \\
Lucratividade & 0,86600 & 0,95090 & 0,19260 & 0,92210 & 0,86600 & 0,16620 \\
Organizacao & 0,34970 & 0,79730 & 0,36160 & 0,71630 & 0,34970 & $-0,00740$ \\
Porte & 0,63250 & 0,77450 & 0,22800 & 0,42190 & 0,63250 & $-0,00010$ \\
Tecnologia & 0,48570 & 0,86700 & 0,34790 & 0,81960 & 0,48570 & 0,00930 \\
Uso Diagnóstico & 0,63410 & 0,89300 & 0,60140 & 0,85210 & 0,63410 & 0,03430 \\
Uso Interativo & 0,76660 & 0,95160 & 0,57330 & 0,93870 & 0,76660 & $-0,06260$ \\
CE & 0,92070 & 0,97210 & 0,65530 & 0,95690 & 0,92070 & 0,08170
\end{tabular}

\begin{tabular}{ccccccc} 
2A RODADA - AFC & AVE & $\begin{array}{l}\text { Composite } \\
\text { Reliability }\end{array}$ & R Square & \multicolumn{2}{l}{ Cronbachs } \\
Ambiente & 0,64610 & 0,87940 & & 0,81800 & 0,64610 & \\
CLV & 0,89310 & 0,96160 & 0,51210 & 0,94000 & 0,89310 & 0,00330 \\
Desempenho & 0,82930 & 0,96040 & 0,54220 & 0,94810 & 0,82930 & 0,02850 \\
Estrategia & 0,46500 & 0,85430 & 0,44490 & 0,79660 & 0,46500 & 0,15750 \\
Lucratividade & 0,86600 & 0,95090 & 0,17780 & 0,92210 & 0,86600 & 0,15290 \\
Organizacao & 0,50200 & 0,85450 & 0,35100 & 0,79330 & 0,50200 & $-0,01820$ \\
Porte & 0,63280 & 0,77480 & 0,22590 & 0,42190 & 0,63280 & $-0,00360$ \\
Tecnologia & 0,48570 & 0,86700 & 0,35370 & 0,81960 & 0,48570 & 0,01530 \\
Uso Diagnóstico & 0,63420 & 0,89300 & 0,60500 & 0,85210 & 0,63420 & 0,04330 \\
Uso Interativo & 0,76660 & 0,95160 & 0,57230 & 0,93870 & 0,76660 & $-0,05700$ \\
ce & 0,92070 & 0,97210 & 0,65540 & 0,95690 & 0,92070 & 0,08080
\end{tabular}




\begin{tabular}{|c|c|c|c|c|c|c|c|c|c|c|c|}
\hline Ambiente & $\begin{array}{l}\text { Ambiente } \\
\mathbf{0 , 8 0 3 8 0}\end{array}$ & CLV & \multicolumn{2}{|c|}{ Desempenhø̄stratégia } & \multicolumn{2}{|c|}{ Lucratividaderganizac } & Porte & Tecnologia & \multicolumn{2}{|c|}{ UsoDiagnostUsolnterativœ } & \\
\hline Desempenho & 0,3565 & 0,6091 & 0,91066 & & & & & & & & \\
\hline Lucratividade & 0,4217 & 0,7156 & 0,6121 & 0,3393 & 0,93059 & & & & & & \\
\hline Organizacao & 0,2856 & 0,208 & 0,2392 & 0,4954 & 0,2764 & 0,70852 & & & & & \\
\hline Porte & $-0,0068$ & 0,0808 & $-0,0224$ & 0,0713 & 0,0455 & 0,1328 & 0,79549 & & & & \\
\hline UsoDiagnóstio & 0,3636 & 0,5153 & 0,5923 & 0,3824 & 0,6983 & 0,2586 & 0,1413 & 0,5279 & 0,79637 & & \\
\hline Usolnterativo & 0,1766 & 0,5544 & 0,7201 & 0,3303 & 0,5212 & 0,2782 & 0,0713 & 0,4493 & 0,6324 & 0,87556 & \\
\hline ce & 0,4166 & 0,7441 & 0,7225 & 0,2963 & 0,741 & 0,2261 & 0,0378 & 0,4513 & 0,5827 & 0,6457 & 0,95953 \\
\hline
\end{tabular}

\section{HIPÓTESES}

Ambiente -> FATORES CONTING

Ambiente $\rightarrow$ MODELOS

FATORES CONTING $>>$ MODELOS

MODELOS $>$ Desempenho MODELOS -> USOS

USOS -> Desempenho

\begin{tabular}{|c|c|c|c|c|c|}
\hline $\begin{array}{l}\text { Original } \\
\text { Sample (0) }\end{array}$ & $\begin{array}{l}\text { Sample } \\
\text { Mean (M) }\end{array}$ & $\begin{array}{l}\text { Standard } \\
\text { Deviation } \\
\text { (STDEV) }\end{array}$ & $\begin{array}{l}\text { Standard } \\
\text { Error } \\
\text { (STERR) }\end{array}$ & $\begin{array}{l}\text { T Statistics } \\
\text { (|O/STERR|) }\end{array}$ & valor $p$ \\
\hline 0,5208 & 0,5413 & 0,0918 & 0,0918 & 5,6744 & 0,00000 \\
\hline 0,2364 & 0,246 & 0,1318 & 0,1318 & 1,7935 & 0,07320 \\
\hline 0,3533 & 0,3382 & 0,1594 & 0,1594 & 2,2160 & 0,02692 \\
\hline 0,3874 & 0,3774 & 0,1535 & 0,1535 & 2,5247 & 0,01173 \\
\hline 0,7109 & 0,7109 & 0,076 & 0,076 & 9,3561 & 0,00000 \\
\hline 0,4633 & 0,4754 & 0,1365 & 0,1365 & 3,3934 & 0,00072 \\
\hline
\end{tabular}

variável de $2 a+V L$ 1a ordem $=$ modelo de mensuração (cargas fatoriais)

$\begin{array}{crrrrrr}\text { FATORES CONTING -> Estrategia } & 0,7596 & 0,7789 & 0,0664 & 0,0664 & 11,4332 & 0,00000 \\ \text { FATORES CONTING -> Organizacao } & 0,7731 & 0,7749 & 0,0684 & 0,0684 & 11,3043 & 0,00000 \\ \text { FATORES CONTING -> Porte } & 0,2808 & 0,3061 & 0,1213 & 0,1213 & 2,3156 & 0,02078 \\ \text { FATORES CONTING -> Tecnologia } & 0,7973 & 0,8083 & 0,062 & 0,062 & 12,8674 & 0,00000 \\ \text { MODELOS -> CLV } & 0,9015 & 0,8969 & 0,0585 & 0,0585 & 15,4057 & 0,00000 \\ \text { MODELOS -> ce } & 0,9192 & 0,9199 & 0,0229 & 0,0229 & 40,1328 & 0,00000 \\ \text { MODELOS - L Lucratividade } & 0,8994 & 0,8971 & 0,0533 & 0,0533 & 16,8606 & 0,00000 \\ \text { USOS -> Uso Diagnostio } & 0,8529 & 0,8537 & 0,0503 & 0,0503 & 16,9732 & 0,00000 \\ \text { USOS -> Uso Interativo } & 0,9462 & 0,9464 & 0,0189 & 0,0189 & 49,9540 & 0,00000\end{array}$

